\title{
1848 et la Seconde République : 50 années de recherches. Bibliographie (1948-1997)
}

Francis Démier, Jean-Luc Mayaud and Anthony Poncier

\section{OpenEdition}

\section{Journals}

Electronic version

URL: http://journals.openedition.org/rh19/115

DOI: $10.4000 /$ rh 19.115

ISSN: $1777-5329$

\section{Publisher}

La Société de 1848

\section{Printed version}

Date of publication: 1 June 1997

ISSN: 1265-1354

\section{Electronic reference}

Francis Démier, Jean-Luc Mayaud and Anthony Poncier, «1848 et la Seconde République : 50 années de recherches. Bibliographie (1948-1997) », Revue d'histoire du XIXe siècle [Online], 14 | 1997, Online since 10 September 2008, connection on 19 April 2019. URL : http://journals.openedition.org/ rh19/115; DOl : 10.4000/rh19.115

This text was automatically generated on 19 April 2019

Tous droits réservés 


\title{
1848 et la Seconde République: 50 années de recherches. Bibliographie (1948-1997)
}

\author{
Francis Démier, Jean-Luc Mayaud and Anthony Poncier
}

1995, Les abolitions de l'esclavage, 1793, 1794, 1848, de L-F Sonthonax à V. Schœlcher. Actes du colloque international tenu à l'Université de Paris VIII, février 1994, Presses Universitaires de Vincennes/Éditions de l'Unesco, 1995, 415 p.

Yoshio ABE, 1962, "Un Enterrement à Ornans et l'habit noir baudelairien", dans Études de langue et littérature française, $\mathrm{n}^{\circ} 1,1962$, pp. 29-41.

Claude ABOUCAYA, 1963, Les structures sociales et économiques de l'agglomération lyonnaise à la veille de la révolution de 1848, esquisse d'une application de la méthode quantitative à l'analyse historique, Paris, Sirey, 1963, 63 p.

Evelyn Bernadette ACKERMAN, 1978, Village on the Seine. Tradition and Change in Bonnières (1815-1914), Ithaca, Cornell University Press, 1978, 185 p.

1949, Actes du Congrès historique du Centenaire de la révolution de 1848, Paris, Presses universitaires de France, 1949, 416 p.

Laure ADLER, 1979, À l'aube du féminisme : les premières journalistes 1830-1850, Paris, Payot, 1979.

Maurice AGULHON, 1956, "La crise dans un département méditerranéen : le cas du Var", dans Ernest LABROUSSE [dir.], Aspects de la crise et de la dépression de l'économie française au milieu du XIXe siècle, 1846-1851. Études, Bibliothèque de la révolution de 1848, tome XIX, Paris, Société d'histoire de 1848, 1956, pp. 316-356.

____, 1958, "L'enquête du Comité du travail de l'Assemblée constituante (1848) : étude critique de son exécution dans deux départements du Midi", dans Annales du Midi, $\mathrm{n}^{\circ} 70$, 1958, pp. 73-85.

, 1960, "La diffusion d'un journal montagnard, le Démocrate du Var sous la deuxième République", dans Provence historique, $\mathrm{n}^{\circ} 39,1960$, pp. 2-27.

, 1970a, Une ville ouvrière au temps du socialisme utopique. Toulon de 1815 à 1851, Paris/La Haye, Mouton, 1970, 368 p. (2e édition 1977) 
, 1970b, La République au village. Les populations du Var de la révolution à la Seconde République, Paris, Plon, 1970, 543 p. (2e édition, Éditions du Seuil, 1979).

, 1971a, "Les chambrées en basse Provence : histoire et ethnologie", dans Revue historique, n 498, avril-juin 1971, pp. 337-368, réédité dans, Maurice AGULHON, Histoire vagabonde. I. Ethnologie et politique dans la France contemporaine, Bibliothèque des histoires, NRF, Paris, Gallimard, 1988, pp. 17-59.

1971b, "L'agriculture et la société rurale du Var dans la première moitié du XIXe siècle", dans Études d'Histoire provençale, 1971, pp. 137-210.

, 1973a, 1848 ou l'apprentissage de la République, Nouvelle histoire de la France contemporaine, tome 7, Paris, Éditions du Seuil, 1973, 253 p. (Nouvelle édition 1992, 290 p.).

1973b, "Esquisse pour une archéologie de la République. L'allégorie civique féminine", dans Annales, économies, sociétés, civilisations, tome 28, n² 1, janvier-février 1973, pp. 5-34.

1975a, "Dix années d'études générales sur 1848 et la Seconde République, 1965-1975", dans Annales historiques de la révolution française, n²22, octobre-décembre 1975, pp. 603-612.

, 1975b, "Le problème de la culture populaire en France autour de 1848", dans Le peuple.-- Romantisme, revue de la Société des études romantiques, $\mathrm{n}^{\circ}$ 9, 1975, pp. 50-64. _-_-, 1975c, Les quarante-huitards, Collection archives, Paris, Gallimard/Julliard, 1975, $253 \mathrm{p}$.

1976a, "L'essor de la paysannerie, 1789-1852. La pauvreté et les classes sociales", dans Étienne JUILLARD [dir.], Apogée et crise de la civilisation paysanne, 1789-1914, tome 3 de Georges DUBY et Armand WALLON [dir.], Histoire de la France rurale, Paris, Éditions du Seuil, 1976, pp. 87-106.

1976b, "L'essor de la paysannerie, 1789-1852. Attitudes politiques", dans Étienne JUILLARD [dir.], Apogée et crise de la civilisation paysanne, 1789-1914, tome 3 de Georges DUBY et Armand WALLON [dir.], Histoire de la France rurale, Paris, Éditions du Seuil, 1976, pp. 143-180.

1979a, "Maxime du Camp, témoin de la bourgeoisie de 1848", dans Maxime DU CAMP, Souvenirs de l'année 1848 [reproduction de l'édition de 1876], Genève, Slatkine Reprint, 1979, réédité dans, Maurice AGULHON, Histoire vagabonde. I. Ethnologie et politique dans la France contemporaine, Bibliothèque des histoires, NRF, Paris, Gallimard, 1988, pp. 232-239.

1979b, Marianne au combat. L'imagerie et la symbolique républicaine de 1789 à 1880, Paris, Flammarion, 1979, $253 \mathrm{p}$.

1980, "Vues nouvelles sur la France rurale au XIXe siècle", dans L.M. CULLEN et Françis FURET [dir.], Irlande et France, XVIIIe-XXe siècles : pour une histoire rurale comparée, Paris, Éditions de l'École des hautes études en sciences sociales, 1980.

1981, "Les utopistes et l'action", dans 1848, les utopismes sociaux. Utopie et action à la veille des journées de février, Paris, CDU-SEDES, 1981, pp. 5-10.

1984, "Classe ouvrière et sociabilité avant 1848", dans P. THANE, Geoffrey CROSSICK et R. FLOYD [dir.], The Power of the Past, Essays for Eric Hobsbawn, Cambridge, Cambridge University Press, 1984, traduction en français dans Maurice AGULHON, Histoire vagabonde. I. Ethnologie et politique dans la France contemporaine, Bibliothèque des histoires, NRF, Paris, Gallimard, 1988, pp. 60-97.

1985, "Politique, images, symboles dans la France post-révolutionnaire", dans Sean WILENTZ [dir.], Rites of Power. Symbolism, Ritual and Politics since the Middle Age, University 
of Pennsylvania Press, 1985, traduction en français dans, Maurice AGULHON, Histoire vagabonde. I. Ethnologie et politique dans la France contemporaine, Bibliothèque des histoires, NRF, Paris, Gallimard, 1988, pp. 283-318.

1988a, "La Seconde République. Première élection au suffrage universel, 10 décembre 1848", dans Léo HAMON et Guy LOBRICHON [dir.], L'élection du chef de l'État en France de Hugues Capet à nos jours, Entretiens d'Auxerre 1987, Paris, Beauchesne, 1988, pp. 111-120.

1988b, "Émile Ollivier, le socialisme et le bonapartisme", dans Maurice AGULHON, Histoire vagabonde. II. Idéologie et politique dans la France contemporaine, Bibliothèque des histoires, NRF, Paris, Gallimard, 1988, pp. 67-81.

1988c, "Les réveils politiques : 1830-1848", dans L'état de la France pendant la Révolution,(1789-1799), Paris, La Découverte, 1988

1989, "Ernest Labrousse historien du social (XIXe siècle)", dans À la mémoire d'Ernest Labrousse.-- Annales historiques de la Révolution française, n² 276, avril-juin 1989, pp. 128-131. 1992, "1848. Il suffragio universale e la politicizzazione delle campagne francesi", dans Dimensionci e problemi della Ricerca storica [La Sapienza], $\mathrm{n}^{\circ}$ 1, 1992, pp. 5-20, réédité "1848, le suffrage universel et la politisation des campagnes françaises", dans Maurice AGULHON, Histoire vagabonde. Tome III : la politique en France, d'hier à aujourd'hui, Bibliothèque des histoires, NRF, Paris, Gallimard, 1996, pp. 61-82.

1989, "La jacquerie de 1358 dans la littérature dramatique, historique et politique en France : 1814-1914", dans Fabienne GAMBRELLE et Michel TREBISCH [dir.], Révolte et société, Actes du VIe colloque d'Histoire au présent. Tome I, Paris, Publications de la Sorbonne, 1989, pp. 268-275.

1997a, Coup d'État et République, La bibliothèque du citoyen, Paris, Presses de sciences po, 1997, 99 p.

1997b, "Le coup d'État était-il inévitable ?", dans Jean TULARD [dir.], Pourquoi réhabiliter le Second Empire? Actes du colloque de Paris, 21 octobre 1995, Paris, Bernard Giovanangeli éditeur, 1997, pp. 51-56.

[dir.], 1983, La ville de l'âge industriel. Le cycle haussmannien (1840-1950), tome 4 de Georges DUBY [dir.], Histoire de la France urbaine, Paris, Éditions du Seuil, 1983, 671 p. Louis GIRARD, Jean-Louis ROBERT et William SERMAN [dir.], 1986, Les maires en

France du Consulat à nos jours, Paris, Publications de la Sorbonne, 1986, $462 \mathrm{p}$. , et Pierre BONTE, 1992, Marianne. Les visages de la République, Découvertes, Paris, Éditions Gallimard, 1992, 128 p.

Janine ALEXANDRE-DEBRAY, 1983, Victor Schœlcher ou la mystique d'un athée, Paris, Librairie académique Perrin, 1983.

I. ALEXANDRESCU, 1968, "120 de ani de la revolutia francesa din Februarie 1848", dans Gazeta de Transilvania, Annali del'Instituto di Studio di istoria, n 1, 1968, pp. 101-180.

Aimé ALLOUIS, 1961, "Proclamation de la constitution de 1848 au Puiset", dans Histoire locale de la Beauce et du Perche, $n^{\circ}$ 5, 1961, pp. 31-32.

Gil Carl ALROY, 1966, "Les radicaux après la révolution de 1848", dans Contrat social, volume 10, n 5, 1966, pp. 290-294.

Jean-Pierre AMALRIC, 1963, "La révolution de $1848 \mathrm{chez}$ les cheminots de la compagnie du Paris-Orléans", dans Revue d'histoire économique et sociale, $\mathrm{n}^{\circ}$ 3, 1963.

Christian AMALVI, 1989, "La jacquerie de 1358 dans la littérature dramatique, historique et politique en France : 1814-1914", dans Fabienne GAMBRELLE et Michel TREBISCH [dir.], Révolte et société, Actes du VIe colloque d'Histoire au présent. Tome I, Paris, Publications de la Sorbonne, 1989, pp. 268-275. 
Peter H. AMANN, 1962, "Revolution : A Redifinition", dans Political Science Quartely, $\mathrm{n}^{\circ}$ 77, 1962, pp. 36-53.

, 1963, "The Changing Outlines of 1848", dans American Historical Review, n 68, 1963, pp. 938-953.

, 1968, "Du neuf on the Banquet of the people, June 1848", dans French historical Studies, volume 5, $\mathrm{n}^{\circ} 3,1968$, pp. 344-350.

, 1970, "A journée in the making : May 15, 1848", dans Journal of Modern History, volume $42, \mathrm{n}^{\circ} 1,1970$, pp. 42-69.

, 1975, Revolution and Mass Democracy. The Paris Club Movement in 1848, Princeton, Princeton University Press, 1975, 370 p.

Ronald AMINZADE, 1993, Ballots and Barricades. Class Formation and Republican Politics in France, 1830-1871, Princeton, Princeton University Press, 1993, 321 p.

A. ANCOURT, 1957, "Des journées de février 1848 au coup d'État du 2 décembre 1851", dans Revue du Rouergue, tome 2, 1957, n 41, pp. 36-58, n 42, pp. 140-162, n 43, pp. 275-300 et $\mathrm{n}^{\circ} 44$, pp. 375-408.

L. ANDRIEU, 1968, "La Garde nationale de Rouen de 1848 à 1871", dans 35e Semaine d'histoire du droit normand, Dieppe, 1967.--Revue historique du droit, $\mathrm{n}^{\circ}$ 2, 1968, pp. 359-360. Pierre ANGRAND, 1948, Étienne Cabet et la République de 1848, collection du Centenaire de la révolution de 1848, Paris, Presses universitaires de France, 1948, 80 p.

E. APPOLIS, 1961, "Les catholiques sociaux dans l'Hérault sous la Seconde République", dans 85e Congrès des Sociétés savantes de Chambéry-Annecy, 1961, pp. 539-558.

P. ARCHAMBAULT, Marcel PRÉLOT, P. HENRY, R. DELAVIGNETTE et autres, 1948 1848. Révolution créatrice, Paris, Blou et Gay, 1948, 231 p.

Félix ARMAND, 1948, Les fouriéristes et les luttes révolutionnaires de 1848 à 1851, collection du Centenaire de la révolution de 1848, Paris, Presses universitaires de France, 1948, 84 p. André ARMENGAUD, 1954, "La question du blé dans la Haute-Garonne au milieu du XIXe siècle", dans Études, Bibliothèque de la révolution de 1848, tome XVI, Paris, Société d'histoire de 1848, 1954, pp. 109-123.

, 1961, Les populations de l'Est-aquitain au début de l'époque contemporaine. Recherches sur une région moins développée (vers 1845-vers 1871), Paris/La Haye, Mouton, 1961, 590 p. 1970, "Note sur le mouvement naturel de la population urbaine comparée à celui de la population rurale, du milieu du XIXe siècle à 1931", dans Grandes villes et petites villes, $3 e$ Colloque de démographie, Lyon--Saint-Étienne--Grenoble 1968, 1970, pp. 479-485.

Pierre ARNAUD et Jean CAMY [dir.], 1986, La naissance du mouvement sportif associatif en France. Sociabilités et formes de pratiques sportives. Actes du colloque de Lyon, 5-8 novembre 1985, Lyon, Presses universitaires de Lyon, 1986, 422 p.

Jean-Paul ARON [dir], 1980, Misérable et glorieuse, la femme au XIXe siècle, Paris, Librairie Arthème Fayard, 1980.

M. AUDIN et R. AUDIN, 1983, "La révolution de 1848 et les dentelliers anglais de Calais", dans Bibliothèque historique et artistique du Pas-de-Calais, $\mathrm{n}^{\circ}$ 93, 1983.

Robert AVEZOU, 1949a, "Frédéric Taulier, maire de Grenoble (1845-1848 ; 1849-1851)", dans La révolution de 1848 dans le département de l'Isère, Grenoble, Comité départemental du Centenaire de la révolution, 1949, pp. 457-478.

1949b, "Notices biographiques sur les députés de l'Isère", dans La révolution de 1848

dans le département de l'Isère, Grenoble, Comité départemental du Centenaire de la révolution, 1949, pp. 511-531.

François BABY, 1972, La guerre des Demoiselles en Ariège (1829-1872), Laroques d'Olmes, chez l'auteur, 1972, 226 p. 
Mounir BACCOUCHE, 1984, "Les déterminants sociaux et politiques du système fiscal français (1789-1918)", dans Revue historique, n 550, avril-juin 1984, pp. 339-367.

L. BADAUD-LACROZE, 1948, Les quarante-huitards, histoire confolentaise, Argenton, 1948, $230 \mathrm{p}$.

Louis BADRE, 1978, "Les remous du commerce du bois dans la région parisienne au milieu du XIXe siècle", dans La forêt en Île-de-France. Actes du colloque de Rambouillet, 1977.-Mémoires de la Fédération des Sociétés historiques et archéologiques de Paris et Île-de-France, tome 28, Paris, 1978, pp. 163-170.

Robert BALLAND, 1963, "De l'organisation à la restriction du suffrage universel en France (1848-1850)", dans Jacques DROZ [dir.], Réaction et suffrage universel en France et en Allemagne (1848-1850). Études, Bibliothèque de la révolution de 1848, tome XXII, Paris, Société d'histoire de 1848, 1963, pp. 67-173.

1982, "Les goguettes rurales autour de Paris au milieu du XIXe siècle", dans Ethnologie française, $\mathrm{n}^{\circ} 3$, tome 12, juillet-septembre 1982, pp. 247-260.

Henri BANGOU, 1973, L'actualité du combat et des idées de Victor Schœlcher, Aurillac, Éditions du Centre, 1973, $30 \mathrm{p}$.

Michel BARAK, 1971, "Quelques tentatives marseillaises d'organisation de la navigation à vapeur (1832-1854)", dans Provence historique, tome 21, fascicule 83, 1971, pp. 38-88. Pierre BARBIER et France VERNILLAT, 1959, "La République de 1848 et le Second Empire", dans Histoire de France par les chansons, tome 7, Paris, Gallimard, 1959, 226 p. Pierre BARRAL, 1973, "Mouvements paysans et troubles agraires en France après la révolution industrielle (1850-1950)", dans Les mouvements paysans dans le monde contemporain. Actes du XIIIe congrès international des sciences historiques, Moscou, 16-23 août 1970.-- Cahiers internationaux d'histoire économique et sociale, n 6, Genève, Droz, 1973, pp. 150-163.

Susanna BARROWS, 1981, Distorting Mirrors. Visions of the Crowd in Late Nineteenth-Century France, New Haven, Yale University press, 1981, traduction française, Miroirs déformants. Réflexions sur la foule en France à la fin du XIXe siècle, Paris, Aubier, 1990, 227 p.

Joseph BARRY, 1969, "1848 again", dans Horizon, volume 11, n² 2, 1969, pp. 67-83. Jean-Michel BARUCH-GOURDEN, 1987, "La police et le commerce ambulant à Paris au XIXe siècle", dans Philippe VIGIER et Alain FAURE [dir.], Maintien de l'ordre et polices en France et en Europe au XIXe siècle, Paris, Créaphis, 1987, pp. 251-267.

Paul BASTID, 1948a, L'avènement du suffrage universel, collection du Centenaire de la révolution de 1848, Paris, Presses universitaires de France, 1948, 76 p.

1948b, Un juriste pamphlétaire : Cornenin, précurseur et constituant de 1848, Paris, Hachette, 1948, 283 p.

Pierre BAUDE, 1948, Centenaire de l'abolition de l'esclavage dans les colonies françaises et de la Seconde République française, 1848-1948. L'affranchissement des esclaves aux Antilles françaises, principalement à la Martinique, Fort-de-France, Martinique, Imprimerie Officielle, 1948, $176 \mathrm{p}$.

John BAUGHMAN, 1959, "The French Banquet Campaign of 1847-1848", dans Journal of Modern History, $\mathrm{n}^{\circ}$ 31, 1959, pp. 1-15.

Pierre BAYAUD, 1963, "Documents sur les élections de 1849", dans Bulletin de la Société de sciences et de lettres de Pau, série 3, tome 23, 1963, pp. 80-84.

Jean BECARUD, 1953, "La noblesse dans les Chambres (1815-1848)", dans Revue internationale d'histoire politique constitutionnelle, $\mathrm{n}^{\circ}$ II, 1953, pp. 189-205. 
Roger BELLET, 1987, "La prostituée emblématique du 24 février 1848 ou le traitement de l'histoire par Daniel Stern et par Flaubert", dans 1848, révolutions et mutations au XIXe siècle, $\mathrm{n}^{\circ} 3,1987$, pp. 41-49.

Edward BERENSON, 1984, Populist Religion and Left-Wing Politics in France, 1830-1852, Princeton, Princeton University Press, 1984.

1989, "A new religion of the left. Christianity and Social Radicalism in France, 1815-1848", dans The French Revolution and the Creation of Modern Political Culture, tome III, François FURET et Mona OZOUF [dir.], The transformation of political culture, 1789-1848, Oxford, Pergamon Press, 1989.

Yvette BERGERON, 1948, "La crise économique de 1846-1848 à Toulouse et dans la HauteGaronne", dans Jacques GODECHOT [dir.], La révolution de 1848 à Toulouse et dans la HauteGaronne, Toulouse, Comité départemental du Centenaire de la révolution de 1848, 1948, pp. 63-134.

Daniel BERNARD, 1987, "Surveillance des itinérants et ambulants dans le département de l'Indre au XIXe siècle et au début du XXe siècle", dans Philippe VIGIER et Alain FAURE [dir.], Maintien de l'ordre et polices en France et en Europe au XIXe siècle, Paris, Créaphis, 1987, pp. 235-250.

Philippe BERNARD, 1957, "La presse républicaine dans le département du Puy-de-Dôme pendant la Seconde République", dans Revue d'Auvergne, n² 2, 1957, pp. 107-124. 1950, "Michel Rocher, commissaire général des cinq départements bretons en 1848", dans Nouvelle revue de Bretagne, 1950.

Alain BERTHO, 1975a, "Mentalités et opinions contre-révolutionnaires dans le Morbihan au XIXe siècle, la Seconde République 1848-1852", dans Bulletin de la Société polymathique du Morbihan, tome 102, 1975, pp. 30-32.

, 1975b, "Le mythe de la chouannerie en Morbihan sous la Seconde République", dans Bulletin de la Société polymathique du Morbihan, tome 102, 1975, pp. 92-132.

Philip A. BERTOCCI, 1978, Jules Simon. Republican, Anticlericalism and Cultural Politics in France, 1848-1886, Columbia, University of Missouri Press, 1978.

Robert J. BEZUCHA, 1971, "Aspects du conflit des classes à Lyon, 1831-1834", dans Le Mouvement social, $\mathrm{n}^{\circ} 76,1971$.

1975, "Mask of Revolution : a study of Popular Culture during the Second French

Republic", dans Roger PRICE [dir.], Revolution and Reaction. 1848 and the Second French Republic, Londres/New York, Croom Helm/Barnes and Nibb, 1975.

BIBLIOTHÈQUE MUNICIPALE DE NANTES, 1948, Catalogue du centenaire de 1848 en France, en Europe et dans l'Union française, organisée par la bibliothèque municipale de Nantes dans le patio du Musée des Beaux-Arts, 8-31 mars 1948, Nantes, Granet, 1948, 62 p.

G. BIDEAU, 1963, "Delacroix au lendemain des journées de juin 1848", dans Écrits de Paris, $\mathrm{n}^{\circ} 219,1963$, pp. 69-73.

Dominique BLANC et Daniel FABRE, 1982, Le brigand de Cavagnac. Le fait divers, le roman, l'histoire, Lagrasse, Éditions Verdier, 1982, 198 p.

Yves BLAYO, 1972, "Size and structure of households in Northern French village between 1836-1861 (Grisy-Suisnes)", dans Household and Family in Past Time, 1972, pp. 255-265.

Alain-Philippe BLERALD, 1988, "La problématique démocratique dans le discours abolitionniste de Victor Schœlcher. Essai de philosophie politique", dans Revue française de science politique, volume 38, $\mathrm{n}^{\circ}$ 2, avril 1988.

Annie BLETON-RUGET, 1997, "La révolution de 1848 : les modèles régionaux", dans Travaux de l'Institut de recherche du val de Saône Mâconnais, n 3, 1997, pp. 13-26. 
Evelyn BLEWER, 1996, "Victor Hugo, élu des lettres et des arts. Histoire d'une élection à l'Assemblée nationale constituante", dans Pierre LAFORGUE [dir.], Pratiques d'écriture.

Mélanges de littérature et d'histoire littéraire offerts à Jean Gaudon, Bibliothèque du XIXe siècle, Paris, Klincksieck, 1996, pp. 309-349.

Frédéric BLUCHE, 1980, Le bonapartisme. Aux origines de la droite autoritaire (1800-1850), Paris, Nouvelles éditions latines, 1980, 367 p.

1981, Le bonapartisme, Que sais-je ? nº 1980, Paris, Presses universitaires de France, $1981,128 \mathrm{p}$.

Katerine BLUNDEN, 1982, Le travail et la vertu, femmes au foyer : une mystification de la révolution industrielle, Paris, Payot, 1982.

Édouard BOEGLIN, 1991, Les Mariannes de la République en Franche-Comté, Besançon, Cêtre, 1991, $144 \mathrm{p}$.

Raphà̀l BOGAT, 1949, Centenaire de la révolution de 1848. Commémoration du Centenaire de l'abolition de l'esclavage, Basse-Terre, Guadeloupe, Imprimerie Officielle, 1949, 47 p.

Albert BOIME, 1971, "The Second Republic's Contest for the Figure of the Republic", dans The Art Bulletin, volume 53, n 1, mars 1971, pp. 68-83.

Paul BoIS, 1956, "La crise dans un département de l'ouest : la Sarthe", dans Ernest LABROUSSE [dir.], Aspects de la crise et de la dépression de l'économie française au milieu du XIXe siècle, 1846-1851. Études, Bibliothèque de la révolution de 1848, tome XIX, Paris, Société d'histoire de 1848, 1956, pp. 272-315.

1960, Paysans de l'Ouest. Des structures économiques et sociales aux options politiques depuis l'époque révolutionnaire dans la Sarthe, Paris/La Haye, Mouton, 1960, 716 p.

M. BOIVIN, 1971, L'opinion publique en Seine-Inférieure : élections et plébiscites, 1848-1914, Rouen, C.R.D.P., 1971, 103 p.

Pierre BOLLE, 1972, "Les protestants dans la Drôme en 1851", dans Religion et politique. Les deux guerres mondiales. Histoire de Lyon et du Sud-Est. Mélanges offerts à M. le Doyen André Latreille, Lyon, Centre d'histoire du catholicisme-Université de Lyon II, 1972, pp. 557-566. G. BONET, 1986, "Document pour servir à l'histoire du coup d'État du 2 décembre 1851 à Montpellier (témoignage d'Eugène Guiter)", dans Études sur l'Hérault, n², 1986 et nº 3, 1987.

Léonce BONIFACE et Ernest DESHEIMER, 1959, "La condition ouvrière à Nice en 1848", dans Nice historique, $\mathrm{n}^{\circ} 1,1959$, pp. 22-30.

Jacques BONNAUD, 1973, La vie à Bagnols sous la Seconde République. Bagnols-sur-Cèze, Sabran, chez l'auteur, 1973, $185 \mathrm{p}$.

R. BONNET, 1968, "1848 en Charente, d'après le journal Le Charentais", dans Études charentaises, $\mathrm{n}^{\circ} 7,1968$, pp. 327-340.

Marie-Joseph BOPP, 1954, "L'œuvre sociale de la haute bourgeoisie haut rhénoise au XIXe siècle", dans La bourgeoisie alsacienne, 1954, pp. 387-402.

Henry BORDEAUX, 1957, "La révolution de 1848", dans Écrits Paris, n 155, 1957, pp. 17-22.

Pierre BOUCHARDON, 1959, "Un drame de la révolution de 1848 : l'assassinat du général Bréa", dans Écrivains contemporains, n 47, 1959, pp. 3-18.

Thomas BOUCHET, 1994, "Victor Prospert, des Trois Glorieuses au Second Empire", dans Écrire des vies, biographie et mouvement ouvrier XIXe-XXe siècles. -- Territoires contemporains, Cahiers de l'IHC, Université de Dijon, $\mathrm{n}^{\circ}$ 1, 1994.

René BOUDARD, 1981, "Pierre Leroux et son imprimerie creusoise de Boussac

(1844-1850)", dans 1848, les utopismes sociaux. Utopie et action à la veille des journées de février, Paris, CDU-SEDES, 1981, pp. 131-137. 
Jacques-Olivier BOUDON, 1997, "Baudin et la barricade du 3 décembre 1851 : histoire et représentation de l'Empire à la République", dans Alain CORBIN et Jean-Marie MAYEUR [dir.], La barricade. Actes du colloque de Paris, 17-19 mai 1995, Paris, Publications de la Sorbonne, 1997, pp. 235-250.

Eugène BOUGEATRE, 1971, La vie rurale dans le Mantois et le Vexin au XIXe siècle, Édition annotée et complétée par Marcel Lachiver, Persan, Imprimerie de Persan-Beaumont, 1971, $287 \mathrm{p}$.

Jacques BOUILLON, 1955, "Les démocrates et l'armée aux élections de 1849", dans L'armée et la Seconde République. Études, Bibliothèque de la révolution de 1848, n XVIII, 1955, pp. 111-120.

1956, "Les démocrates-socialistes aux élections de 1849", dans Revue française de science politique, janvier-mars 1956, pp. 70-95.

André BOULANGE, 1966-1967, "La révolution de 1848 à Troyes", dans Société académique agricole de l'Aube, tome 103, $\mathrm{n}^{\circ}$ 8, 1966, pp. 130-132 et tome 104, 1967, pp. 295-300.

Michel BOULET, 1982, "Un type original d'enseignant : le professeur départemental d'agriculture (1836-1912)", dans Les Cahiers aubois d'histoire de l'éducation, n 6, 1982, pp. 39-52.

, 1983, "La création de l'enseignement professionnel agricole en France

(1848-1880)", dans Wilhem FRIJHOFF [dir.], L'offre d'école : éléments pour une étude comparée des politiques éducatives au XIXe siècle/The Supply of Schooling: Contributions to a Comparative Study of Educational Policy in the XIXth Century. Actes du troisième colloque international de l'Association internationale pour l'histoire de l'éducation, Sèvres, 27-30 septembre 1981, Paris, 1983, pp. 187-195.

1987, "Les colonies agricoles : une forme d'enseignement ?", dans Annales d'histoire des enseignements agricoles, $\mathrm{n}^{\circ}$ 2, décembre 1987, pp. 51-61.

Patrice BOURDELAIS et Jean-Yves RAULOT, 1987, Une peur bleue. Histoire du choléra en France, 1832-1854, Paris, Payot, 1987, $310 \mathrm{p}$.

Jean BOURDON, 1949, "Le costume en France avant 1848 et son évolution ultérieure", dans Actes du Congrès historique du Centenaire de la révolution de 1848, Paris, Presses universitaires de France, 1949, pp. 243-254.

Dominique BOUREL, 1995, "Les juifs à Berlin et à Paris", dans Ilja MIECK, Horst MÖLLER et Jürgen VOSS [dir.], Paris und Berlin in der Revolution 1848/Paris et Berlin dans la révolution de 1848. Colloque organisé par la Ville de Paris; l'Historische Kommission zu Berlin et l'Institut historique allemand, Paris, 23-25 novembre 1992, Sigmaringen, Jan Thorbecke Verlag, 1995, pp. 229-240.

Georges BOURGIN, 1948, 1848, naissance et mort d'une république, Paris, Les deux sirènes, 1948, $189 \mathrm{p}$.

et Max TERRIER, 1948, 1848, Bibliothèque du Centenaire de 1848, Paris, Éditions Tel, 1948,2 p. +22 reproductions.

Nicolas BOURGUINAT, 1997, "L'État et les violences frumentaires en France sous la Restauration et la Monarchie de Juillet", dans Ruralia. Revue de l'Association des ruralistes français, ${ }^{\circ}$ 1, 1997, pp. 11-33.

Christian BOUSSUGES, 1995, "L'implantation difficile de la Banque de France en RhôneAlpes (1848-1870)", dans Cahiers d'histoire, tome 40, n 2, 1995, pp. 115-137.

P. BOUTEILLER, 1949, La révolution de 1848 vue par les Hongrois, Paris, Presses universitaires de France, 1949, $166 \mathrm{p}$. 
André BOUTON, 1970, "La conditions des salariés au milieu du XIXe siècle dans la Sarthe", dans Bulletin de la Société agricole, des sciences, des arts de la Sarthe, série 4, tome 7, n - 14, 1970, pp. 406-428.

Philippe BOUTRY, 1986, Prêtres et paroisses au pays du curé d'Ars, Paris, Éditions du cerf, 1986.

Frank Paul BOWMAN, 1987, Le christ des barricades, 1789-1948, Jésus depuis Jésus, Paris, Cerf, 1987, $361 \mathrm{p}$.

Ferdinand BOYER, 1958, "Les rapports entre la France et la Piémont sous le premier ministère de Jules Bastide (11 mai-28 juin 1848)", dans Revue d'histoire moderne et contemporaine, tome 5, avril-mai 1958, pp. 129-136.

1965, "L'armée des Alpes en 1848", dans Revue historique, tome 233, fascicule 1, 1965, pp. 71-100.

, 1967, La Seconde République, Charles-Albert et l'Italie du Nord en 1848, Paris, Pedone, $1967,348 \mathrm{p}$.

1971, "Lysimaque Tavernier, agent vice-consul de la République française à Civitavecchia (1848)", dans Stendhal Club, n 51, 1971, pp. 246-248.

F. BRACCO, 1982-1983, "Democrazia diretta e democrazia rappresentativa nel dibattito tra democratici e socialisti in Francia 1850-1851", dans Annali della Facolta di Scienze politiche, Universita di Perugia, 1982-1983, Materiali di Storia, $\mathrm{n}^{\circ}$ 7, pp. 579-614. Lucien BRAYE, 1959, "La révolution de 1848 à Bar-le-Duc", dans Bulletin de la Société des lettres, des sciences, des arts de Bar-le-Duc, volume 9, n² 2, 1959, pp. 35-52.

Yves BRAVARD, 1957, "Saint-Étienne-de-Tinée dans le second tiers du XIXe siècle", dans Nice historique, tome 60, fascicule 3-4, 1957, pp. 124-127.

Claude-Isabelle BRELOT, 1977, "Pour une histoire des forêts comtoises pendant la première moitié du XIXe siècle : le procès de la Haute-Joux", dans Travaux présentés par les membres de la Société d'Émulation du Jura, 1977 et 1978, pp. 181-255.

1979a, "Les préfets dans la vie comtoise (1800-1870)", dans Tricentenaire du rattachement de la Franche-Comté à la France. Actes des journées d'études: de l'intégration de la province à la création de la région de Franche-Comté, Besançon, 19-20 décembre 1978, Besançon, Université de Franche-Comté, Faculté de Droit et Sciences Économiques, 1979, pp. 37-62. 1979b, "Le sentiment provincial en Franche-Comté pendant la première moitié du XIXe siècle : persistances et sociologie", dans Provinces et États dans la France de l'Est, Actes du Colloque de l'Association interuniversitaire de l'Est, Besançon, 3-4 octobre 1977, Paris, Les Belles-Lettres, 1979, pp. 109-126.

1988, "Une politique traditionnelle de gestion du patrimoine foncier en FrancheComté au XIXe siècle", dans Les noblesses européennes au XIXe siècle. Actes du colloque de l'École française de Rome, novembre 1985, Rome, École française de Rome/Université de Milan, 1988, pp. 221-254.

1992, La noblesse réinventée. Nobles de Franche-Comté de 1814 à 1870, Besançon, Annales littéraires de l'Université de Besançon, 1992, 2 volumes, 1242 p. 1995, "L'espace châtelain au XIXe siècle", dans Château et territoire. Limites et mouvances. Première rencontre internationale d'archéologie et d'histoire en Périgord, Périgueux, 23-24-25 septembre 1994, Besançon, Annales littéraires de l'Université de Besançon, 1995, pp. 207-216.

Yves BRETON, 1985, "Les économistes, le pouvoir politique et l'ordre social en France en 1830 et 1851", dans Histoire, économie et société, 2e trimestre 1985, pp. 233-252.

Jean-Louis BRIQUET, 1997, La tradition en mouvement. Clientélisme et politique en Corse, Paris, Éditions Belin, 1997, 303 p. 
Pierre BROCHON, 1957, La chanson française. Le pamphlet du pauvre, du socialisme utopique à la révolution de 1848, Paris, Éditions sociales, 1957, 208 p.

Jean BRON, 1968, Histoire du mouvement ouvrier français. Tome 1 : le droit à l'existence du début du XIXe siècle à 1884, Paris, Éditions ouvrières, 1968, 255 p.

Pierre BROUÉ, 1957, "Un saint-simonien dans l'arène politique : Laurent de l'Ardèche (1848-1852)", dans Cahiers d'histoire, tome 2, n 1, 1957, pp. 59-79.

Jean BRUHAT, 1948, Les journées de Février 1848, collection du Centenaire de la révolution de 1848, Paris, Presses universitaires de France, 1948, 75 p..

, 1966, "Anticléricalisme et mouvement ouvrier en France avant 1914", dans Le Mouvement Social, $\mathrm{n}^{\circ}$ 57, 1966.

Anne-Marie BRULEAUX, Régine GALMONT et Serge MAM LAM FOUCK [dir.], 1986, Deux siècles d'esclavage en Guyane française, 1652-1848, CEGER, Centre guyanais d'études et de recherches, Cayenne, Paris, Éditions L'Harmattan, 1986, 341 p.

D. BRUNEAU, L. PEYGNAUD et F. NAUDIN, 1948, Aspects de la révolution de 1848 dans l'Indre, Châteauroux, Imprimerie de Badel, 1948, 52 p.

Geoffrey BRUUN, 1958, Revolution and reaction, 1848-1852. A mid-century watershed, New York/Toronto/Londres, 1958.

Georges Jean BUGLER, 1970, Histoire de Valentigney au XIXe siècle, du village ancien au centre industriel moderne, Montbéliard, les Presses de l'Est, 1970, 152 p.

Maréchal BUGEAUD, 1997, La guerre des rues et des maisons. Manuscrit inédit présenté par Maité Bouyssy, Paris, Jean-Paul Rocher éditeur, 1997, 157 p.

André BURGUIERE et Jacques REVEL [dir.], 1989, Histoire de la France. Tome 1. L'État et les pouvoirs, Paris, Éditions du Seuil, 1989, 656 p.

Richard D.E. BURTON, 1994, La famille coloniale. La Martinique et la mère-patrie, 1789-1992, Paris, Éditions L'Harmattan, 1994, 308 p.

Charles-Olivier CARBONNEL, 1961, "Les députés des Pyrénées-Orientales de 1815 à 1870", dans C.E.R.C.A., 1961, n 13-14, pp. 330-355.

Jacques CAILLÉ, 1949, "Les relations de la France et du Maroc sous la Deuxième République", dans Actes du Congrès historique du Centenaire de la révolution de 1848, Paris, Presses universitaires de France, 1949, pp. 397-407.

J. CAIN, 1948, La révolution de 1848. Exposition organisée par le Comité national du centenaire, Paris, Bibliothèque nationale, 1948, $206 \mathrm{p}$.

1976, The Cambridge History of Africa, tome 5, c.1790-c.1870, Cambridge, Cambridge University Press, 1976, 617 p.

Gratien CANDACE, 1948, "Victor Schœlcher, l'abolition de l'esclavage", dans Comptes rendus mensuels des séances de l'Académie des sciences coloniales, $\mathrm{n}^{\circ}$ 3, 1948, pp. 97-138.

J. CARNAC, 1948, George Sand révolutionnaire, Paris, Hier et aujourd'hui, 1948.

Paul CARNOT, 1948, Hippolyte Carnot et le ministère de l'Instruction publique, collection du Centenaire de la révolution de 1848, Paris, Presses universitaires de France, 1948, 68 p. François CARON, 1962, "La Compagnie du Nord et ses fournisseurs, 1845-1848", dans Revue du Nord, tome XLV, nº 179, octobre-décembre 1962, pp. 349-389.

, 1973, Histoire de l'exploitation d'un grand réseau. La Compagnie du chemin de fer du Nord, 1846-1937, Paris/La Haye, Mouton, 1973, 619 p.

Jean-Claude CARON, 1987, "Maintenir l'ordre au Pays latin : la Jeunesse des écoles sous surveillance, 1815-1848", dans Philippe VIGIER et Alain FAURE [dir.], Maintien de l'ordre et polices en France et en Europe au XIXe siècle, Paris, Créaphis, 1987, pp. 329-346.

1989, "Révoltes étudiantes, révoltes agissantes ? Le poids des révoltes étudiantes dans la vie politique française (1815-1848)", dans Fabienne GAMBRELLE et Michel 
TREBISCH [dir.], Révolte et société, Actes du VIe colloque d'Histoire au présent, tome II, Paris, Publications de la Sorbonne, 1989, pp. 194-204.

1991, Générations romantiques. Les étudiants de Paris et le quartier Latin (1814-1851),

Paris, Librairie Armand Colin, 1991, 435 p.

1992, "Une approche de la sociabilité de la jeunesse : la presse étudiante à Paris

(1829-1850)", dans Jeunesses au XIXe siècle.-- 1848, révolutions et mutations au XIXe siècle, $\mathrm{n}^{\circ} 8$, 1992, pp. 75-86.

1997, "Aux origines du mythe : l'étudiant sur la barricade dans la France

romantique (1827-1851)", dans Alain CORBIN et Jean-Marie MAYEUR [dir.], La barricade. Actes du colloque de Paris, 17-19 mai 1995, Paris, Publications de la Sorbonne, 1997, pp. 185-196.

Pierre CASPARD, 1974, "Aspects de la lutte des classes en 1848 : le recrutement de la garde nationale mobile", dans Revue historique, $\mathrm{n}^{\circ}$ 511, juillet-septembre 1974, pp. 81-106. Jean CASSOU, 1948, Le quarante-huitard, collection du Centenaire de la révolution de 1848, Paris, Presses universitaires de France, 1948, 72 p.

1969, Catalogue de l'exposition: Trois mois au pouvoir, organisée pour la célébration du centenaire de la mort de Lamartine à Paris, Hôtel de ville, 1969, Paris, Imprimerie municipale, 1969.

Shulamit CATTANE, 1968, "The local Alsatian press on the anti-Jewish riots in 1848", dans Zion, volume 33, n 1-2, 1968, pp. 96-98.

Roland CATY et Éliane RICHARD, 1980, "Contribution à l'étude du monde du négoce marseillais de 1815 à 1870 : l'apport des successions", dans Revue historique, nº 536, octobre-décembre 1980, pp. 337-364.

Antonin CAYRÉ, 1948, "La révolution de 1848 à Toulouse et dans la Haute-Garonne des journées de février aux journées de juin", dans Jacques GODECHOT [dir.], La révolution de 1848 à Toulouse et dans la Haute-Garonne, Toulouse, Comité départemental du Centenaire de la révolution de 1848, 1948, pp. 135-234.

Raymond CAZELLES, 1971, "Le Duc d'Aumale et la presse", dans Études d'histoire de la presse, XVIIe-XXe siècle.-- Revue d'histoire moderne et contemporaine, tome 18, octobredécembre 1971, pp. 589-609.

1948, Centenaire de 1848 et du Manifeste communiste.-- La Revue socialiste, numéro spécial, 1948.

1949, Centenaire de 1848. 1848 dans la Drôme et l'histoire de la Seconde République, Valence, Société d'archéologie de la Drôme, 1949, 50 p.

1948, Centenaire de la révolution de 48.-- Europe, tome 26, n 26, février $1948,320 \mathrm{p}$.

Aimé CÉSAIRE, Léopold S. SENGHOR, Gaston MONNERVILLE, Édouard

DEPREUX, 1948, Centenaire de la révolution de 1848, commémoration du centenaire de

l'abolition de l'esclavage, Paris, Presses Universitaires de France, 1948, 48 p.

Jean-Pierre CHALINE, 1969, "À la recherche de la bourgeoisie rouennaise du

XIXe siècle", dans Amis Flaubert, n 35, 1969, pp. 18-30.

1970, "Les souvenirs d'un bourgeois de Rouen : Jean Baptiste Curmer (1782-1870)", dans Annales de Normandie, $\mathrm{n}^{\circ} 1,1970$, pp. 21-39.

Pierre CHALMIN, 1948, "Une institution militaire de la Seconde République : la garde nationale mobile", dans Études d'histoire moderne et contemporaine, tome 2, 1948, pp. 37-83. 1955, "La crise morale de l'armée française", dans L'armée et la Seconde République.

Études, Bibliothèque de la révolution de 1848, n XVIII, 1955, pp. 28-76.

1959, "Les réactions morales de l'armée des Alpes au printemps de 1849", dans $83 e$

Congrès des Sociétés savantes d'Aix-Marseille, 1959, pp. 181-190. 
Jean-Michel CHAPOULIE, 1989, "L'enseignement primaire supérieur, de la loi Guizot aux écoles de la IIIe République", dans Revue d'histoire moderne et contemporaine, tome 36, juillet-septembre 1989, pp. 413-437.

Christophe CHARLE, 1980, Les hauts fonctionnaires en France au XIXe siècle, Paris, Gallimard-Julliard, 1980, 269 p. , 1991, Histoire sociale de la France au XIXe siècle, Paris, Éditions du Seuil, 1991, 399 p. et Régine FERRÉ [dir.], 1985, Le personnel de l'enseignement supérieur en France au XIX e et XXe siècles. Colloque des 25-26 juin 1984, Paris, Éditions du Centre national de la recherche scientifique, 1985.

Albert CHARLES, 1962, "L'émigration basco-béarnaise sous la Monarchie de Juillet et le Second Empire", dans Annales du Midi, tome 74, n 57, 1962, pp. 39-64.

Thérèse CHARMASSON, 1986, "L'enseignement agricole et horticole dans les écoles normales et les écoles primaires, 1838-1879", dans Annales d'histoire des enseignements agricoles, $\mathrm{n}^{\circ} 1$, octobre 1986, pp. 45-58.

Jeannine CHARON-BORDAS, 1994, Ouvriers et paysans au milieu du XIXe siècle. L'enquête de 1848 sur le travail, Paris, Publisud, 1994, 513 p.

James CHASTAIN, 1974, "Jules Bastide et l'unité allemande en 1848", dans Revue historique, $\mathrm{n}^{\circ}$ 511, juillet-septembre 1974, pp. 51-72.

Jacques CHASTENET, 1968, "Révolutions spontanées (1848-1968)", dans Revue de Paris, $\mathrm{n}$ ' 6-7, 1968, pp. 1-8.

Abel CHATELAIN, 1976, Les migrants temporaires en France de 1800 à 1914 Histoire économique et sociale des migrants temporaires des campagnes françaises au XIXe siècle et au début du XXe siècle, Lille, Publications de l'université de Lille III, 1976, 2 volumes, 1215 p.

Alfred CHAUDEURGE, 1962, Qu'un sang impur, des Trois glorieuses à la fosse commune, Paris, $1962,160 \mathrm{p}$.

Marie-Claude CHAUDONNERET, 1987, La figure de la République. Le concours de 1848, Paris, Réunion des musées nationaux, 1987.

, 1995, "La révolution de 1848 et les arts en France", dans Ilja MIECK, Horst MÖLLER et Jürgen VOSS [dir.], Paris und Berlin in der Revolution 1848/Paris et Berlin dans la révolution de 1848. Colloque organisé par la Ville de Paris; l'Historische Kommission zu Berlin et l'Institut historique allemand, Paris, 23-25 novembre 1992, Sigmaringen, Jan Thorbecke Verlag, 1995, pp. 299-320.

Martial CHAULANGES, 1964, "Souvenirs d'un artisan menuisier (Claude Canard), 1848-1852", dans 88e congrès des Sociétés savantes, Clermont-Ferrand, 1964, pp. 951-955. Liliane CHAULEAU, 1979, La vie quotidienne aux Antilles françaises au temps de Victor Schœlcher, XIXe siècle, Paris, Éditions Hachette, 1979, 371 p.

Pierre CHAUNU, 1948, Eugène Sue et la Seconde république, collection du Centenaire de la révolution de 1848, Paris, Presses universitaires de France, 1948, 71 p.

Frédéric CHAUVAUD, 1984, "L'usure au XIXe siècle : le fléau des campagnes", dans Ethnographie de la violence.-- Études rurales, n 95-96, juillet-décembre 1984, pp. 293-313. 1989, "Tensions et conflits : aspects de la vie rurale au XIXe siècle d'après les archives judiciaires. L'exemple de l'arrondissement de Rambouillet (1811-1871)", dans Bulletin du Centre d'histoire de la France contemporaine, n 10, 1989, pp. 95-102.

1990, "Les jeunes délinquants de Seine-et-Oise et la colonie agricole et pénitentiaire de Mettray", dans Philippe VIGIER et Alain FAURE [dir.], Répression et prison politiques en France et en Europe au XIXe siècle, Paris, Créaphis, 1990, pp. 253-267.

1991, "Les figures du monstre dans la seconde moitié du XIXe siècle", dans Violence, brutalité, barbarie.-- Ethnologie française, $\mathrm{n}^{\circ} 3$, tome 21, juillet-septembre 1991, pp. 243-253. 
1992, "Violence juvénile, violence familiale ? (1830-1880)", dans Jeunesses au XIXe siècle.--1848, révolutions et mutations au XIXe siècle, $\mathrm{n}^{\circ}$ 8, 1992, pp. 39-48.

1995, Les passions villageoises au XIXe siècle. Les émotions rurales dans les pays de Beauce, du Hurepoix et du Mantois, Paris, Éditions Publisud, 1995, 272 p.

1997a, "L'élision des traces. L'effacement des marques de la barricade à Paris (1830-1871)", dans Alain CORBIN et Jean-Marie MAYEUR [dir.], La barricade. Actes du colloque de Paris, 17-19 mai 1995, Paris, Publications de la Sorbonne, 1997, pp. 269-282.

1997b, "Les violences rurales et l'émiettement des objets au XIXe siècle. Lectures de la ruralité", dans Cahiers d'histoire, tome 42, n 1, 1997, pp. 49-88.

Paul CHAUVET, 1956, Les ouvriers du livre en France de 1789 à la constitution de la Fédération du livre, Paris, Librairie Marcel Rivière, 1956.

Sylvie CHEVALLEY, 1988, "Rachel et la Marseillaise", dans 1848, révolutions et mutations au XIXe siècle, $\mathrm{n}^{\circ} 4,1988$, pp. 109-112.

Louis CHEVALIER, 1958, Classes laborieuses et classes dangereuses à Paris pendant la première moitié du XIXe siècle, Paris, Plon, 1958, réédition, Paris, Librairie générale française, 1978, $729 \mathrm{p}$.

Gérard CHOLVY, 1973, Religion et société au XIXe siècle : le diocèse de Montpellier, Lille, Presses universitaires de Lille, 1973, 2 volumes.

1974, "Sociétés, genre de vie et mentalités dans les campagnes françaises de 1815 à 1880", dans L'Information historique, $\mathrm{n}^{\circ}$ 4, 1974, pp. 155-166.

1976a, "Le catholicisme populaire en France au XIXe siècle", dans Bernard PLONGERON [dir.], Le christianisme populaire, les dossiers de l'histoire, Paris, Le Centurion, 1976.

1976b, "Réalités de la religion populaire dans la France contemporaine (XIXe-début XXe siècles)", dans Bernard PLONGERON [dir.], La religion populaire dans l'Occident chrétien, approches historiques, Paris, Éditions Beauchesne, 1976.

1995, "Les élections du 13 mai 1849 dans le département de l'Hérault", dans

Pratiques et cultures politiques dans la France contemporaine, Montpellier, 1995 pp. 73-85.

et Yves-Marie HILAIRE, 1985, Histoire religieuse de la France contemporaine. Tome I, 1800-1880, Toulouse, Éditions Privat, 1985, 352 p.

Thomas CHRISTOFFERSON, 1973, "Les conceptions sociales des notables de Marseille sous la Seconde République", dans Annales du Midi, tome 85, n 114, 1973, pp . 423-433.

L. CLARENC, 1965, "Le code de 1827 et les troubles forestiers dans les Pyrénées centrales au milieu du XIXe siècle", dans Annales du Midi, juillet-septembre 1965, pp. 293-317.

Timothy J. CLARK, 1969, "A Bourgeois Dance of Death : Max Buchon on Courbet", dans The Burlington Magazine, $\mathrm{n}^{\circ} 111,1969$, pp. 208-212 et pp. 286-290.

1973a, The Absolute Bourgeois. Artists and Politics in France, 1848-1851, London, Thames and Hudson, 1973, 224 p., traduction française, Le bourgeois absolu. Les artistes et la politique en France de 1848 à 1851, Paris, Art édition, 1992, 310 p.

1973b, Image of the People. Gustave Courbet and the 1848 Revolution, London, Thames and Hudson, 1973, 208 p., traduction française, Une image du peuple. Gustave Courbet et la révolution de 1848, Paris, Art édition, 1991, 285 p.

Fernando CLAUDIN, 1976, Marx, Engels y la revolución de 1848, Siglo Veintiuno de España editores, 1976, traduction en français, Marx, Engels et la révolution de 1848, Paris, Librairie François Maspero, 1980, 462 p.

Laurent CLAVIER et Louis HINCKER, 1997, "La barricade de juin 1848 : une construction historique", dans Alain CORBIN et Jean-Marie MAYEUR [dir.], La barricade. Actes du colloque de Paris, 17-19 mai 1995, Paris, Publications de la Sorbonne, 1997, pp. 209-220. 
Marie Thérèse CLOITRE, 1973, "Aspect de la vie politique dans le département du Finistère de 1848 à 1870", dans Bulletin de la Société archéologique du Finistère, tome 99, n² 2, 1973, pp. 731-802.

Alfred COBBAN, 1952, "Administrative Pressure in the Election of the French Constituent Assembly, April 1848", dans Bulletin of the Institute of Historical Research, ${ }^{\circ} 25$, 1952, pp. 133-159.

Martine COCAUD, 1996, "Les cadres de la rénovation agricole en Ille-et-Vilaine dans la première moitié du XIXe siècle", dans Revue d'histoire moderne et contemporaine, tome 43 , juillet-septembre 1996, pp. 479-495.

Georges COCHON, 1969, Nous la Gauche, devant Louis-Napoléon, Paris, Flammarion, 1969, $251 \mathrm{p}$.

Félix-Paul CODACCIONI, 1976, De l'inégalité sociale dans une grande ville industrielle. Le drame de Lille de 1850 à 1914, Lille, Éditions universitaires de Lille III, 1976, 444 p.

Georges COGNIOT, 1948a, La question sociale en 1848 et la loi Falloux, Paris, Hier et aujourd'hui, 1948, $243 \mathrm{p}$.

, 1948b, "Proudhon et la révolution de 1848", dans Cahiers du communisme, 1948, pp. 579-7599.

William B. COHEN, 1980, The French Encounter with Africans : White Response to Blacks, 1530-1880, Bloomington, Indiana, 1980, traduction en français, Français et Africains. Les Noirs dans le regard des Blancs, Paris, Éditions Gallimard, 198I, 409 p.

Jean-Pierre COLLIGNON, 1984, Médailles politiques et satiriques, décorations et insignes de la Deuxième République française, 1848-1852, Paris/Lille/Lyon/Reims, J.P. Collignon édition, 1984.

Irene COLLINS, 1959, The Governement and the Newspaper Press in France, 1814-1881, London, Oxford University Press, 1959.

Claude COLLOT, 1970, "L'industrie textile meusienne en 1848", dans Bulletin de la Société d'histoire et d'archéologie de la Meuse, nº 7, 1970, pp. 99-118.

Yvan COMBEAU et Prosper EVE, 1996, La Réunion républicaine au XIXe siècle. L'avènement de la IIe et de la IIIe République à La Réunion, 1848/1870, Collection Futur antérieur, Le Port, La Réunion, Les Deux Mondes, 1996, 189 p.

COMITÉ DU CENTENAIRE DE LA RÉVOLUTION DE 1848, CAYENNE, 1948, L'abolition de l'esclavage et la question sociale, Cayenne, Imprimerie Paul Laporte, 1948, $27 \mathrm{p}$.

COMITÉ DÉPARTEMENTAL MARNAIS DE CÉLÉBRATION DU CENTENAIRE DE LA REÉVOLUTION DE 1848, 1948, Le Département de la Marne et la révolution de 1848, Châlonssur-Marne, Archives de la Marne, 1948.

Suzanne COQUERELLE, 1955a, "Les droits collectifs et les troubles agraires dans les Pyrénées en 1848", dans Actes du 78e Congrès national des sociétés savantes, Toulouse, 1953, Paris, Imprimerie nationale, 1955.

__-_, 1955b, "L'armée et la répression dans les campagnes (1848)", dans L'armée et la Seconde République. Études, Bibliothèque de la révolution de 1848, tome XVIII, Paris, Société d'histoire de 1848, 1955, pp. 121-159.

Alain CORBIN, 1974, "Limousins migrants, Limousins sédentaires. Contribution à l'histoire de la région limousine au XIXe siècle (1845-1880)", dans Le mouvement social, $\mathrm{n}$ - 88, juillet-septembre 1974, pp. 113-125.

_.--, 1975, Archaïsme et modernité en Limousin au XIXe siècle. 1845-1880. Tome I, La rigidité des structures économiques, sociales et mentales. Tome II, La naissance d'une tradition de gauche, Paris, Marcel Rivière, 1975, 2 volumes,1168 p. 
1982, "L'hygiène publique et les "excreta" dans la ville pré-haussmannienne", dans Anthropologie culturelle dans le champ urbain.-- Ethnologie française, $\mathrm{n}^{\circ} 2$, tome 12 , avril-juin 1982, pp. 127-130.

1991, "Histoire de la violence dans les campagnes françaises au XIXe siècle. Esquisse d'un bilan", dans Violence, brutalité, barbarie.-- Ethnologie française, $\mathrm{n}^{\circ} 3$, tome 21 , juilletseptembre 1991, pp. 224-236.

1993, "La violence rurale dans la France du XIXe siècle et son dépérissement :

l'évolution de l'interprétation politique", dans La violence politique dans les démocraties européennes occidentales.-- Cultures \& conflits, n 9-10, printemps-été 1993, pp. 61-73.

1994, Les cloches de la terre. Paysage sonore et culture sensible dans les campagnes au XIXe siècle, Paris, Éditions Albin Michel, 1994, 361 p.

et Jean-Marie MAYEUR [dir.], 1997, La barricade. Actes du colloque de Paris, 17-19 mai 1995, Paris, Publications de la Sorbonne, 1997, 522 p.

P. CORDONNIER-DÉTRIE, 1948, Catalogue de l'exposition rétrospective du centenaire de la révolution de 1848. Musée de Tesse, Le Mans, juillet 1848, Le Mans, Imprimerie commerciale, $1948,72 \mathrm{p}$.

Auguste CORNU, 1948a, Karl Marx et la révolution de 1848, collection du Centenaire de la révolution de 1848, Paris, Presses universitaires de France, 1948, 76 p.

1948b, Karl Marx et la pensée moderne, Paris Éditions sociales, 1948, 191 p.

Armand COSSON, 1978, "Industrie de la soie et population ouvrière à Nimes de 1815 à

1848", dans Économie et société en Languedoc-Roussillon de 1789 à nos jours. Actes du colloque de Montpellier, 25-26 octobre 1976, Montpellier, Université Paul Valéry, 1978, pp. 189-214.

Paul COSTE-FLORET, 1949, Allocution prononcée à l'occasion du transfert des dépouilles mortelles de Victor Schœlcher et de Félix Eboué au Panthéon, ministère de la France d'outremer, 1949, $11 \mathrm{p}$.

Alain COTTEREAU, 1986, "The Distinctiveness of Working-Class Cultures in France, 1848-1900", dans Ira KATZNELSON et Aristide R. ZOLBERG [dir.], Working-Class Formation. Nineteenth-Century Patterns in Western Europe and the United States, Princeton, Princeton University Press, 1986, pp. 111-154.

Marvin R. COX, 1968, "The liberal legitimists and the party of order under the Second French Republic", dans French historical Studies, volume 5, nº 4, 1968, pp. 446-464. P. COUDERC, 1975, "La révolution industrielle dans l'Allier, naissance d'une cité industrielle : Commentry (1820-1867)", dans Notre Bourdonnais, série 8, n 194, 1975, pp. 286-288.

Armand CUVILLIER, 1948, P.J.P. Buchez et les origines du socialisme chrétien, collection du Centenaire de la révolution de 1848, Paris, Presses universitaires de France, 1948, 83 p. 1954, Un journal d'ouvriers L'Atelier, 1840-1850, Paris, Éditions Ouvrières, 1954.

Serge DAGET, 1987, Répertoire des expéditions françaises à la traite négrière illégale (1814-1850), Nantes, Centre de recherche sur l'histoire du monde atlantique/Comité nantais d'études en sciences humaines, 1987.

J.-P. DAMAGGIO, 1982, Le Tarn-et-Garonne et ses démocrates, 1848-1851, Montauban, 1982. Cheryl DANIERI, 1991, Credit Where Credit Due : The Mont-de-Piété of Paris, 1777-1851, New York, Garland, 1991, 283 p.

J. DANIGO, 1972, "La correspondance politique de Vincent Audren de Kerdrel (1815-1899)", dans Bulletin de la Société polymathique du Morbihan, 1972, pp. 4-5. , 1973, "L'abbé Jean-Marie Le Blanc, député du Morbihan à l'Assemblée nationale constituante, à travers sa correspondance parlementaire (1848-1849)", dans Bulletin de la Société polymathique du Morbihan, 1973, pp 133-171. 
Adrien DANSETTE, 1961, Louis Napoléon à la conquête du pouvoir, Paris, Hachette, 1961, $420 \mathrm{p}$.

Adeline DAUMARD, 1957, "Les archives notariales et l'étude de la mobilité sociale dans la bourgeoisie parisienne pendant la première du XIXe siècle", dans Bulletin de la société d'histoire moderne, série 12, $\mathrm{n}^{\circ} 1,1957, \mathrm{pp}$. 3-6.

___-, 1958, "Sur l'histoire sociale du XIXe siècle : Paris et les Archives de

l'Enregistrement", dans Annales, Économies, sociétés, civilisations, n² 2, 1958, pp. 289-303. , 1963a, La bourgeoisie parisienne de 1815 à 1848, Paris, S.E.V.P.E.N., 1963, 661 p. , 1963b, "Une référence pour l'étude des sociétés urbaines en France aux XVIIIe et XIXe siècles. Projet de code socio-professionnel", dans Revue d'histoire moderne et contemporaine, tome 10, juillet-septembre 1963, pp. 186-210.

1965, Maisons de Paris et propriétaire parisiens au XIXe siècle, 1809-1880, Paris, Éditions

Cujas, 1965, $284 \mathrm{p}$.

____, 1972, "L'évolution des structures sociales en France à l'époque de l'industrialisation (1815-1914)", dans Revue historique, n 502, avril-juin 1972, pp. 325-346.

1973a, "Problèmes généraux et synthèse des résultats", dans Les fortunes françaises au XIXe siècle, 1973, pp. 3-177.

1973b, "Les fortunes des Parisiens au XIXe siècle", dans Les fortunes françaises au XIX e siècle, 1973, pp. 181-267.

1973c, "Conclusion générale sur les fortunes françaises au XIXe siècle", dans Les fortunes françaises au XIXe siècle, 1973, pp. 587-590. $\mathrm{n}^{\circ} 9,1975$.

1975, "Le peuple dans la société française à l'époque romantique", dans Romantisme,

1987, Les bourgeois et la bourgeoisie en France depuis 1815, Paris, Aubier, 1987, 430 p.

Noèlle DAUPHIN, 1994, "Physionomie de Versailles en 1848 : quelques observations tirées du recensement municipal de 1848", dans Alain FAURE, Alain PLESSIS et JeanClaude FARCY [dir.], La terre et la cité. Mélanges offerts à Philippe Vigier, Paris, Éditions Créaphis, 1994, pp. 123-137.

Jean DAUTRY, 1948, Histoire de la révolution de 1848 en France, Paris, Éditions hier et aujourd'hui, 1948, $375 \mathrm{p}$.

1957, 1848 et la IIe République, Paris, Éditions Sociales, 1957, 340 p.

Marcel DAVID, 1967, "Formation ouvrière et pensée ouvrière sur la culture en France depuis le milieu du XIXe siècle", dans Niveaux de culture et groupes socoiaux, Paris, 1967, pp. 213-245.

___-_, 1992, Le Printemps de la Fraternité. Genèse et vicissitudes, 1830-1851, Paris, Aubier, 1992, $396 \mathrm{p}$.

James C. DAVIES, 1962, "Toward a Theory of Revolution", dans American Sociological Review, n² 27, 1962, pp. 5-19.

André DEJOUY, 1971, "Vaujours au service de l'ordre républicain", dans Vieux Montfermeil, $\mathrm{n}^{\circ}$ 51, 1971, pp. 15-16.

Emile De GROOT 1953, "Contemporary political opinion and the Revolution of 1848 " dans History, volume 38, n 133, 1953, pp. 134-154.

1988, De la chaîne à la liberté : l'esclavage et la Martinique pendant deux siècles, Fort-deFrance, Martinique, Bureau du Patrimoine, 1988, 88 p.

1988, De la traite à l'esclavage, du XVIIIe au XIXe siècle. Actes du colloque international sur la traite des Noirs, Nantes, 1985, Nantes, Centre de recherche sur l'histoire du monde atlantique/Société française d'histoire d'outre-mer, 1988, 2 volumes. 
Édouard De LEPINE, 1978, Questions sur l'histoire antillaise. Trois essais sur l'Abolition, l'Assimilation, l'Autonomie, Fort-de-France, Éditions Désormeaux, 1978, 282 p.

Frederick A de LUNA, 1969, The french Républic under Cavaignac, 1848, Princeton, Princeton University Press, 1969, $451 \mathrm{p}$.

Henri DELANNE, 1951, "Besançon à la veille de la révolution de février 1848", dans Bulletin de la Fédération des sociétés savantes de Franche-Comté, 1951, pp. 140-143.

1956, "Autour d'un centenaire. Les débuts de la Seconde République à Besançon, de février à juin 1848", dans Mémoires de l'Académie des sciences, belles lettres et arts de Besançon, volume 171, 1956, pp. 74-85.

R. DELAVIGNETTE, 1948, "1848, révolution créatrice", dans La Nouvelle journée, Paris, Bloud et Gay, 1948.

J. DELAY, 1964, "Alexandre Dumas, candidat aux premières élections à Joigny en 1848", dans Écho d'Auxerre, n 51, 1964, pp. 33-35.

Philippe DELISLE, 1997, Renouveau missionnaire et société esclavagiste à la Martinique, 1815-1848, Paris, Éditions Publisud, 1997, 404 p.

Bernard DELPAL, 1980, La vie religieuse dans les paroisses du diocèse de Valence au milieu du XIXe siècle (1840-1857); Valence, Éditions Peuple Libre, 1980.

1989, Entre paroisse et commune : les catholiques drômois au milieu du XIXe siècle, Valence, Éditions Peuple libre, 1989.

Paul DELSALLE, 1984, "'Les briseurs de vitres" : émeutes populaires à Roubaix entre 1830 et 1848", dans Histoire du Rousillon et questions diverses, Actes du 106e Congrès national des Sociétés savantes, Perpignan, 1981. Section d'histoire moderne et contemporaine, tome II, Paris, Éditions du Comité des travaux historiques et scientifiques, 1984, pp. 217-236.

Francis DÉMIER, 1982, "Les ouvriers de Rouen parlent à un économiste en juillet 1848", dans Le Mouvement social, avril-juin 1982, pp. 13-31.

Anthony DENHOLM, 1972, France in Revolution 1848, Londres, Wiley, 1972, 185 p.

Michel DENIS, 1966, "La Mayenne en 1848 : les Républicains de la veille", dans Bulletin communal d'histoire de la Mayenne, $\mathrm{n}^{\circ} 12,1966, \mathrm{pp} .12-17$.

1977, Les royalistes de la Mayenne et le monde moderne (XIXe-XXe siècles), Paris, Klincksieck, 1977.

1992, "1815-1848. Que faire de la Révolution française ?", dans Jean-François

SIRINELLI [dir.], Histoire des droites en France. Tome I : Politique, Paris, Éditions Gallimard, 1992, pp. 13-88.

Jacques DENIZET, 1990, Sarda Garriga. L'homme qui avait foi en l'homme, La Réunion, Éditions C.N.H./Académie de La Réunion, 1990, 192 p.

1948, Le département de la Marne et la révolution de 1848, Châlons-sur-Marne, Comité départemental du Centenaire de 1848 de la Marne, 1948, 98 p.

Yves DEPELSENAIRE, 1994, "Sur une œuvre "réaliste" : l'Enterrement à Ornans", dans Les Amis de Gustave Courbet, Bulletin no 90/91, 1994, pp. 15-20.

Jean-Michel DEREX, 1971, "Si j'étais élu (Gibert un candidat à l'Assemblée législative en juin1849, expose son programme à l'évêque de Meaux)", dansBulletin de la Société d'histoire et d'art du diocèse de Meaux, 1971, pp. 61-64.

Simone DERRUAU-BONNIOL, 1957, "Le socialisme dans l'Allier de 1848 à 1914", dans Cahiers d'histoire, $\mathrm{n}^{\circ}$ 2, 1957, pp. 115-162.

A. DESAUNAIS, 1948, "La révolution de 1848 dans le département du Jura (24 février-10 décembre 1848)", dans Volume du centenaire de la révolution de 1848 dans le Jura.-- Mémoires de la Société d'émulation du Jura pour 1946-1948, Lons-le-Saunier, 1948, pp. 49-359. 
M. DESAUNAYS, 1949, "Le commissariat de Jules Grévy dans le Jura (15 mars-19 avril 1848)", dans Actes du Congrès historique du Centenaire de la révolution de 1848, Paris, Presses universitaires de France, 1949, pp. 343-356.

Frédérique DESBUISSONS, 1997, "Gustave Courbet et le frontispice du n 2 du Salut public", dans Alain CORBIN et Jean-Marie MAYEUR [dir.], La barricade. Actes du colloque de Paris, 17-19 mai 1995, Paris, Publications de la Sorbonne, 1997, pp. 151-166.

Gabriel DÉSERT, 1951, "1848 dans l'arrondissement de Caen", dans Annales de Normandie, avril 1951, pp. 125-131.

, 1956a, "Aspects agricoles de la crise : la région de Caen", dans Ernest LABROUSSE [dir.], Aspects de la crise et de la dépression de l'économie française au milieu du XIXe siècle, 1846-1851. Études, Bibliothèque de la révolution de 1848, tome XIX, Paris, Société d'histoire de 1848, 1956, pp. 37-64.

1956b, "Le milieu ouvrier caennais à la fin de la Monarchie de Juillet", dans Actes du 81e Congrès national des Sociétés savantes, Rouen-Caen, 1956, Paris, Imprimerie nationale, 1956, pp. 619-635.

1975a, Une société rurale au XIXe siècle. Les paysans du Calvados, 1815-1895, Lille, Service de reproduction des thèses-Université de Lille III, 1975 (Thèse soutenue en 1971), 3 volumes, 1247 p. +212 p.

1975b, "Les Normands et le bonapartisme", dans Annales de Normandie, tome 25, juin 1975, pp. 117-123.

1976, "L'essor de la paysannerie, 1789-1852. Vers le surpeuplement ?", dans Étienne JUILLARD [dir.], Apogée et crise de la civilisation paysanne, 1789-1914, tome 3 de Georges DUBY et Armand WALLON [dir.], Histoire de la France rurale, Paris, Éditions du Seuil, 1976, pp. 59-86.

et Robert SPECKLIN, 1976, "L'essor de la paysannerie, 1789-1852. Victoire sur la disette", dans Étienne JUILLARD [dir.], Apogée et crise de la civilisation paysanne, 1789-1914, tome 3 de Georges DUBY et Armand WALLON [dir.], Histoire de la France rurale, Paris, Éditions du Seuil, 1976, pp. 107-142.

Jean-Marie DESPORT, 1989, De la servitude à la liberté: Bourbon des origines à 1848, La Réunion, 0céan éditions, 1989, 119 p.

Henri DESROCHES, 1981, Solidarités ouvrières. I. Sociétaires et compagnons dans les associations coopératives (1831-1900), Paris, éditions ouvrières, 1981.

Marcel DESSAL, 1948, La révolution de 1848 et la Seconde République dans le département d'Eure-et-Loir, Chartres, Imprimerie Lainé et Tantet, 1948, 68 p.

Jean-Michel DEVEAU, 1970, La révolution de 1848 à Rochefort-sur-Mer, février 1848-juin 1848, La Rochelle, Centre départemental de documentation pédagogique, 1970, $42 \mathrm{p}$.

Jean-Claude DEVOS, 1984, "La répercussion des événements de Clamecy de décembre 1851 dans l'Yonne", dans Histoire régionale de 1610 à nos jours. Questions diverses, Actes du $107 e$ Congrès national des Sociétés savantes, Brest 1982 Section d'histoire moderne et contemporaine, tome II, Paris, Éditions du Comité des travaux historiques et scientifiques, 1984, pp. 117-130.

et Denise DEVOS, 1984, "L'insurrection de 1851 à Barcelonnette", dans Le Dauphiné, histoire régionale et questions diverses, Actes du 108e Congrès national des Sociétés savantes, Grenoble, 1983. Section d'histoire moderne et contemporaine, tome II, Paris, Éditions du Comité des travaux historiques et scientifiques, 1984, pp. 69-80.

Gaston DEZ, 1971, "Un Châtelleraudais constituant de 1848 : Pierre Pleignard (1795-1870)", dans Bulletin de la Société Aantique de l'Ouest, série 4, tome 11, 1971, pp. 103-144. 
José DHERS, 1963, "Le premier suffrage universel de 1848 et les pittoresques votes des militaires", dans Revue des Comminges, tome 76, trimestre 4, 1963, pp. 304-309.

Yolène DILAS-ROCHERIEUX, 1991, "Utopie et communisme, Étienne Cabet de la théorie à la pratique", dans Revue française de science politique, volume 41, n 5, octobre 1991, pp. 676-692.

H. DINE, 1965, "Émeutes et paniques de 1848 en Poitou et en Charente", dans Actes du 89e Congrès national des Sociétés savantes, Lyon, 1964. Section d'histoire moderne et contemporaine, Paris, Bibliothèque nationale, 1965, pp. 949-962.

1992, Le XIXe siècle et la Révolution française, Actes des journées d'études de la Société d'histoire de la révolution de 1848 et des révolutions du XIXe siècle, Nanterre, octobre 1989, Paris,

Éditions Créaphis, 1992, 424 p.

Édouard DOLLÉANS, 1948, Proudhon, Paris, Gallimard, 1948, 529 p.

et J.-L. PUECH, 1948, Proudhon et la révolution de 1848, collection du Centenaire de la révolution de 1848, Paris, Presses universitaires de France, 1948, 79 p.

Albert DOMINIQUE, 1948, Sèves indomptables, 1848-1849, Paris, Les éditions ouvrières, $1948,559 \mathrm{p}$.

Pierre DOMINIQUE, 1948, Les journées de 48, Paris, Flammarion, 1948, 298 p. 1966, Le Deux décembre, Paris, Librairie académique Perrin, 1966, 361 p. 1967, Les journées de juin 1848, Paris, Berger-Levrault, 1967, 256 p.

Maurice DOMMANGET, 1948a, Un drame politique en 1848, Blanqui et le document Tashereau, Paris, Les deux sirènes, 1948, $246 \mathrm{p}$.

1948b, La révolution de 1848 et le drapeau rouge.-- Spartacus, cahiers mensuels, 2e série, $\mathrm{n}$ - 3, mars 1948, $80 \mathrm{p}$.

1967, "Les Jacques dans la tradition révolutionnaire et la chanson", dans Le mouvement social, $\mathrm{n}^{\circ}$ 58, janvier-mars 1967, pp. 113-125.

1969, Auguste Blanqui, des origines à la révolution de 1848. Premiers combats et premières prisons, Paris, Mouton, 1969, $352 \mathrm{p}$.

1972, Auguste Blanqui et la révolution de 1848, Paris/La Haye, Mouton, 1972, 277 p.

Ausoumane DORE, 1974, "Les foyers et les hauts-fourneaux en Bourgogne au XIXe siècle : leur rôle dans l'évolution démographique de cette région", dans L'industrie, colloque, Metz 1972, Association interuniversitaire de l'Est, n 17, 1974, pp. 161-175.

Général DOUMENC, 1949, "L'armée et les journées de Juin", dans Actes du Congrès historique du Centenaire de la révolution de 1848, Paris, Presses universitaires de France, 1949, pp. 255-266.

Seymour DRESCHER, 1991, "British Way, French Way : Opinion Building and Revolution in the Second French Slave Emancipation", dans American Historical Review, juin 1991, pp. 709-734.

François-Georges DREYFUS, 1956, "La crise dans un département de l'est : le Bas-Rhin", dans Ernest LABROUSSE [dir.], Aspects de la crise et de la dépression de l'économie française au milieu du XIXe siècle, 1846-1851. Études, Bibliothèque de la révolution de 1848, tome XIX, Paris, Société d'histoire de 1848, 1956, pp. 226-249.

1975, Droite et gauche en Languedoc-Roussillon. Actes du colloque de Montpellier, 9-10 juin 1973, Montpellier, Université Paul Valéry, 1975, 377 p.

Jean-Claude DROUIN, 1962a, "Les candidats landais aux élections législatives du 13 mai 1849", dans Bulletin de la Société de Borda, $\mathrm{n}^{\circ} 305,1962$, pp. 64-77.

1962b, "Les élections législatives du 13 mai 1849 dans le canton de la commune de Peyrehorade", dans Bulletin de la Société de Borda, n³ 307, 1962, pp. 272-284. 
1966-1967, "Sociétés et élections dans l'arrondissement de Bazas sous la Seconde République", dans Cahiers Bazadais, n 11, 1966-1967, pp. 13-33 et n¹2, 1967, pp. 32-45. , 1967, "Les premières élections au suffrage universel dans l'arrondissement de Libourne et particulièrement dans le canton de Sainte-Foy-la-Grande (avril 1848 à mai 1849)", dans Revue historique de Bordeaux, tome 16, n² 2, 1967, pp. 121-134.

1970, "Notes sur les élections à Bayonne et à Pau de 1848 à 1870", dans Société des sciences et des lettres de Bayonne, $\mathrm{n}^{\circ}$ 24, 1970, pp. 297-306.

1972, "Les élections du 13 mai 1849 dans le département des Landes", dans Bulletin de la société de Borda, $\mathrm{n}^{\circ} 348,1972$, pp. 463-478, et n³49, 1973, pp. 65-85.

, 1973, Les élections législatives du 13 mai 1849 dans l'Aquitaine occidentale, Paris,

Hachette, 1973, 377 p.

Jacques DROZ, 1966, "Religious aspects of the Revolution of 1848 in Europe", dans French Society and Culture, Eleutherian Mills Colloquium 1964, 1966, pp. 134-149.

[dir.], 1963, Réaction et suffrage universel en France et en Allemagne (1848-1850). Études, Bibliothèque de la révolution de 1848, tome XXII, Paris, Société d'histoire de 1848, 1963, $180 \mathrm{p}$.

Charles DUBIE, 1965, Les désordres de la Barousse en 1848, Melun, Imprimerie administrative, 1965, $36 \mathrm{p}$.

Jean DUBOIS, 1962, Le vocabulaire politique et social en France de 1869 à 1872, Paris, Librairie Larousse, 1962.

Léon DUBREUIL, 1961, "La révolution de 48 en Bretagne : le conflit Morhéry-Tassel (mars 1848)", dans Cahiers d'Iroise, 8e année, n 3, 1961, pp. 169-177.

André DUBUC, 1948, "Les émeutes de Rouen et d'Elbeuf", dans Études d'histoire contemporaine, tome II, 1948, pp. 243-275.

1949, "Frédéric Deschamps, commissaire de la République en Seine-Inférieure (février-mai 1848)", dans Actes du Congrès historique du Centenaire de la révolution de 1848, Paris, Presses universitaires de France, 1949, pp. 381-396.

1960, "Une lettre sur les débuts de la révolution de 1848 à Paris", dans Annales de Normandie, $\mathrm{n}^{\circ} 3,1960$, pp. 281-282.

1969, "Une déclaration politique de Bouilhet en 1848", dans Amis de Flaubert, $\mathrm{n}^{\circ} 35$, 1969, pp. 14-17.

Bernard DUCASSE, 1966, "Fêtes de la Fraternité et banquets civiques à Libourne en 1848", dans Revue d'histoire et d'archéologie du Libournais, tome 34, n 119, 1966, pp. 3-8. Cl. DUCHET et M. LAUNAY, 1965, "Georges Sand et l'armée en 1848. Quatre lettres inédites", dans Revue d'histoire littéraire de France, n 1, 1965, pp. 78-91.

Robert DUFOURG, 1953-1954, "La révolution de 1848 à Bordeaux dans les mémoires d'Antoine Gautier", dans Revue d'histoire de Bordeaux, tome 2, $\mathrm{n}^{\circ} 1,1953$, pp. 37-48 et tome 3, n 1, 1954, pp. 73-84.

Jean DUHART et Janine DUHART, 1973, La révolution de 1848 à Givors (26 février-15 juillet), Paris, Éditions sociales, 1973, 155 p.

Jean-Baptiste DUMAY, 1976, Mémoires d'un militant ouvrier du Creusot (1841-1905), Paris/ Grenoble, Maspero/Presses universitaires de Grenoble, 1976, 431 p. (Présentation par Pierre PONSOT).

Georges DUPEUX, 1956, "Aspects agricoles de la crise : le département du Loir-et-Cher", dans Ernest LABROUSSE [dir.], Aspects de la crise et de la dépression de l'économie française au milieu du XIXe siècle, 1846-1851. Études, Bibliothèque de la révolution de 1848, tome XIX, Paris, Société d'histoire de 1848, 1956, pp. 65-92. 
1962, Aspects de l'histoire sociale et politique du Loir-et-Cher (1848-1914), Paris/La Haye, Mouton, 1962, $631 \mathrm{p}$.

1964, La société française, 1789-1960, Paris, Armand Colin, 1964, 296 p.

Catherine DUPRAT, 1993, "Pour l'amour de l'humanité". Le temps des philanthropes. La philanthropie, parisienne des Lumières à la Monarchie de Juillet, Paris, Éditions du Comité des travaux historiques et scientifiques, 1993, 485 p., tome 2 à paraître.

Jean DUPUY, 1961, "Le socialisme en Loir-et-Cher de 1795 à 1852", dans Bulletin de la Société archéologique et scientifique du Vendômois, 1961, pp. 39-54.

Roger DUPUY, 1981, "Les paysans et la politique (1750-1850)", dans Les paysans et la politique.-- Annales de Bretagne et des pays de l'Ouest, numéro spécial, 1981.

Jean-Baptiste DUROSELLE, 1949, "Les catholiques et le problème ouvrier en 1848", dans Actes du Congrès historique du Centenaire de la révolution de 1848, Paris, Presses universitaires de France, 1949, pp. 267-276.

1951, Les débuts du catholicisme social (1822-1870), Paris, Presses universitaires de France, 1951.

René DURR, 1969, "Le drapeau rouge à Joigny (25 juin 1848) : l'affaire Fouffé", dans Bulletin de la Société des sciences et histoire naturelle de l'Yonne, 1969 (1967-1968) vol 102, p 173-92.

Georges DUVEAU, 1948a, Raspail, collection du Centenaire de la révolution de 1848, Paris, Presses universitaires de France, 1948, 64 p.

1948b, La pensée ouvrière sur l'éducation pendant la Seconde République et le Second Empire, Paris, Domat-Montchrestien, 1948, 351 p.

1949, "Les relations internationales dans la pensée ouvrière (1840-1865)", dans Actes du Congrès historique du Centenaire de la révolution de 1848, Paris, Presses universitaires de France, 1949, pp. 277-284.

1965, 1848, Collection Idées, Paris, Gallimard, 1965, 250 p.

Meldvin EDELSTEIN, 1993, "La participation électorale des Français (1789-1870)", dans Revue d'histoire moderne et contemporaine, tome 40, octobre-décembre 1993, pp. 629-642. Jean EFFER, Jacques MAIRESSE et Jean-Marie CHANUT, 1986, "La culture du blé au milieu du XIXe siècle : rendement, prix, salaires et autres coûts", dans Annales, économies, sociétés, civilisations, tome $41, \mathrm{n}^{\circ}$ 6, novembre-décembre 1986, pp. 1273-1302.

Jean EICH, 1948, Thionville et son arrondissement en 1848, Metz, Coopérative d'édition et d'impression, 1948, $39 \mathrm{p}$.

Léo ELISABETH, 1983, "L'abolition de l'esclavage à la Martinique", dans Annales des Antilles, Mémoires de la Société d'histoire de la Martinique, nº 5, Fort-de-France, 1983, $155 \mathrm{p}$.

Marcel ÉMERIT, 1974, "Le saint-simonisme dans les Charentes", dans Le mouvement social , n8 88, juillet-septembre 1974, pp. 93-112.

1981, "Les Saint-Simoniens sous la Seconde République", dans 1848, les utopismes sociaux. Utopie et action à la veille des journées de février, Paris, CDU-SEDES, 1981, pp. 113-129.

[dir.], 1949, La révolution de 1848 en Algérie. Mélanges d'histoire, Paris, Publication du Comité central pour la Commémoration de la révolution de 1848 en Algérie, 1949, 191 p. André ENCREVÉ, 1972, "Les milieux dirigeants du protestantisme français et les problèmes sociaux, sous la Deuxième République", dans Revue d'histoire moderne et contemporaine, tome 19, juillet-septembre 1972, pp. 434-468.

1975, "Protestantisme et politique. Les protestants du Midi en décembre 1851", dans Droite et gauche en Languedoc-Roussillon. Actes du colloque de Montpellier, 9-10 juin 1973, Montpellier, Université Paul Valéry, 1975, pp. 161-195. 
1973, Encyclopédie antillaise, volume IV, Economie et perspectives, Éditions Désormeaux, Fort-de-France, 1973, $416 \mathrm{p}$.

1948, L'Époque de 1848 à Marseille et dans les Bouches-du-Rhône, art et histoire. Catalogue de l'exposition organisée du 20 juin au 15 juillet 1948, pour le centenaire de la Seconde République, Marseille, Imprimerie de Leconte, 1948, 100 p;

Ed. ESMONIN, 1949, "Introduction", dans La révolution de 1848 dans le département de l'Isère, Grenoble, Comité départemental du Centenaire de la révolution, 1949, pp. V-XXVII.

1970, L'esprit républicain. Colloque d'Orléans, 4 et 5 septembre 1970, Paris, Klincksieck, 1972, $464 \mathrm{p}$.

Christian ESTÈVE, 1996, "Recherches sur la revendication paroissiale dans le Cantal de la première moitié du XIXe siècle", dans Revue de la haute Auvergne, n 1, 1996, pp. 47-104. D.-O. EVANS, 1948, Le socialisme romantique. Pierre Leroux et ses contemporains, Paris, Librairie Marcel Rivière, 1948, 262 p.

Josette FALLOPE, 1992, Esclaves et citoyens. Les Noirs à la Guadeloupe au XIXe siècle dans les processus de résistance et d'intégration (1802-1910) , Basse-Terre, Société d'histoire de la Guadeloupe, 1992, 713 p.

Jean-Claude FARCY, 1977, "Les archives judiciaires de l'histoire rurale : l'exemple de la Beauce au XIXe siècle", dans Revue historique, octobre-décembre 1977, pp. 313-352.

__-_, 1989, Les paysans beaucerons au XIXe siècle, Chartres, Société archéologique d'Eureet-Loir, 1989, 2 volumes, $1236 \mathrm{p}$.

1992, Guide des archives judiciaires et pénitentiaires, 1800-1958, Paris, Éditions du Centre national de la recherche scientifique, 1992, 1175 p.

, 1994, "Le cadastre et la propriété foncière au XIXe siècle", dans Alain FAURE, Alain PLESSIS et Jean-Claude FARCY [dir.], La terre et la cité. Mélanges offerts à Philippe Vigier, Paris, Éditions Créaphis, 1994, pp. 33-52.

George W. FASEL, 1968, "The French Election of April 23, 1848. Suggestions for a Revision", dans French Historical Studies, tome 5, 1968, pp. 285-298.

1972, "Urban workers in provincial France, February-june 1848", dans International Review of Social History, volume 17, 1972, pp. 661-674.

1974, "The wrong revolution : French Republicanism in 1848", dans French

Historical Studies, volume 8, $\mathrm{n}^{\circ} 4,1974$, pp. 654-677.

Alain FAURE, 1974, "Mouvements populaires et mouvement ouvrier à Paris (1830-1834)", dans Le Mouvement social, $\mathrm{n}^{\circ}$ 88, Juillet-septembre 1974, pp. 51-92.

1978, Paris Carême-prenant. Du Carnaval à Paris au XIXe siècle, 1800-1914, Paris, Hachette, 1978, $179 \mathrm{p}$.

1987, "Nos intentions... et quelques résultats", dans Philippe VIGIER et Alain FAURE [dir.], Maintien de l'ordre et polices en France et en Europe au XIXe siècle, Paris, Créaphis, 1987, pp. 13-20.

1990, "À la recherche des réfugiés et des prisonniers politiques", dans Philippe VIGIER et Alain FAURE [dir.], Répression et prison politiques en France et en Europe au XIXe siècle, Paris, Créaphis, 1990, pp. 9-18.

et Jacques RANCIERE, 1976, La parole ouvrière 1830-1851, Paris, UGE-10/18, 1976.

Jean FAURY, 1980, Cléricalisme et anticléricalisme dans le Tarn 1848-1900, Toulouse, Presses de l'Université de Toulouse-Le-Mirail, 1980.

Roger FAYOLLE, 1969, "Aspects politiques de la critique de Sainte-Beuve (octobre 1849-1850)", dans Romantisme et politique, Colloque de Saint-Cloud 1969, 1969, pp. 255-64. 
François FEJTö, 1949, "Paris des années 40, capitale de la révolution", dans Actes du Congrès historique du Centenaire de la révolution de 1848, Paris, Presses universitaires de France, 1949, pp. 357-370.

[dir.], 1948, 1848 dans le monde. Le printemps des peuples, Paris, Éditions de Minuit, 1948, 2 volumes.

André FERMIGIER, 1986, "Mérimée et l'inspection des monuments historiques", dans Pierre NORA [dir.], Les lieux de mémoire. La Nation, Bibliothèque illustrée des histoires, N.R.F., Paris, Gallimard, 1986, volume II, pp. 593-611.

Jean-Jacques FERNIER, Patrick LE NOUENE et Jean-Luc MAYAUD, 1989, Courbet et Ornans, Paris, Éditions Herscher, 1989, 130 p.

Félix FERRAND, 1984, "La Seconde République en Baronnies (Drôme)", dans Histoire régionale de 1610 à nos jours. Questions diverses, Actes du 107e Congrès national des Sociétés savantes, Brest 1982 Section d'histoire moderne et contemporaine, tome II, Paris, Éditions du Comité des travaux historiques et scientifiques, 1984, pp. 77-102.

Jean-Louis FERRIER, 1980, Courbet, un Enterrement à Ornans. Anatomie d'un chef-d'œuvre, Paris, Denoèl-Gonthier, 1980, 107 p.

Inez FISCHER-BLANCHET, 1981, "Troubles paysans en Guadeloupe à l'époque de l'émancipation : l'affaire Sénécal", dans Cimarrons, I, Institut caraïbe de recherches historiques, Paris, Éditions Jean-Michel Place, 1981.

Georges FOESSEL, 1973, "Strasbourg sous la Seconde République, 1848-1852 : une vie tumultueuse et passionnée", dans Table ronde Pasteur à Strasbourg.-- Saisons d'Alsace, $\mathrm{n}^{\circ} 45$, 1973, pp. 9-29.

H. FORESTIER, 1957-1965, L'Yonne au XIXe siècle, 4 volumes, Auxerre, 1957-1965.

Thomas R. FORSTENZER, 1981, French Provincial Police and the Fall of the Second Republic. Social Fear and Counterrevolution, Princeton, Princeton University Press, 1981, $336 \mathrm{p}$. William FORTESCUE, 1988, Revolution and Counter-Revolution in France, 1815-1852, Oxford, Basil Blackwell, 1988, $90 \mathrm{p}$.

A. FORTIN, 1950, Contribution à l'histoire de la révolution de 1848 dans le Pas-de-Calais, Arras, $1950,128 \mathrm{p}$.

Georges FOURNIER, 1994, Démocratie et vie municipale en Languedoc, du milieu du XVIIIe siècle au début du XIXe siècle, Toulouse, 1994, 2 volumes, 481 p. et 454 p.

Laura Levine FRADER, 1978, "Paysannerie et syndicalisme révolutionnaire : les ouvriers viticoles de Coursan (1850-1914)", dans Cahiers d'histoire de l'Institut Maurice Thorez, 4e trimestre 1978.

1991, Peasants and Protest. Agricultural Workers, Politics, and Unions in the Aude, 1850-1914, Berkeley, University of California Press, 1991, 274 p.

Geneviève FRAISSE, 1976, "Les femmes libres en 1848. Moralisme et féminisme", dans Révoltes logiques, 1, 1976.

Guy FRAMBOUR, 1959, "Un commissaire du gouvernement provisoire de la République, Guépin", dans Annales de Bretagne, tome 56, n 3, 1959, pp. 329-346.

1971, "Les élections législatives et présidentielles en 1848 dans la Loire-Inférieure", dans Bulletin de la Société archéologique et historique de Nantes, tome 107, 1971, pp. 40-51. 1970, La France de la bourgeoisie, 1815-1850, Paris, Culture et art, 1970, 255 p.

Alexis FRANCOIS, 1953, "Gustave Flaubert, Maxime Ducamp et la révolution de 1848", dans Revue d'histoire littéraire de France, $\mathrm{n}^{\circ}$ 1, 1953, pp. 44-56.

M. FRANCOIS, 1960, "Lettre d'un voltigeur du 17e Léger à propos des fusillades de Lyon en 1849", dans Carnet de Sabretache, série 5, volume 6, 1960, pp. 465-466. 
Étienne FRESNAY et Étienne ROSSET, 1981, La Seconde République dans les PyrénéesOrientale, 1848-1851, Perpignan, Direction des services d'archives, 1981, 167 p.

Michael FRIED, 1983, "The Structure of Beholding in Courbet's Burial at Ornans", dans Critical Inquiry, 9, nº 4, summer 1983, pp. 635-683.

J. FROMAGEOT, 1967, "Lorsque nos aïeux allaient aux urnes... en 1848", dans Écho d'Auxerre, n 68, 1967, pp. 30-34.

Sudel FUMA, 1979, Esclaves et citoyens. Le destin de 62000 Réunionnais en 1848. Histoire de l'insertion des affranchis de 1848 à la société réunionnaise, FRDOI, Saint-Denis, Imprimerie Cazal, 1979.

1983, Le grand blocage, 1830-1848, Saint-Denis, Éditions Presses de développement, 1983.

1989, "L'abolition de l'esclavage à La Réunion en 1848 : de l'homme-objet à l'homme rejeté ", dans Actes du Colloque international Slavery in South West Indian Ocean (1985), Mahatma Gandhi Institute, 1989, pp. 383-396.

, 1994, Histoire d'un peuple. La Réunion (1848-1900), Les Cahiers de notre histoire, La Réunion, Éditions C.N.H./Université de La Réunion, 1994, 273 p.

François FURET, 1988, La Révolution de Turgot à Jules Ferry, 1770-1880, Paris, Hachette, 1988, $526 \mathrm{p}$.

et Mona OZOUF [dir.], 1993, Le siècle de l'avènement républicain, Bibliothèque des histoires, NRF, Paris, Editions Gallimard, 1993, 477 p.

Emmanuel FUREIX, 1997, "De l'"autel de l'anarchie" au Golgotha : la barricade de juin 1848 en représentation", dans Alain CORBIN et Jean-Marie MAYEUR [dir.], La barricade. Actes du colloque de Paris, 17-19 mai 1995, Paris, Publications de la Sorbonne, 1997,

pp. 221-234.

Germain GABORIT, 1962, "Le général Martin de Bourgon", dans Bulletin de la Société archéologique et historique de Charente, $\mathrm{n}^{\circ}$ 7, Supplément, 1962, p. 40.

Henri GACHOT, 1974, "Comment l'Alsace fut informée des évènements de 1848 par le télégraphe aérien", dans Diligence d'Alsace, n 12, 1974, pp. 61-69.

Camille GAGNON, 1970, En Bourgogne sous la Seconde République, Moulins, Éditions des Cahiers bourbonnais, 1970.

Françoise GAILLARD, 1980, "Gustave Courbet et le réalisme. Anatomie de la réception critique d'une œuvre : Un Enterrement à Ornans", dans Revue d'histoire littéraire de la France, n 6, novembre-décembre 1980, pp. 978-996.

Jeanne GAILLARD, 1954, "La question du crédit et les almanachs autour de 1850", dans Études, Bibliothèque de la révolution de 1848, tome XVI, Paris, Société d'histoire de 1848, 1954, pp. 79-87.

Roger GARAUDY, 1948, "Le communisme matérialiste en France avant 1848. Un précurseur : Théodore Dezamy", dans La Pensée, n 18, 1948, pp. 37-47.

Gilbert GARRIER, 1988, "Les délits de chasse en Velay et en Beaujolais au XIXe siècle d'après les archives judiciaires", dans L'imaginaire de la chasse. Hier et demain, Paris/ Chalon-sur-Saône, Hatier/Atelier CRC France, 1988, pp. 95-107.

D. GARRIGUES, 1948, Département de la Haute-Garonne. Centenaire de la Seconde république, 1848-1948. Exposition de souvenirs et documents organisée par la bibliothèque municipale de Toulouse, février-mars 1948, Toulouse, Imprimerie de Camili et Fournié, 1948, 79 p. Jean GARRIGUES, 1992, "Les image de la révolution de 1830 à 1848 : enjeux politiques d'une mémoire", dans Le XIXe siècle et la Révolution française, Actes des journées d'études de la Société d'histoire de la révolution de 1848 et des révolutions du XIXe siècle, Nanterre, octobre 1989, Paris, Editions Créaphis, 1992, pp. 91-102. 
Alain GARRIGOU, 1991, "Le brouillon du suffrage universel. Archéologie du décret du 5 mars 1848", dans Genèses, n 6, 1991, pp. 161-178.

1992, Le vote et la vertu. Comment les Français sont devenus électeurs, Paris, Presses de la Fondation nationale des sciences politiques, 1992, 286 p.

François GASNAULT, 1986, Guinguettes et lorettes. Bals publics et danse sociale à Paris entre 1830 et 1870, Paris, Aubier, 1986, 343 p.

Vicomtesse de GASTINES, 1970, "Lamartine en 1848 jugé par Madame d'Agoult", dans Bulletin de la Société d'agriculture, des sciences, des arts de la Sarthe, tome 72, série 4, tome 7, n - 14, 1970, p. 439.

Pierre GAUDIN et Claire REVERCHON, 1986, "L'événement dans le légendaire historique : l'exemple de la résistance au coup d'État de Louis-Napoléon Bonaparte dans la Drôme", dans L'événement, Actes du colloque organisé à Aix-en-Provence par le Centre méridional d'histoire sociale en septembre 1983, Aix-en-Provence, Université de Provence, 1986.

Marie-Véronique GAUTHIER, 1992, Chanson, sociabilité et grivoiserie au XIXe siècle, Paris, Aubier, 1992, 312 p.

Geneviève GAVIGNAUD, 1985, "La propriété privée des terres en Roussillon : respect et contestations de 1789 à 1849", dans Jean NICOLAS [dir.], Mouvements populaires et conscience sociale, XVIe-XIXe siècles, Actes du colloque de l'Université Paris VII-CNRS, 24-26 mai 1984, Paris, Maloine, 1985, pp. 253-260.

Pierre GAYNE, 1970-1971, "L'abbé Edmond de Cazalès, député du Tarn-et-Garonne sous la Seconde République (1804-1876)", dans Bulletin de la Société archéologique du Tarn-etGaronne, tome 96, 1970-1971, pp. 81-104.

Victor GELU, 1971, Marseille au XIXe siècle, Collection Civilisations et mentalités, Paris, Plon, 1971, $476 \mathrm{p}$.

Sharif GEMIE, 1988, "'A Danger to Society" ? Teachers and Authority in France, 1833-1850", dans French History, volume 2, n³ 3, septembre 1988, pp. 264-287.

Marie-Claude GENET-DELACROIX, 1997, "La barricade : donner un corps à l'histoire (1830-1848-1871)", dans Alain CORBIN et Jean-Marie MAYEUR [dir.], La barricade. Actes du colloque de Paris, 17-19 mai 1995, Paris, Publications de la Sorbonne, 1997, pp. 113-124.

Pierre GENEVRAY, 1948a, "Le clergé, les catholiques de Toulouse et de la Haute-Garonne sous la république de 1848", dans Jacques GODECHOT [dir.], La révolution de 1848 à Toulouse et dans la Haute-Garonne, Toulouse, Comité départemental du Centenaire de la révolution de 1848, 1948, pp. 235-356.

, 1948b, "L'État et les protestants du Réveil : la réaction conservatrice et la liberté religieuse sous la République de 1848", dans Bulletin de la Société d'histoire du protestantisme français, juillet-septembre 1948, pp. 115-121.

Jocelyne GEORGE, 1989, Histoire des maires (1789-1939), Paris, Plon,1989, 285 p. 1991, "Région, nation, tradition : six thèses sur le Var de 1800 à 1945", dans Revue historique, $\mathrm{n}^{\circ}$ 579, juillet-septembre 1991, pp. 157-178.

1994, "Mémoire révolutionnaire et tradition municipale républicaine. Le cas du Var au XIXe siècle", dans Michel VOVELLE [dir.], Révolution et République. L'exception française, Paris, Kimé, 1994, pp. 534-545.

Pierre GEORGEL, 1975, "Les transformations de la peinture vers 1848, 1855, 1863", dans Revue de l'art, $\mathrm{n}^{\circ} 27,1975$, pp. 62-77.

P. GÉRAUDEL, 1949, "Les sources manuscrites parisiennes de l'histoire de la deuxième République", dans Actes du Congrès historique du Centenaire de la révolution de 1848, Paris, Presses universitaires de France, 1949, pp. 85-89. 
Paul GERBOD, 1951, "L'enseignement dans le Puy-de-Dôme de 1848 à 1854", dans Revue d'Auvergne, tome 65, $\mathrm{n}^{\circ}$ 348-349, 1951, pp. 145-223.

1965, La condition universitaire en France au XIXe siècle, Paris, Presses universitaires de France, 1965, $720 \mathrm{p}$.

1981, "La scène parisienne et sa représentation de l'histoire nationale dans la première moitié du XIXe siècle", dans Revue historique, $\mathrm{n}^{\circ}$ 539, juillet-septembre 1981, pp. 3-30.

1988, "La révolution enseignée à la jeunesse française dans la première moitié du XIXe siècle", dans Revue historique, n 568, octobre-décembre 1988, pp. 429-446.

Raoul GERMON, 1968a, "Les élections de 1848 à l'Assemblée Constituante", dans Bulletin de la Société mauzéenne d'histoire locale, n 17, 1968, pp. 21-23 et n 19, 1968, pp. 20-29.

1968b, "Le cordonnier Fayette, commandant de la Garde Nationale", dans Bulletin de la Société mauzéenne d'histoire locale, $\mathrm{n}^{\circ}$ 18, 1968, pp. 13-23.

Pierre GEYRAUD, 1954, "Victor Hugo et les journées de 48", dans Miroir de l'histoire, n 53, 1954, pp. 707-708.

Gisela GEYWITZ, 1965, Das Plebiszit von 1851 in Frankreich, Tubingen, 1965, VIII-281 p. J. GEZTESI, 1948, La révolution de 1848 vue par les témoins, Paris, Amiot-Dumont, 1948, $333 \mathrm{p}$.

Werner GIESSELMANN, 1993, "Die Manie des Revolte" Protest unter der französischen Julimonarchie (1830-1848) : Halbband, Munich, R. Oldenbourg Verlag München, 1993, 2 volumes, $1086 \mathrm{p}$.

Bertrand GILLE, 1959, La banque et le crédit en France de 1815 à 1848, Paris, Presses universitaires de France, 1959, 380 p.

1964, "Les crises vues par la presse économique et financière (1815-1848)", dans

Revue d'histoire moderne et contemporaine, tome 11, janvier-mars 1964, pp. 5-30.

1968, La sidérurgie française au XIXe siècle. Recherches historiques, Genève, Librairie Droz, 1968, 317 p.

Marcel GILET, 1956, "Aspect de la crise de 1846 à 1851 dans le bassin houiller du Nord", dans Revue du Nord, n 149, 1956, pp. 15-27.

1972, "Au XIXe siècle, industrialisation linéaire ou industrialiation par bonds", dans

Revue économique, volume $23, \mathrm{n}^{\circ}$ 5, 1972, pp. 723-752.

Jeanne GILMORE, 1997, La République clandestine, 1818-1848, Paris, Aubier, 1997

(traduction française), $452 \mathrm{p}$.

Louis GIRARD, 1964, La Garde nationale, 1814-1871, Paris, Librairie Plon, 1964, 388 p.

1968, La IIe République, Paris, Calmann-Lévy, 1968, 318 p.

1977, "Caractères du bonapartisme dans la seconde moitié du XIXe siècle", dans

Karl HAMMER et Peter Claus HARTMANN [dir.], Le bonapartisme. Phénomène historique et mythe politique, Actes du 13e colloque historique franco-allemand, Augsbourg, 26-30 septembre 1975, Munich, Artemis Verlag Zürich und München, 1977.

1981, La Deuxième République et le Second Empire (1848-1870), Nouvelle histoire de Paris, Paris, A.P.H.P./Hachette, 1981, 471 p.

1983, "Les élections législatives de 1852 à Paris", dans Revue historique, n 545, janvier-mars 1983, pp. 69-97.

1987, "La troupe face aux insurrections parisiennes (1830-1848)", dans Philippe

VIGIER et Alain FAURE [dir.], Maintien de l'ordre et polices en France et en Europe au XIXe siècle , Paris, Créaphis, 1987, pp. 53-60.

1986, Napoléon III, Paris, Librairie Arthème Fayard, 1986, 550 p. 
Raoul GIRARDET, 1955, "Autour de quelques problèmes", dans L'armée et la Seconde République. Études, Bibliothèque de la révolution de 1848, tome XVIII, Paris, Société d'histoire de 1848, 1955, pp. 3-16.

Gaston GIRAUDIAS, 1959, "Deux députés des Deux-Sèvres à l'Assemblée Constituante de 1848 (correspondante inédite de Jules Richard et Antoine Bangier)", dans Bulletin de la Société antique de l'Ouest, série 4, tome 5, trimestre 2, 1959, pp. 99-161.

Henri GOALLOU, 1970, "Hamon, Commissaire du gouvernement , puis préfet d'Ille-etVilaine (3 mars 1848-24 janvier 1849)", dans Information historique, $\mathrm{n}^{\circ} 3$, 1970, pp. 121-123. , 1973, "Les élections à l'Assemblée législative en Ille-et-Vilaine (13 mai 1849)", dans Annales de Bretagne, tome 81, $\mathrm{n}^{\circ}$ 3-4, 1973.

Justin GODART, 1948, À Lyon, en 1848. Les Voraces, collection du Centenaire de la révolution de 1848, Paris, Presses universitaires de France, 1948, 71 p.

Jacques GODECHOT, 1948, "Il y a cent ans", dans Jacques GODECHOT [dir.], La révolution de 1848 à Toulouse et dans la Haute-Garonne, Toulouse, Comité départemental du Centenaire de la révolution de 1848, 1948, pp. 7-20.

1954, "La crise de 1846-1847 dans le sud-ouest de la France", dans Études, Bibliothèque de la révolution de 1848, tome XVI, Paris, Société d'histoire de 1848, 1954, pp. 88-108.

1971, Les révolutions de 1848, Collection le Mémorial des siècles, les évènements du XIXe siècle, Paris, Albin Michel, 1971, 503 p.

[dir.], 1948, La révolution de 1848 à Toulouse et dans la Haute-Garonne, Toulouse, Comité départemental du Centenaire de la révolution de 1848, 1948, 414 p.

[dir.], 1966, La presse ouvrière, 1819-1850. Angleterre, Etats-Unis, France, Belgique, Italie, Allemagne, Tchécoslovaquie, Hongrie, Bibliothèque de la révolution de 1848, tome XXIII, Paris, Société d'histoire de 1848, 1966, 312 p.

Jacques GOEDORP, 1967, "La révolution de 1848. Le rôle des artistes et le destin d'un tableau patriotique, Les Enrôlement volontaires de 1792 par Thomas Couture", dans Revue de sciences humaines, fascicule 128, 1967, pp. 559-585.

François GOGUEL, 1987, "Un siècle d'élections législatives dans l'Yonne (1848-1946)", dans Léo HAMON [dir.], Du jansénisme à la laïcité. Le jansénisme et les origines de la déchristianisation, Premiers Entretiens d'Auxerre, 1983, Paris, Editions de la Maison des sciences de l'homme, 1987, pp. 191-216.

Paul GONNET, 1956, "Le cas de la Côte-d'Or", dans Ernest LABROUSSE [dir.], Aspects de la crise et de la dépression de l'économie française au milieu du XIXe siècle, 1846-1851. Études, Bibliothèque de la révolution de 1848, tome XIX, Paris, Société d'histoire de 1848, 1956, pp. 250-271.

1960, "La presse et l'opinion à Nice en 1848", dans Provence historique, tome 10, fascicule 39, 1960, pp. 3-10.

M. GONTARD, 1977, "Le comportement politique des instituteurs des Basses-Alpes sous la Seconde République", dans Provence historique, avril-juin 1977.

1980, "Justice et politique. Les magistrats des Basses-Alpes sous la IIe République", dans Provence historique, janvier-mars 1980.

Roland GOSSELIN, 1992, Les almanachs républicains, Tradition révolutionnaire et culture politique des masses populaires de Paris, 1840-1851, Paris/Sainte-Foy, Canada, Éditions L'harmattan/Les presses de l'Université Laval, 1992, 330 p.

Rémi GOSSEZ, 1953, "La résistance à l'impôt : les quarante-cinq centimes", dans Bibliothèque de la révolution de 1848, tome XV, 1953. 
1955, "Notes sur la composition et l'attitude politique de la troupe", dans L'armée et la Seconde République. Études, Bibliothèque de la révolution de 1848, tome XVIII, Paris, Société d'histoire de 1848, 1955, pp. 77-110.

1956a, "À propos de la carte des troubles de 1846-1847", dans Ernest LABROUSSE [dir.], Aspects de la crise et de la dépression de l'économie française au milieu du XIXe siècle, 1846-1851.-- Études, Bibliothèque de la révolution de 1848, tome XIX, Paris, Société d'histoire de 1848, 1956, pp. 1-3.

, 1956b, "Diversité des antagonismes sociaux vers le milieu du XIXe siècle", dans Revue économique, mai 1956.

1966, "Presse parisienne à destination des ouvriers, 1848-1851", dans Jacques GODECHOT [dir.], La presse ouvrière 1819-1850, Bibliothèque de la révolution de 1848, tome XXII, 1966.

1967, Les ouvriers de Paris. L'organisation, 1848-1851, Bibliothèque de la révolution de 1848 , tome XXIV, Paris, Société d'histoire de la révolution de 1848, 1967, $446 \mathrm{p}$. 1972, "Mil huit cent quarante-huit", dans La Commune de 1871. Actes du colloque de Paris, 21-23 mai 1971.-- Le mouvement social, $n^{\circ}$ 79, avril-juin 1972, pp. 33-47.

1985, "Éléments pour un historique de la Société d'histoire de la révolution de 1848 et des révolutions du XIXe siècle, 1904-1940", dans 1848, révolutions et mutations au XIXe siècle, $\mathrm{n}^{\circ} 1,1985$, pp. 17-38.

1986, "La Société de "1848" (1945-1980)", dans 1848, révolutions et mutations au XIXe siècle, $\mathrm{n}^{\circ}$ 2, 1986, pp. 13-22.

et Françoise GRÉE, 1990, "Ouvrières prévenues d'insurrection", dans Philippe VIGIER et Alain FAURE [dir.], Répression et prison politiques en France et en Europe au XIXe siècle, Paris, Créaphis, 1990, pp. 47-63.

et Philippe VIGIER, avec Jean-Claude CARON et Pierre LENOËL, 1989, "1848-1948, les printemps des peuples. Le centenaire en France", dans Histoires de centenaires ou le devenir des révolutions. Contributions à l'histoire des centenaires des révolutions de 1830, 1848, 1870 et 1871 en France et en Europe.--1848, révolutions et mutations au XIXe siècle, nº 5, 1989, pp. 45-53.

Pierre GOUJON, 1969, "Le vignoble de Saône-et-Loire au XIXe siècle, 1815-1870 (Résumé de thèse de 3e cycle)", dans Bulletin du Centre d'histoire économique et sociale de la région lyonnaise, 1969, n² 2, pp. 16-22.

1973, Le vignoble de Saône-et-Loire au XIXe siècle (1815-1870), Lyon, Centre d'histoire économique et sociale de la région lyonnaise, 1973, $494 \mathrm{p}$.

1976, "Le temps des révolutions inachevées", dans Jean-Pierre HOUSSEL [dir.], Histoire des paysans français du XVIIIe siècle à nos jours, Roanne, Éditions Horvath, 1976, pp. 103-295.

1989, La cave et le grenier. Vignobles du Chalonnais et du Mâconnais au XIXe siècle, Lyon/ Paris, Presses Universitaires de Lyon/Éditions du Centre national de la recherche scientifique, 1989, $288 \mathrm{p}$..

1993, Le vigneron citoyen. Mâconnais et Chalonnais (1848-1914), Paris, Éditions du Comité des travaux historiques et scientifiques, 1993, $325 \mathrm{p}$.

1997a, "La mise en place de la Deuxième République dans les campagnes

mâconnaises", dans Travaux de l'Institut de recherche du val de Saône Mâconnais, n 3, 1997, pp. 57-66.

, 1997b, "La résistance au coup d'État du 2 décembre dans le Mâconnais", dans

Travaux de l'Institut de recherche du val de Saône Mâconnais, n 3, 1997, pp. 67-78. 
P. GOURDELIER, 1966, "Un Parthenaisien (Théophile Jouffrault) à Paris pendant les journées de juin 1848", dans Bulletin de la société d'histoire et d'archéologie du Parthenay, $\mathrm{n}$ - 15, 1966, pp. 38-40.

GRANDILHON, 1952, Affiches politiques et économiques de la Marne, 1848-1852, Châlons-surMarne, Archives de la Marne, 1952, 16 p.

Jacques GRANDJONC, 1981, "Utopisme, socialisme, internationalisme. Recherches internationales sur les contacts personnels, intellectuels et organisationnels entre socialistes européens avant la révolution de 1848", dans 1848, les utopismes sociaux. Utopie et action à la veille des journées de février, Paris, CDU-SEDES, 1981, pp. 219-231.

H. GRIMAL, 1948, Derrière les barricades. Le peuple de Paris à la conquête de la liberté, Paris, Bourrelier, 1948, $96 \mathrm{p}$.

André GUES, 1975, "Les expéditions armées de 1848", dans Écrits Paris, n 344, 1975, pp. 82-88.

André GUESLIN, 1978, Les origines du Crédit agricole (1840-1914), Nancy, Annales de l'Est/ Université de Nancy II, 1978, 454 p. 1987, L'Invention de l'économie sociale, Le XIXe siècle français, Paris, Economica, 1987.

Mirkine GUETZEVITCH, 1948, Les idées constitutionnelles de 1848, collection du Centenaire de la révolution de 1848, Paris, Presses universitaires de France, 1948.

Paul GUICHONNET, 1949, "L'enquête de 1849 sur les besoins de la Savoie", dans Annales savoisiennes, 1ère année, $\mathrm{n}^{\circ} 1,1949$, pp. 42-60.

1953, "William de la Rive, un temoin genevois de la révolution de 1848", dans Société d'histoire de la révolution de 1848, tome 15, 1953, pp. 143-163.

Pierre GUILLAUME, 1963a, "Grèves et organisations ouvrières chez les mineurs de la Loire au milieu du XIXe siècle", dans Le Mouvement social, avril-juin 1963, pp. 5-18.

, 1963b, "La situation économique et sociale du département de la Loire d'après

l'"Enquête sur le travail agricole et industriel" du 25 mai 1848", dans Revue d'histoire moderne et contemporaine, tome 10, janvier-mars 1963, pp. 5-34.

1966, La Compagnie des mines de la Loire (1846-1854). Essai sur l'apparition de la grande industrie capitaliste en France, Paris, Presses universitaires de France, 1966, 248 p.

Henri GUILLEMIN, 1948a, Lamartine, collection du Centenaire de la révolution de 1848, Paris, Presses universitaires de France, 1948, 88 p.

, 1948b, La tragédie de 1848, Genève, Milieu du monde, 1948, $412 \mathrm{p}$.

, 1951, Le coup du 2 décembre, Paris, Éditions Gallimard, 1951, 475 p.

1961, "Lamartine et Berne en 1848", dans 1ères Journées d'étude lamartiniennes,

Macôn, 1961, pp. 25-32.

1967, La première résurrection de la République, 24 février 1848. Trente journées qui ont fait la France, tome 24, Paris, Gallimard, 1967, 571 p.

Alain GUILLOT, 1969, "La tendance politique de LÉducation sentimentale", dans Annales de la Faculté de Droit de Lille, 1969, pp. 167-183.

Christine GUIONNET, 1996, "Élections et apprentissage de la politique. Les élections municipales sous la Monarchie de Juillet", dans Revue française de science politique, volume 46, nº 4, août 1996, pp. 555-579.

1997, L'apprentisage de la politique moderne. Les élections municipales sous la Monarchie de Juillet, Paris, Éditions L'Harmattan, 1997, 328 p.

Pierre GUIRAL, 1964, "Brèves observations sur le travaill des enfants dans les Bouchesdu-Rhône au milieu du XIXe siècle", dans 8 e Colloque sur l'artisanat, Aix-en-Provence, 1964, pp. 45-56. 
, 1986, Adolphe Thiers ou de la nécessité en politique, Paris, Librairie Arthème Fayard, $1986,622 \mathrm{p}$.

[dir.], 1969, La société française (1815-1914) vue par les romanciers, Paris, Librairie Armand Colin, 1969, $250 \mathrm{p}$.

Éliane GURY, 1975, "Les débuts de la Seconde République dans les Vosges (févrierdécembre 1848) : étude politique", dans Bulletin de la Société lorraine d'études locales, $\mathrm{n}^{\circ} 49$, 1975, pp. 13-29.

Marius François GUYARD, 1973, "Lamartine homme politique", dans Annales de l'Académie d'Alsace, n 1, 1973, pp. 16-20.

Georges GUYONNET, 1959, "Un document nouveau sur le pillage du Raincy en 1848", dans Bulletin de la société d'histoire du Raincy, $\mathrm{n}^{\circ}$ 26, 1959, pp. 42-43.

Michèle HADDAD, 1983, "Une mystification de Gustave Courbet", dans Les Amis de Gustave Courbet, Bulletin n 69, 1983, pp. 1-14.

Daniel HALEVY, 1948, La vie de Proudhon, Paris, Delamain et Boutelleau, 1948, 449 p. J. Stephen HALZETT, 1973, "A french conception of républician education : the Cranot ministry 1848?", dans Peadagogia historical, tome 13, $\mathrm{n}^{\circ}$, 1973, pp. 48-72.

A. HAMELIN, 1954, "La Seconde République dans le Loir-et-Cher", dans Études, Bibliothèque de la révolution de 1848, tome XVI, Paris, Société d'histoire de 1848, 1954, pp. 141-158.

Léo HAMON [dir.], 1994, Les républicains sous le Second Empire, 9es Entretiens d'Auxerre, 1992, Paris, Éditions de la Maison des sciences de l'homme, 1994, 215 p.

et Guy LOBRICHON [dir.], 1988, L'élection du chef de l'État en France de Hugues Capet à nos jours, Entretiens d'Auxerre 1987, Paris, Beauchesne, 1988, 242 p.

P. HAMON, 1949, "François Ponsard et la Deuxième République", dans La révolution de 1848 dans le département de l'Isère, Grenoble, Comité départemental du Centenaire de la révolution, 1949, pp. 499-509.

Michael P. HANAGAN, 1989, "Nascent Proletarians : Migrations Patterns and Class Formation in the Sptéphanois Region, 1840-1880", dans Philip E. OGDEN et Paul E. WHITE [dir.], Migrants in Modern France. Population Mobility in the Later Nineteenth and Twentieth Centuries, Londres, Unwin Hyman, 1989, pp. 74-96.

Vladimir HANGA, 1970, "La proclamation d'Islaz (Déclaration des droits de l'homme et du citoyen, 1848) et l'influence française", dans Revue internationale de droit comparé (Paris), n 3, 1970, pp. 491-501.

June HARGROVE, 1986, "Les statues de Paris", dans Pierre NORA [dir.], Les lieux de mémoire. La Nation, Bibliothèque illustrée des histoires, N.R.F., Paris, Gallimard, 1986, volume III, pp. 243-282.

Michel HAU, 1976, La croissance économique de la Champagne de 1810 à 1969, Strasbourg, Association des publications près les universités de Strasbourg, 1976, 179 p.

1987, L'industrialisation de l'Alsace (1803-1939), Strasbourg, Association des

Publications près les Universités de Strasbourg, 1987, 549 p.

Annette HAUDIQUET, "Éclat et déclin des salons organisés dans les villes du nord de la France de 1815 à 1848", dans Les salons retrouvés. Éclat de la vie artistique dans la France du Nord, 1815-1848, Lille, Association des conservateurs des Musées du Nord-Pas-de-Calais, 1993, pp. 11-30.

Heinz-Gerhard HAUPT et Philippe VIGIER [dir.], 1979, L'atelier et la boutique.-- Le Mouvement social, $\mathrm{n}^{\circ}$ 108, juillet-septembre 1979.

[dir.], 1981, Petite entreprise et politique.-- Le Mouvement social, $\mathrm{n}^{\circ} 114$, janvier-mars $1981,158 \mathrm{p}$. 
Michael J. HEFFERNAN, 1989, "The Parisian Poor and the Colonization of Algeria during the Second Republic", dans French History, volume 3, n 4, décembre 1989, pp. 377-403. F.W.J. HEMMINGS, 1971, Culture and society in France, 1848-1898, New York, Charles Scribner's Sons, 1971, $280 \mathrm{p}$. William Otto HENDERSON, 1970, La révolution industrielle, 1780-1914, Collection histoire illustrée de l'Europe, Paris, Flammarion, 1970, 215 p.

Simone HENRY, 1948, "La campagne des banquets à Toulouse", dans Jacques GODECHOT [dir.], La révolution de 1848 à Toulouse et dans la Haute-Garonne, Toulouse, Comité départemental du Centenaire de la révolution de 1848, 1948, pp. 53-62.

Henri HERAIL, 1965, "Élections à l'Assemblée constituante de 1848", dans Revue du Tarn, série 3, nº 39, 1965, pp. 361-374.

Colin HEYWOOD, 1981, "The Role of thr French Peasantry in French Industrialization, 1815-1880", dans Economic History, tome 34, août 1981, pp. 359-376.

Henri HIEGEL, 1953-1954, "Le catholicisme social en Moselle de 1822 à 1851", dans Cahiers lorrains, $\mathrm{n}^{\circ} 3,1953$, pp. 36-40 et $\mathrm{n}^{\circ}$ 3, 1954, pp. 40-44.

Yves-Marie HILAIRE, 1977, Une chrétienté au XIXe siècle? La vie religieuse des populations du diocèse d'Arras (1840-1914), Villeneuve-d'Ascq, Publications de l'Université de Lille III, 1977, 2 volumes, $1017 \mathrm{p}$.

Jean-Pierre HIRSCH, 1991, Les deux rêves du commerce. Entreprise et institution dans la région lilloise (1780-1860), Paris, Édition de l'École des hautes études en sciences sociales, 1991, $534 \mathrm{p}$.

1989, Histoires de centenaires ou le devenir des révolutions.-- 1848, révolutions et mutations au XIXe siècle, $\mathrm{n}^{\circ}$ 5, 1989, $217 \mathrm{p}$.

1991, Histoire de la France coloniale, volume 1, Paris, Librairie Armand Colin, 1991, 847 p. Eric J. HOBSBAWM, 1959, Primitive Rebels, Manchester, Manchester University Press, 1959, traduction française : Les primitifs de la révolte dans l'Europe moderne, Paris, Librairie Arthème Fayard, 1966, $222 \mathrm{p}$.

1962, The Age of Revolution, Londres, Weidenfeld and Nicolson, 1962, traduction française : L'ère des révolutions, Paris, Librairie Arthème Fayard, 1969, $434 \mathrm{p}$

1975, The Age of Capital, 1848-1875, Londres, Weidenfeld and Nicolson, 1975, traduction française : L'ère du capital, (1848-1875), Paris, Librairie Arthème Fayard, 1978, $468 \mathrm{p}$.

Raymond HUARD, 1971, "La défense du suffrage universel sous la Seconde République", dans Annales du Midi, nº 103, juillet-septembre 1971, pp. 315-336.

1975, "Montagne rouge et montagne blanche en Languedoc-Roussillon sous la Seconde République", dans Droite et gauche en Languedoc-Roussillon. Actes du colloque de Montpellier, 9-10 juin 1973, Montpellier, Université Paul Valéry, 1975, pp. 139-160.

1979, "La préhistoire des partis. Le Parti républicain dans le Gard de 1848 à 1881", dans Le mouvement social, $\mathrm{n}^{\circ} 107$, avril-juin 1979, pp. 3-14.

1980, "La génèse des partis politiques modernes en France. Y-a-t-il une spécificité populaire ?" dans La classe ouvrière française et la politique, Paris, Éditions sociales, 1980. 1982, La préhistoire des partis. Le mouvement républicain en Bas-Languedoc, 1848-1881, Paris, Presses de la Fondation nationale des sciences politiques, 1982, $520 \mathrm{p}$. 1984, "Souvenir et tradition révolutionnaires : le Gard 1848-1851", dans Annales historiques de la Révolution française, octobre-décembre 1984.

1985, "Existe-t-il une "politique populaire" ?", dans Jean NICOLAS [dir.], Mouvements populaires et conscience sociale, XVIe-XIXe siècles. Actes du colloque de l'Université Paris VII-CNRS, 24-26 mai 1984, Paris, Maloine, 1985, pp. 57-68. 
1986, "Sociabilité et politique en Languedoc méditerranéen des lendemains de la Restauration à la fin de 1849", dans Etienne FRANCOIS [dir.], Sociabilité et société bourgeoise en France, en Allemagne et en Suisse (1750-1850), Paris, Editions Recherches sur les civilisations, 1986, pp. 299-312.

1991, Le suffrage universel en France (1848-1946), Paris, Aubier, 1991, 493 p.

, 1992, "L'organisation du suffrage universel sous la Seconde République", dans

Serge BERSTEIN et Odile RUDELLE [dir.], Le modèle républicain, Paris, Presses universitaires de France, 1992, pp. 71-90.

1995, "Le suffrage universel", dans Jean-Yves MOLLIER et Pascal ORY [dir.], Pierre Larousse et son temps, Paris, Larousse, 1995, pp. 207-224.

1996, La naissance du parti politique en France, Paris, Presses de Sciences Po, 1996.

Ronald HUBSCHER, 1971, "La rente foncière dans le département du Pas-de-Calais au cours de la seconde moitié du XIXe siècle (1846-1914)", dans Revue historique, $\mathrm{n}^{\circ}$ 498, avriljuin 1971, pp. 369-392.

, 1979, L'agriculture et la société rurale dans le Pas-de-Calais du milieu du XIXe siècle à 1914, Arras, Mémoires de la C.D.M.H. du Pas-de-Calais, 1979, 2 volumes, 964 p.

Jesus IBAROLLA, 1971, Recherches sur la société grenobloise vers le milieu du XIXe siècle à partir des Tables de successions et des absences, Paris/La Haye, Mouton, 1971, 280 p.

François IGERSHEIM, 1993, Politique et administration dans le Bas-Rhin (1848-1870), Strasbourg, Presse universitaires de Strasbourg, 1993.

Joseph E. INIKORI, 1979, "La traite négrière et les économies atlantiques de 145I à 1870", dans La traite négrière du XVe au XIXe siècle, Histoire générale de l'Afrique, Études et documents 2, Paris, Unesco, 1979, pp. 58-91

INSTITUT DE CULTURE OUVRIÈRE, 1948, 1848. Une page d'histoire ouvrière, Marly-le-Roi, ICO, 1948, $53 \mathrm{p}$.

L. JACOB, 1948, La révolution de 1848 dans le Nord,, Lille, Comité départemental de la célébration du centenaire, 1948, 24 p.

Gérard JACQUEMET, 1984, Belleville au XIXe siècle, du faubourg à la ville, Paris, Éditions de l'École des hautes études en sciences sociales, 1984, $454 \mathrm{p}$.

R. JACQUIN, 1972, "L'ordre social en 1848 : la contribution de l'Académie des sciences morales et politiques", dans Revue des sciences religieuses, $n^{\circ} 2,1972$, pp. 144-152.

André JARDIN et André-Jean TUDESQ, 1973, La France des notables, tome 1 : l'évolution générale, 1815-1848; tome 2 : la vie de la nation, 1815-1848, Paris, Éditions du Seuil, 1973, 2 volumes.

G. JARLOT, 1958, "Le droit au travail", dans Gregorianum, n³ 3, 1958, pp. 548-584.

Louis JASSERON, 1964, "L'expédition des Voraces en Savoie", dans Fureteur, n 7-8, 1964, pp. 222-224.

Lucien JAUME, 1991, "Tocqueville et le problème du pouvoir exécutif en 1848", dans Revue française de science politique, volume 41, n 6, décembre 1991, pp. 739-755.

Pierre JEAMBRUN, 1991, Jules Grévy ou la République debout, Paris, Tallandier, 1991, 464 p. J.-F. JEANJEAN, 1948, La révolution de 1848 dans le département de l'Aude, Carcassonne, Chez l'auteur/imprimerie Gabelle, 1948, 131 p.

André JEANNET, 1984, La Seconde République en Saône-et-Loire, Mâcon, Images de Saôneet-Loire, 1984, $142 \mathrm{p}$.

Lawrence JENNINGS, 1969, "L'abolition de l'esclavage par la IIe République et ses effets en Louisiane, 1848-1858", dans Revue française d'histoire d'outre-mer, tome 56, n² 205, 1969, pp. 375-397. 
1970, "Lamartine's Italian policy in 1848, a reexamination", dans Journal of Modern History, volume 42, n³, 1970, pp. 331-341.

1972, "The parisian press and french foreign affairs in 1848, dans Canadian Journal History, volume $7, \mathrm{n}^{\circ} 2,1972$, pp. 119-127.

1973, France and Europe in 1848. A study of French Foreign Affairs in Time of Crisis, Oxford, Clarendon Press, 1973, 280 p. 1976, "French Policy towards Trading with African and Brazilian Slave Merchants, 1840-1853", dans Journal of African History, volume 17, 1976, pp. 515-528. 1980, "The French Press and Great Britain's Campaign against the Slave Trade, 1830-1848", dans Revue française d'histoire d'outre-mer, n 246-247, 1980, pp. 5-24. 1988, French Reaction to British Slave Emancipation, Baton Rouge, Louisiane, 1988. Jean-Pierre JESSENNE, 1983, "Le pouvoir des fermiers dans les villages d'Artois (1770-1848)", dans Annales, économies, sociétés, civilisations, tome 38, n³, mai-juin 1983, pp. 702-734.

1987, Pouvoir au village et révolution. Artois, 1760-1848, Lille, Presses universitaires de Lille, 1987, $308 \mathrm{p}$.

Christopher JOHNSON, 1974, Utopian Communism in France. Cabet and the Icarians, 1839-1851 , Ithaca/Londres, Cornel University Press, 1974.

Peter M. JONES, 1980a, "La République au village in southern Massif central", dans Historical Journal, tome 23, 1980, pp. 793-812.

1980b, "Political Commitment and Rural Society in the Southern Massif central", dans Europeans Studies Review, tome 10, 1980, pp; 337-356.

1981, "Parish, Seigneurie and the Community of Inhabitants in Southern Massif Central during the Eignteenth and Nineteenth Centuries", dans Past and Present, $\mathrm{n}^{\circ}$ 91, mai 1981, pp. 74-108.

1982, "An Improbable Democracy : Nineteenth Century Elections in the Massif Central", dans The English Historical Review, volume 97, n 384, juillet 1982, pp. 530-557. 1985, Politics and Rural Society. The Southern Massif Central c. 1750-1880, Cambridge, Cambridge University Press, 1985, 374 p.

R. JOUANNE, 1948, La révolution de 1848 dans le département de l'Orne. Commentaire de l'exposition des archives départementales, juin-septembre 1948, Alençon, Imprimerie PouletMalassis, 1948, $52 \mathrm{p}$.

Louis JOUBERT, 1948, "Les conséquences géographiques de l'émancipation des Noirs aux Antilles, 1848", dans Cahiers d'Outre-Mer, avril-juin 1948.

R. JOUCLA-RUAU, 1965, "La répression à Marseille et dans les Bouches-du-Rhône après les journées de juin 1848", dans Conférence de l'Institut historique de Provence, ${ }^{\circ} 1,1965$, pp. 170-171.

Étienne JUILLARD [dir.], 1976, Apogée et crise de la civilisation paysanne, 1789-1914, tome 3 de Georges DUBY et Armand WALLON [dir.], Histoire de la France rurale, Paris, Éditions du Seuil, 1976, 573 p.

Charles-André JULIEN, 1948a, "La révolution de 1848 et les territoires d'outre-mer", dans Revue socialiste, janvier-février 1948.

1948b, "Schœlcher et l'abolition de l'esclavage", dans Le Larousse mensuel, mai 1948. R. JUPIN, 1973, "La révolution de février 1848 à Chatellerault", dans Bulletin de la Société d'antiquité de l'Ouest, tome 12, trimestre 3, 1973, pp. 220-227.

Bernard KALAORA et Antoine SAVOYE, 1986, La forêt pacifiée. Sylviculture et sociologie au XIXe siècle. Les forestiers de l'Ecole de Le Play, experts des sociétés pastorales, Paris, L'Harmattan, 1986, 134 p. 
Slawomir KALEMBKA, 1990, "Les émigrés polonais, victimes de la répression politique (1848-1870)", dans Philippe VIGIER et Alain FAURE [dir.], Répression et prison politiques en France et en Europe au XIXe siècle, Paris, Créaphis, 1990, pp. 305-314.

Yvette KATAN, 1984, "Les colons de 1848 en Algérie : mythe et réalités", dans La France et ses colonies.-- Revue d'histoire moderne et contemporaine, tome 31, avril-juin 1984, pp. 177-202.

1986, "Le voyage “organisé” d'émigrants parisiens vers l'Algérie, 1848-1849", dans Études de cas : Algérie, Canada, États-Unis.-- L'Émigration française, Publications de la Sorbonne, $\mathrm{n}^{\circ} 1,1986$.

L. KIECHEL, 1974, "Aspects de la révolution de 1848 dans la région frontalière", dans Société d'histoire du musée d'Huningu, n² 22, 1974, pp. 60-90.

Jean-Pierre KINTZ, 1971, "Emile Kuss, maire de Strasbourg en 1870, journaliste et militant politique sous la Seconde République (1848-1851)", dans Annuaire de la Société des amis du vieux Strasbourg, $\mathrm{n}^{\circ}$ 2, 1971, pp. 95-123.

Ursula E. KOCH, 1995, "La presse et son public à Paris et à Berlin (1848-1849). Une étude exploratoire", dans Ilja MIECK, Horst MÖLLER et Jürgen VOSS [dir.], Paris und Berlin in der Revolution 1848/Paris et Berlin dans la révolution de 1848. Colloque organisé par la Ville de Paris; l'Historische Kommission zu Berlin et l'Institut historique allemand, Paris, 23-25 novembre 1992, Sigmaringen, Jan Thorbecke Verlag, 1995, pp. 19-78.

Sandrine KOTT, 1987, "Enjeux et significations d'une politique sociale : la Société industrielle de Mulhouse (1827-1870)", dans Revue d'histoire moderne et contemporaine, tome 34, octobre-décembre 1987, pp. 640-659.

Odile KRAKOVITCH, 1987, "La mise en pièces des théâtres : la censure des spectacles au XIXe siècle", dans Philippe VIGIER et Alain FAURE [dir.], Maintien de l'ordre et polices en France et en Europe au XIXe siècle, Paris, Créaphis, 1987, pp. 287-300.

1992, "La révolution à travers le théâtre de 1815 à 1870 : à chaque génération sa peur", dans Le XIXe siècle et la Révolution française, Actes des journées d'études de la Société d'histoire de la révolution de 1848 et des révolutions du XIXe siècle, Nanterre, octobre 1989, Paris, Editions Créaphis, 1992, pp. 57-74.

Albert KREBS, 1960, "La loterie des Lingots d'or", dans Aux carrefours de l'histoire, $\mathrm{n}^{\circ} 30$, 1960, pp. 320-330.

Annie KRIEGEL, Rémi GOSSEZ et Jacques ROUGERIE, 1962, "Sources et méthodes pour une histoire sociale de la classe ouvrière", dans Le Mouvement social, juillet-septembre 1962.

Fernand L'HUILLIER, 1993, Lamartine en politique, Strasbourg, Presses universitaires de Strasbourg, 1993, 256 p.

Ernest LABROUSSE, 1949, "1848, 1830, 1789. Comment naissent les révolutions", dans Actes du Congrès historique du Centenaire de la révolution de 1848, Paris, Presses universitaires de France, 1949, pp. 1-30.

, 1956, "Panoramas de la crise", dans Ernest LABROUSSE [dir.], Aspects de la crise et de la dépression de l'économie française au milieu du XIXe siècle, 1846-1851. Études, Bibliothèque de la révolution de 1848, tome XIX, Paris, Société d'histoire de 1848, 1956, pp. I-XXIV.

[dir.], 1956, Aspects de la crise et de la dépression de l'économie française au milieu du XIXe siècle, 1846-1851. Études, Bibliothèque de la révolution de 1848, tome XIX, Paris, Société d'histoire de 1848, 1956, 356 p.

René LACOUR, 1954, "La révolution de 1848 dans le Beaujolais et la campagne lyonnaise", dans Albums crocodile, $n^{\circ}$ 5, 1954, pp. 1-32 et n 6, 1954, pp. 33-68. 
Jean LACROIX, 1949, Vienne sous la Seconde République, Vienne, Imprimerie TernerMartin, 1949, $79 \mathrm{p}$.

Régis LADOUS, 1985, "Les unions chrétienes de jeunes gens de 1844 à 1878. Les étapes et les causes de la construction d'un mouvement international", dans Gérard CHOLVY [dir.], Mouvements de jeunesse chrétiens et juifs : Sociabilité juvénile dans un cadre européen, 1799-1968, Paris, Éditions du Cerf, 1985, pp. 125-140.

Maurice LAIREZ, 1960, "Revue de la garde nationale et de l'armée par Monsieur LouisNapoléon Bonaparte, élu président de la République", dans Briquet, n² 2, 1960, n.p.

René LAMARQUE, 1948, "La fin de la Seconde république à Toulouse", dans Jacques GODECHOT [dir.], La révolution de 1848 à Toulouse et dans la Haute-Garonne, Toulouse, Comité départemental du Centenaire de la révolution de 1848, 1948, pp. 357-399.

Jean LAMBERT-DANSETTE, 1954, "Recrutement et évolution d'un patronat du Nord : quelques familles du patronat du textile de Lille-Armentières (1789-1914)", dans Société d'études de la province de Cambrai, tome 43, n 16, 1954, pp. 1-44.

1971, "Le patronat, sa période triomphante (1830-1880)", dans Bulletin de la Société d'histoire moderne, série $14, \mathrm{n}^{\circ} 18,1971$, pp. 2-13.

William L. LANGER, 1966, The pattern of urban Revolution in 1848", dans French Society and Culture, Eleutherian Mills Colloquium, 1964, 1966, pp. 89-118.

, 1969, Political and Social Upheaval, 1832-1852, New York, Harper and Row, 1969.

Claude LANGLOIS et Jean POIRIER [dir.], 1988, Raspail et la vulgarisation médicale, Paris, Vrin, 1988.

Oruno D. LARA, 1979, "Résistance et esclavage : de l'Afrique aux Amériques noires", dans La traite négrière du XVe au XIXe siècle, Histoire générale de l'Afrique, Études et documents 2, Paris, Unesco, 1979, pp. 105-123.

1992, Caraibes en construction : espace, colonisation, résistance, Paris/Épinay, Éditions du Centre de recherches Caraibes-Amériques, 1992, 2 volumes, 1560 p. , 1997, Les Caraibes, Que sais-je ?, n 2267, Paris, Presses Universitaires de France, 1997 (réédition), $128 \mathrm{p}$.

H. LARDAAS, 1948, 1848, une révolution, Paris, Hachette, 1948, 178 p.

Jean-Paul LARTIGUE, 1965, "La révolution de 1848 à Tulle", dans Bulletin de la Société des lettres et des sciences de Corrèze, tome 64, 1965, pp. 36-48.

Jean LASPOUGEAS, 1973, "Une étude sur la fortune du clergé (du Calvados) au

XIXe siècle (1840-1880), par Guislaine Robert-Debeugny", dans Annales de Normandie, $\mathrm{n}^{\circ} 3$, 1973, pp. 268-271.

Claude LATTA, 1987, "Le maintien de l'ordre à Lyon (février-juillet 1848)", dans Philippe VIGIER et Alain FAURE [dir.], Maintien de l'ordre et polices en France et en Europe au XIXe siècle , Paris, Créaphis, 1987, pp. 61-85.

André LATREILLE et René REMOND, 1962, Histoire du catholicisme en France, Paris, Spes, 1962.

Maurice de LAUGARDIERE, 1958, Le clergé du Berry aux élections de 1848, Bourges, Tardy, 1958, $128 \mathrm{p}$.

Marcel LAUNAY, 1975, "Les procès-verbaux de visites pastorales dans le diocèse de Nantes au milieu du XIXe siècle", dans Annales de Bretagne et des pays de l'Ouest, tome 83, $\mathrm{n}$ - $2,1975$.

1982, Le diocèse de Nantes sous le Second Empire, Nantes, CIC Éditions, 1982, 2 volumes.

Philippe LE BOMIN, 1968, "Les évènements de 1848 à Mantes", dans Mantois, n² 2, 1968, pp. 207-222. 
Général LE BRETON, 1961, "Souvenirs de l'année 1848", dans Revue de Paris, nº 5, 1961, pp. 96-112.

Louis LE GUILLOU, 1971, "Une lettre inédite de Lammenais à George Sand, 23 juillet 1848", dans Cahiers mennaisiens, n 1, 1971, pp. 35-37.

Patrick LE NOUËNE, 1993a, "Justifications et débats autour des expositions dans le Nord et dans les régions de 1815 à 1848", dans Les salons retrouvés. Éclat de la vie artistique dans la France du Nord, 1815-1848, Lille, Association des conservateurs des Musées du Nord-Pas-deCalais, 1993, pp. 31-42.

1993b, "Débats autour de la réception des œuvres exposées dans le nord de la France de 1815 à 1848", dans Les salons retrouvés. Éclat de la vie artistique dans la France du Nord, 1815-1848, Lille, Association des conservateurs des Musées du Nord-Pas-de-Calais, 1993, pp. 43-60.

Lucette LE VAN-LEMESLE, 1980, "La promotion de l'économie politique en France au XIXe siècle jusqu'à son introduction dans les facultés (1815-1881)", dans Revue d'histoire moderne et contemporaine, tome 27, avril-juin 1980, pp. 270-294.

Jean LE YAOUANQ, 1974, 1848 en Europe, Paris, Presses universitaires de France, 1974, $96 \mathrm{p}$.

Ary LEBLOND, 1948, "Sarda Garriga. Un Bonaparte émancipateur des noirs à l'île de la Réunion, 1848", dans Revue des deux mondes, 15 juin 1948.

Yves LECLERCQ, 1987, Le réseau impossible (1820-1852). La résistance au système des grandes compagnies ferroviaires et la politique économique en France, Genève/Paris, Droz, 1987, 288 p. , 1990, "L'Etat, les entreprises ferroviaires et leurs profits en France (1830-1860)", dans Les transports.-- Histoire, économie et société, 1er trimestre 1990, pp. 39-63. 1991, "Les débats d'orientation économique de la France (1815-1850)", dans

Économie et société. Histoire quantitative de l'économie française, série AF 16, n² 2, février 1991, pp. 91-119.

LECOMPT 1959, "L'agitation ouvrière à Roubaix et à Tourcoing en 1848 et 1849", dans Bulletin communal d'histoire du Nord, tome 37, 1959, pp. 28-29.

Bernard-Pierre LECUYER, 1987, "Médecins et observateurs sociaux : les Annales d'hygiène publique et de médecine légale (1820-1850)", dans Pour une histoire de la statistique. Tome I, contributions, Paris, Institut national de la statistique et des études économiques, 1987, pp. 445-476.

Henry LEFAI, 1958, "Huysmans, l'enfant de 1848", dans Bulletin de la société J.K. Huysmans, $\mathrm{n}^{\circ} 36,1958$, pp. 323-329.

André LEFEVRE, 1968, "La reconnaissance de la Seconde Republique par L'Angleterre", dans Revue d'histoire diplomatique, $\mathrm{n}^{\circ}$ 3, 1968, pp. 213-231.

Anne LEFEBVRE-TEILLARD, 1981, "L'intervention de l'État dans la constitution des sociétés anonymes, 1807-1867", dans Revue historique de droit français et étranger, n³, 1981, pp.

Jean LEFLON, 1948, L'Église de France et la révolution de 1848, Paris, Bloud et Gay, 1948, $135 \mathrm{p}$.

Émile LEHOUCK, 1981, "Utopie et antisémitisme : le cas d'Alphonse Toussenel", dans 1848, les utopismes sociaux. Utopie et action à la veille des journées de février, Paris, CDU-SEDES, 1981, pp. 151-160.

Évelyne LEJEUNE-RESNICK, 1991, Femmes et associations (1830-1880), Paris, Éditions Publisud, 1991. 
1992, "L'éducation domestique (1830-1856). Méthode pédagogique ou mission sociale ?", dans Jeunesses au XIXe siècle.--1848, révolutions et mutations au XIXe siècle, $\mathrm{n}^{\circ} 8$, 1992, pp. 49-58.

Henry LEMERY, 1962, Martinique, terre française. Le conflit des races et l'opinion métropolitaine. Victor Schœlcher, Paris, Éditions Maisonneuve et Larose, 1962, 145 p. Henri LEMOINE, 1965, "Un homme de 48 : Joseph-Augustin Guinard, colonel de la Garde Nationale, député de la Seine", dans Bulletin de la Société d'histoire de Paris, 1965, pp. 38-39. Thierry LENTZ, 1997, "Le coup d'État du 2 décembre 1851 signait-il la faillite de la constitution du 4 novembre 1848 ?", dans Jean TULARD [dir.], Pourquoi réhabiliter le Second Empire? Actes du colloque de Paris, 21 octobre 1995, Paris, Bernard Giovanangeli éditeur, 1997, pp. 37-43.

Pierre LÉON, 1974, Géographie de la fortune et structures sociales à Lyon au XIXe Siècle (1815-1914), Lyon, Centre d'histoire économique et sociale de la région lyonnaise, 1974, $440 \mathrm{p}$.

Émile LÉONARD, 1948, "Le protestantisme français en 1848", dans Bulletin de la Société d'histoire du protestantisme français, juillet-septembre 1948, pp. 82-113.

Yves LEQUIN, 1977, Les ouvriers de la région lyonnaise (1848-1914). Tome I, la formation de la classe ouvrière régionale. Tome II, Les intérêts de classe et la République, Lyon, Presses universitaires de Lyon, 1977, 2 volumes, 573 p. et 500 p.

J. LESCURE, 1948, 1848, poème dramatique en trois journées, Paris/Genève, Les trois collines, 1948, 215 p.

Sophie-Anne LETERRIER, 1995, L'institution des sciences morales, Paris, Éditions l'Harmattan, 1995.

Fernand LETESSIER, 1971-1972, "Autour du général Cavaignac : documents inédits", dans Bulletin de la Société d'agriculture, sciences et arts de la Sarthe, tome 73, n 16, 1971-1972, pp. 338-404.

Paul LEUILLIOT, 1960, "Le 13 juin 1849 à Colmar et dans le Haut-Rhin, le procès de Besançon (novembre 1849) d'après le Compte rendu des assises du Doubs", dans Annuaire de la Société d'histoire et de littérature de Colmar, tome 10, 1960, pp. 106-122.

, 1962, "Le dossier universitaire d'un professeur révoqué du collège de Colmar :

Émile Jolibois, président de la Société républicaine de Colmar en 1848", dans Annuaire de la Société historique et littéraire de Colmar, tome 12, 1962, pp. 68-82.

, 1964, "La société républicaine de Colmar en 1848 (d'après ses procès verbaux)", dans Annuaire de la Société historique et littéraire de Colmar, tome 14, 1964, pp. 71-104. , 1967, "Défense et illustration de l'histoire locale", dans Annales, économies, sociétés, civilisations, tome 22, $\mathrm{n}^{\circ} 1$, janvier-février 1967, pp. 154-177.

1972, "La fin de la Seconde République à Mulhouse (1849-1852)", dans Bulletin $d u$ musée historique de Mulhouse, tome 80, 1972, pp. 133-173.

Pierre LÉVÊQUE, 1966, "Les élections de 1849 en Côte-d'Or", dans Recherches sur les forces politiques de la France de l'Est depuis 1787.-- Cahiers de l'Association interuniversitaire de l'Est, $\mathrm{n}$ - 8-9, 1966, pp. 105-138.

1978, "D'un empire à l'autre : permanences et changements (1814-1860)", dans Jean RICHARD [dir.], Histoire de la Bourgogne, Toulouse, Privat, 1978, pp. 341-394.

1983a, Une société provinciale : La Bourgogne sous la Monarchie de Juillet, Paris, Éditions de l'École des hautes études en sciences sociales/Librairie Touzot, 1983, 798 p. 1983b, Une société en crise : La Bourgogne au milieu du XIXe siècle, Paris, Éditions de l'École des hautes études en sciences sociales/Librairie Touzot, 1983, 592 p. 
1992, Histoire des forces politiques en France. Tome I : 1789-1880, Paris, Librairie

Armand Colin, 1992, $370 \mathrm{p}$.

, 1996, "L'évolution électorale des campagnes de la Bourgogne du Sud (1848-1995)", dans Serge BIANCHI [dir.], Les campagnes bourguignonnes dans l'histoire. Actes du colloque d'Auxerre (28-30 septembre 1995).-- Histoire et sociétés rurales, n 5, 1er semestre 1996, pp. 180-188.

1997a, "Le discours de Mâcon, évènement national", dans Travaux de l'Institut de recherche du val de Saône Mâconnais, n 3, 1997, pp. 27-34.

, 1997b, "Le "parti Lamartine" en Mâconnais (1831-1857)", dans Travaux de l'Institut de recherche du val de Saône Mâconnais, $\mathrm{n}^{\circ}$ 3, 1997, pp. 43-55.

Claude LÉVY, 1954, "Note sur les fondements sociaux de l'insurrection de décembre 1851 en province", dans L'Information historique, 1954, pp. 142-145.

1963, "Les journées parisiennes de juin 1848 d'après des études récentes", dans Bulletin de la Société d'études historiques de la région parisienne, n 112-113, 1963, pp. 19-26.

, 1994, "Les proscrits du 2 décembre", dans Léo HAMON [dir.], Les républicains sous le Second Empire, 9es Entretiens d'Auxerre, 1992, Paris, Éditions de la Maison des sciences de l'homme, 1994, pp. 15-32.

Maurice LEVY-LEBOYER, 1964, Les banques européennes et l'industrialisation internationale dans la première moitié du XIXe siècle, Paris, Presses universitaires de France, 1964, 815 p. Jean LHOMME, 1960, La grande bourgeoisie au pouvoir (1830-1880). Essai sur l'histoire sociale de la France, Paris, Presses universitaires de France, 1960, 378 p.

Daniel LIGOU, 1963, "Une candidature ouvrière (Capelle aîné, mécanicien) aux élections législatives de 1848 à Montauban", dans Revue d'histoire éonomique et sociale, volume 41, n -1, 1963, pp. 100-105.

R. LIMOUZIN-LAMOTHE, 1948, Un archevêque aux barricades : Monseigneur Affre. Conférences à l'hôpital des Quinze-Vingts, le 25 mai 1948, Paris, Centre catholique des intellectuels français, 1948, $40 \mathrm{p}$. , 1949, "Du nouveau sur la mort de Mgr Affre, archevêque de Paris", dans Actes du Congrès historique du Centenaire de la révolution de 1848, Paris, Presses universitaires de France, 1949, pp. 371-380.

LIOGIER, 1971, "Le travail des enfants dans le département de la Loire au milieu du XIXe siècle", dans Bulletin du vieux Saint-Étienne, $\mathrm{n}^{\circ}$ 84, 1971, pp. 13-15.

Robert R. LOCKE, 1978, Les fonderies et forges d'Alais à l'époque des premiers chemins de fer, 1829-1874. La création d'une entreprise moderne, Paris, Éditions Marcel Rivière et Cie, 1978, $299 \mathrm{p}$.

Léo A. LOUBERE, 1957, "Les idées de Louis Blanc sur le nationalisme, le colonialisme et la guerre", dans Revue d'histoire moderne et contemporaine, tome 4, janvier-mars 1957, pp. 33-63.

1968, "The Emergence of the Extreme Left in Lower Languedoc, 1848-1851 : Social and Economic Factor in Politics", dansAmercian Historical Review, $\mathrm{n}^{\circ} 73,1968$, pp. 1019-1051.

1974, Radicalism in Mediterranean France. Its Rise and Decline, 1848-1914, Albany, State University of New York Press, 1974, p.

Jacques LOVIE, 1949, "Quelques aspects de la "révolution" chambérienne", dans Annales savoisiennes, 1ère année, $\mathrm{n}^{\circ} 1$ et $\mathrm{n}^{\circ} 2,1949$, pp. 31-41 et pp. 36-44.

1965, "Qui était les Voraces? (D'après des documents inédits sur les évènements d'avril 1848 en Savoie et à Lyon)", dans Annales du Centre d'enseignement supérieur de Chambéry, $\mathrm{n}^{\circ} 3,1965$, pp. 99-152 
1969, "Une annexion manquée. L'expédition lyonnaise d'avril 1848 en Savoie (Chambéry et l'affaire des Voraces)", dans Annales du Centre d'enseignement supérieur de Chambéry, $\mathrm{n}^{\circ} 7,1969$, pp. 17-80.

Georges LUBIN, 1971, "Impression d'un ancien Préfet de l'Indre (Marc Dufraisse) au procès de 1849 devant la haute cour de Bourges (lettre à George Sand)", dans Revue de l'Académie du Centre, 1971, pp. 32-39.

, 1972, Correspondance de George Sand. Tome 9 : janvier 1849-décembre 1850. Textes réunis, classés et annotés, Paris, Garnier Frères, 1972, 1020 p.

Jean LUCAS-DUBRETON, 1958, "Les journées de juin 1848", dans Miroir de l'histoire, n - 100, 1958, pp. 496-504.

LUU-RICHARD, 1965, "L'opinion publique à Amiens de février à juin 1848, d'après la presse", dans Bulletin de la Société antique de Picardie, trimestre 1, 1965, pp. 5-16.

Howard MACHIN et Vincent WRIGHT, 1989, "Les élèves de l'École nationale

d'administration de 1848-1849", dans Revue d'histoire moderne et contemporaine, tome 36, octobre-décembre 1989, pp. 605-639.

Jacques MADAULE, 1969, "La politique de Lamartine", dans Europe, nº 483-484, 1969, pp. 43-53.

Edmond MAESTRI, 1994, Les îles du Sud-Ouest de l'Océan Indien et la France de 1815 à nos jours, Paris, Éditions L'Harmattan, 1994.

Claudette MAINZER, 1981, "Une histoire de cimetière", dans Ornans à l'Enterrement. Tableau historique de figures humaines, Ornans, Musée G. Courbet, 1981, pp. 11-23.

1988, "Le manifeste réaliste de Gustave Courbet", dans Les Amis de Gustave Courbet, Bulletin $n^{\circ} 79,1988$, pp. 18-50.

Jean MAITRON, 1960-1961, "La personnalité du militant ouvrier français dans la seconde moitié du XIXe siècle", dans Le militant ouvrier français dans la seconde moitié du XIXe siècle.-Le Mouvement Social, $\mathrm{n}^{\circ}$ 33-34, octobre 1960-mars 1961.

[dir.], 1964-1966, Dictionnaire biographique du mouvement ouvrier français. I :

1789-1864, de la Révolution française à la Première Internationale, Paris, Éditions Ouvrières, 1964-1966, 3 volumes.

Serge MAM LAM FOUCK, 1982, La Guyane française de la colonisation à la départementalisation. La formation de la société créole guyanaise, Fort-de-France, Éditions Désormeaux, 1982, $190 \mathrm{p}$.

,1987, Histoire de la société guyanaise. Les années cruciales, 1848-I946, Paris, Éditions Caribéennes, 1987, 249 p.

Charles MANGLOLTE, 1948, "La presse en 1848 dans le Jura", dans Volume du centenaire de la révolution de 1848 dans le Jura.-- Mémoires de la Société d'émulation du Jura pour 1946-1948, Lons-le-Saunier, 1948, pp. 33-48.

Christiane MARCILHACY, 1959, "Les caractères de la crise sociale et politique de 1846 à 1852 dans le département du Loiret", dans Revue d'histoire moderne et contemporaine, tome 6, janvier-mars 1959, pp. 5-59.

Plon,1962.

1962, Le diocèse d'Orléans sous l'épiscopat de Mgr Dupanloup, 1849-1878, Paris,

1964, Le diocèse d'Orléans au milieu du XIXe siècle. Les hommes et leurs mentalités, Paris, Sirey,1964, $493 \mathrm{p}$.

Yannick MAREC, 1988, 1848 à Rouen. Les Mémoires du citoyen Cordhomme, oncle de Maupassant, Luneray, éditions Bertout, 1988, 227 p.

Ted W. MARGADANT, 1974, "Peasant Protest in the Second Republic", dans Journal of Interdisciplinary History, tome 5, n 1, Summer 1974. 
1979, French Peasants in Revolt. The Insurrection of 1851, Princeton, Princeton

University Press, 1979, 379 p.

Maurice MARGUERITE, 1969, "Lamartine et la paysannerie", dans Europe, 1969,

pp. 62-86.

Roger MARLIN, 1955a, "Un journal légitimiste de province sous la Seconde République :

L'Union franc-comtoise", dans Revue d'histoire moderne et contemporaine, tome 2, janvier-mars 1955 , pp. 67-75.

1955b, "L'élection présidentielle de L.N. Bonaparte dans le Doubs, le 10 décembre

1848", dans Annales littéraires de l'Université de Besançon, volume 7, 1955, pp. 33-46.

, 1957a, "Un problème d'affouage en Franche-Comté au milieu du XIXe siècle", dans

Revue d'histoire économique et sociale, $\mathrm{n}^{\circ}$ 2, 1957, pp. 167-197.

1957b, "L'épuration politique dans le Doubs à la suite du coup d'État du 2 décembre

1851", dans Nouvelle revue de Franche-Comté, n 15, 1957, pp. 167-183 et n 16, 1957,

pp. 233-249.

Pierre MARMIN, 1966, "Une élection municipale mouvementée à Chemilly-sur-Yonne en 1848", dans Écho d'Auxerre, n 66, 1966, p. 23.

Paul MARQUION, 1973, "Élections (à Orange, 1848-1851-1852)", dans Bulletin des amis

d'Orange, $\mathrm{n}^{\circ}$ 51, 1973, pp. 1-3.

Bernard MARREY, 1981, "Les réalisations des utopistes dans les travaux publics et

l'architecture, 1840-1848", dans 1848, les utopismes sociaux. Utopie et action à la veille des

journées de février, Paris, CDU-SEDES, 1981, pp. 193-216.

Gaston MARTIN, 1948a, L'abolition de l'esclavage (27 avril 1848), collection du Centenaire de la révolution de 1848, Paris, Presses universitaires de France, 1948, 64 p.

, 1948b, "L'abolition de l'esclavage", dans Revue d'histoire des colonies, Paris, $\mathrm{n}$

-123-124, 1948.

1948c, La révolution de 1848, Que sais-je ? n²95, Paris, Presses universitaires de

France, 1948, 120 p.

Gaston MARTIN-GÉRY, 1948, 1848. Montbrison. Musée d'Allard. Exposition du centenaire de la révolution de 1848, Montbrison, Imprimerie du Théolier, 1948, 24 p.

Jean-Clément MARTIN, 1996, Révolution et Contre-révolution en France de 1789 à 1995. Les rouages de l'histoire, Rennes, Presses universitaires de Rennes, 1996, 229 p.

Louis MARTIN, 1948, La ville et l'arrondissement de Pontarlier il y a un siècle.-- Les Cahiers du haut Doubs, $\mathrm{n}^{\circ}$ 2, 1948, $63 \mathrm{p}$.

Marc MARTIN, 1981, "Journalistes parisiens et notoriété (vers 1830-1870). Pour une histoire sociale du journalisme", dans Revue historique, $\mathrm{n}^{\circ}$ 539, juillet-septembre 1981 , pp. 31-74.

Anne MARTIN-FUGIER, 1990, La vie élégante ou la formation du Tout-Paris, 1815-1848, Paris, Librairie Arthème Fayard, 1990, 448 p.

Laurent MARTY, 1982, Chanter pour survivre, culture ouvrière, travail et technique dans le textile, Roubaix 1850-1914, Liévin, Fédération Léo Lagrange, 1982.

Henri MAURIN et Jacques LENTGE [dir.], 1979-1980, Le Mémorial de La Réunion, 1848-1882, Saint-Denis de La Réunion, Australe éditions, 1979-1980, 5 volumes.

Jean-Luc MAYAUD, 1979, Les paysans du Doubs au temps de Courbet. Étude économique et sociale des paysans du Doubs au milieu du XIXe siècle, Paris, Les Belles-Lettres, 1979, 295 p.

1979-1980, "Persistance des droits d'usage communautaires en Franche-Comté au

XIXe siècle : controverses autour de la vaine pâture", dans Travaux de la Société d'émulation du Jura, 1979-1980, pp. 335-346. 
, 1981a, "Sel et politique en Franche-Comté au milieu du XIXe siècle : le "député du sel" Demesmay", dans Le sel et son histoire. Colloque de l'Association Interuniversitaire de l'Est, octobre 1979, Nancy, Publications de l'Université de Nancy II, 1981, pp. 141-156.

1981b, "Courbet, peintre de notables à l'enterrement... de la République", dans Ornans à l'enterrement : Tableau historique de figures humaines. Catalogue de l'exposition d'Ornans, 1981, Paris-Ornans, 1981, pp. 40-76.

1986a, Les Secondes Républiques du Doubs, Paris, Les Belles-Lettres, 1986, 475 p.

, 1986b, "Les paysans du Doubs et la Seconde République : genèse d'une paysannerie conservatrice", dans Bulletin des ruralistes français, $n^{\circ}$ 35, 3e trimestre 1986, pp. 13-20.

1988, "Chasse noble, chasse villageoise, chasse de classe au XIXe siècle ?", dans L'imaginaire de la chasse. Hier et demain, Paris/Chalon-sur-Saône, Hâtier/Atelier CRC France, 1988, pp. 77-93.

1989, "La révolution de 1848 : une histoire sainte revisitée", dans Frédéric BLUCHE et Stéphane RIALS [dir.], Les révolutions françaises. Les phénomènes révolutionnaires en France du Moyen-Age à nos jours, Paris, Librairie Arthème Fayard, 1989, pp. 327-340 et pp. 482-484. 1990, "Les paysanneries françaises face à la Seconde République", dans 1848, révolutions et mutations au XIXe siècle, $\mathrm{n}^{\circ}$ 6, 1990, pp. 55-64.

1994, "Une histoire rurale éclatée (1945-1993) ? La France du XIXe siècle", dans Alain FAURE, Alain PLESSIS et Jean-Claude FARCY [dir.], La terre et la cité. Mélanges offerts à Philippe Vigier, Paris, Éditions Créaphis, 1994, pp. 21-31.

1995a, "Ruralité et politique dans la France du XIXe siècle", dans Ghislain BRUNEL et Jean-Marc MORICEAU [dir.], L'histoire rurale en France. Actes du colloque de Rennes (6-7-8 octobre 1994).-- Histoire et sociétés rurales, $\mathrm{n}^{\circ}$ 3, 1er semestre 1995, pp.133-136 et pp. 143-149.

1995b, "Noblesses et paysanneries de 1789 à 1914 : des rapports d'exclusion ?", dans Claude-Isabelle BRELOT [dir.], Noblesses et villes (1780-1914). Actes du colloque de Tours, 17-19 mars 1994. Tours, Université de Tours/Maison de sciences de la ville, 1995, pp. 55-69. 1996, "Les biens communaux en France du XVIIIe au XXe siècle", dans Joan J. BUSQUETA et Enric VICEDO [dir.], Béns comunals als Països Catalans i a l'Europa contemporània. Sistemes agraris, organització social i poder local als Països Catalans, Lerida, Institut d'estudis ilerdencs, 1996, pp. 553-577.

,1997, "1848-1998 : un cent-cinquantenaire scientifique et républicain", dans Travaux de l'Institut de recherche du val de Saône Mâconnais, n 3, 1997, pp. 9-11.

MBAYE GUEYE, 1983, L'Afrique et l'esclavage, Paris, Éditions Martinsart, 1983, 338 p. James C. McCARTHY, 1975, "Courbet's Ideological Contradictions and the Burial at Ornans", dans The Art Journal, n³5, 1975, pp. 12-16.

Peter McPHEE, 1974, "The crisis of radical republicanims in the French Revolution of 1848 ", dans Historical Studies, volume 16, $\mathrm{n}^{\circ} 62,1974$, pp. 71-88.

1976, "The Seed-Time of the Republic : Society and Politics in the PyrénéesOrientales, 1848-1851", dans Australian Journal of Politics and History, n²2, 1976, pp. 196-213.

1977, The Seed-Times of the Republic: Society and Politics in the Pyrénées-Orientales, 1846-1852, Melbourne, 1977, traduction française revue : Les semailles de la République dans les Pyrénées-Orientales, 1846-1852. Classes sociales, politique et culture, Perpignan, Publications de l'olivier, 1995, $507 \mathrm{p}$.

1986, "Electoral Democraty and Direct Democraty in France (1789-1851)", dans

European History Quaterly, volume 16, 1986, pp. 77-96. 
1989, "La mainmorte du passé ? Les images de la Révolution française dans les mobilisations politiques rurales sous la IIe République", dans L'image de la Révolution française. Actes du congrès mondial pour le bicentenaire, tome 2, Oxford, Pergamon Press, 1989.

1992, The Politics of Rural Life. Political Mobilization in the French Countryside, 1846-1852, Oxford, Clarendon Press, 1992, 310 p.

Neil McWILlIAM, 1993, Dreams of Happiness. Social Art and the French Left, 1830-1850, Princeton, Princeton University Press, 1993, 385 p.

Françoise MÉLONIO, 1984, "Tocqueville et la restauration du pouvoir temporel du pape (juin-octobre 1849)", dans Revue historique, n 549, janvier-mars 1984, pp. 110-123.

1993a, Tocqueville et les Français, Paris, Aubier, 1993, 408 p.

1993b, "1848 : la république intempestive", dans François FURET et Mona OZOUF

[dir.], Le siècle de l'avènement républicain, Bibliothèque des histoires, NRF, Paris, Éditions Gallimard, 1993.

Bernard MÉNAGER, 1983, La vie politique dans le département du Nord de 1851 à 1877, Lille, Atelier de reproduction des thèses de Lille III, 1983.

, 1988a, Les Napoléon du peuple, Paris, Aubier, 1988, 446 p.

1988b, "Les plébiscites du second Empire", dans Léo HAMON et Guy LOBRICHON

[dir.], L'élection du chef de l'Etat en France de Hugues Capet à nos jours, Entretiens d'Auxerre 1987, Paris, Beauchesne, 1988, pp. 121-130.

1992, "1848-1871. Autorité ou liberté", dans Jean-François SIRINELLI [dir.], Histoire des droites en France. Tome I : Politique, Paris, Editions Gallimard, 1992, pp. 89-146.

1997, "Le bonapartisme pouvait-il être parlementaire ?", dans Jean TULARD [dir.], Pourquoi réhabiliter le Second Empire? Actes du colloque de Paris, 21 octobre 1995, Paris, Bernard Giovanangeli éditeur, 1997, pp. 123-130.

Louis MÉNARD, 1957, "Prologue d'une révolution, février-juin 1848", dans Le Crapouillot, Paris, 1957, $64 \mathrm{p}$.

René MERLE, 1989, "L'intervention politique dans l'idiome natal dans le Sud-Est de la Révolution au Second Empire", dans Revue d'histoire moderne et contemporaine, tome 36, janvier-mars 1989, pp. 134-145.

Jean MERLEY, 1972, L'industrie en Haute-Loire de la fin de la Monarchie de Juillet aux débuts de la Troisième République, Lyon, Centre d'histoire économique et sociale de la région lyonnaise, 1972, $450 \mathrm{p}$.

1974, La Haute-Loire de la fin de l'Ancien Régime aux débuts de la Troisième République (1776-1886), Le Puy, Cahiers de la Haute-Loire, 1974, 667 p.

Pierre MERLIN, 1992, "Image, tradition religieuse et politique. Analyse de deux caricatures antibonapartistes", dans Travaux présentés par les membres de la Société d'émulation du Jura, 1992, pp. 83-93.

1993, "Aux origines du parti républicain dans le Jura. Un aspect de la crise finale de la Seconde République : la sociabilité jurassienne dans la tourmente (mai-1849décembre 1851)", dans Travaux présentés par les membres de la Société d'émulation du Jura, 1993, pp. 239-285.

1994, "Le coup d'État du 2 décembre 1851 dans le Jura", dans Travaux présentés par les membres de la Société d'émulation du Jura, 1994, pp. 155-182.

John M. MERRIMAN, 1974, "Social Conflict in France and the Limoges Revolution of April 27, 1848", dans Societas. A Review of Social history, n 4, hiver 1974, pp. 21-38. , 1978, The Agony of the Republic. The Repression of the Left in Revolutionary France, 1848-1851, New Haven/Londres, Yale University Press, 1978, 198 p. 
1988, "Le maintien de l'ordre à la périphérie des villes (1815-1851)", dans Cahiers

$d u$ Centre de recherches historiques, $\mathrm{n}^{\circ} 2$, octobre 1988, pp. 51-70.

1991, The Margins of City Life. Explorations on the French Urban Frontier, 1815-1851,

Oxford, Oxford University Press, 1991, 318 p., traduction française : Aux marges de la ville. Faubourgs et banlieues en France, 1815-1870, Paris, Éditions du Seuil, 1994, 401 p.

Chantal METZGER, 1981, "Utopie sociale française et socialistes allemands vers 1840", dans 1848, les utopismes sociaux. Utopie et action à la veille des journées de février, Paris, CDUSEDES, 1981, pp. 233-243.

Peter MEYERS, 1978, "Teachers in Revolutionary France : The Instituteurs in 1848", dans Consortium on Revolutionary Europe Proceedings 1977, Athens, 1978, pp. 151-161.

Stéphane MICHAUD, 1981, "Flora Tristan. Les Promenades dans Londres", dans 1848, les utopismes sociaux. Utopie et action à la veille des journées de février, Paris, CDU-SEDES, 1981, pp. 139-150. 1985.

[dir.], 1985, Un fabuleux destin : Flora Tristan, Dijon, Presses Universitaires de Dijon,

Jean-Yves MOLLIER et Nicole SAVY [dir.], 1992, Usages de l'image au XIXe siècle, Paris, Créaphis, 1992, $257 \mathrm{p}$.

André MIDAS, 1950, "Victor Schœlcher and Emancipation in the French West Indies", dans Caribbean Historical Review, n 1, décembre1950, pp. 110-123.

Ilja MIECK, Horst MÖLLER et Jürgen VOSS [dir.], 1995, Paris und Berlin in der Revolution 1848/Paris et Berlin dans la révolution de 1848. Colloque organisé par la Ville de Paris; l'Historische Kommission zu Berlin et l'Institut historique allemand, Paris, 23-25 novembre 1992, Sigmaringen, Jan Thorbecke Verlag, 1995, 320 p.

1981, 1848, les utopismes sociaux. Utopie et action à la veille des journées de février, Paris, CDU-SEDES, 1981, $290 \mathrm{p}$.

1948, 1848, une révolution créatrice, Paris, Hier et aujourd'hui, 1948, 375 p.

Yves MILLET, 1948, Un centenaire. La révolution de 1848 dans l'arrondissement d'Avesnes, Avesnes, Éditions de l'Observateur, 1948, 95 p.

France MIOCHE, 1972, "Les élections présidentielles à Jozerand en décembre 1848", dans Brayuds et Combrailles, $\mathrm{n}^{\circ} 2,1972$, pp. 10-14.

Émile MIREAUX, 1961, "L'Académie des sciences morales et politiques en 1848" dans Revue des deux mondes, $\mathrm{n}^{\circ} 1,1961, \mathrm{pp} .37-50$.

1965, "Un témoin de la révolution de 1848 : Louis Reybaud"”, dans Revue des deux mondes, $\mathrm{n}^{\circ} 3,1965$, p. 330.

Sylvain MOLINIER, 1948, Blanqui, collection du Centenaire de la révolution de 1848, Paris, Presses universitaires de France, 1948.

Jean-Yves MOLLIER, 1987, "Belle-île-en-Mer, prison politique (1848-1858)", dans Philippe VIGIER et Alain FAURE [dir.], Maintien de l'ordre et polices en France et en Europe au XIXe siècle, Paris, Créaphis, 1987, pp. 185-211.

A.I. MOLOK, 1954, "Problèmes de l'insurrection de juin 1848", dans Questions d'histoire, tome 2, 1954, pp. 58-100.

1963, "Les mouvements révolutionnaires dans les banlieues de Paris, pendant l'insurrection de juin 1848", dans Annuaire d'études françaises, 1963, pp. 90-119.

L. MONNIER et H. SICAMOIS, 1949, La Révolution de 1848 en Vendée. Les députés de Vendée aux assemblées de 1848, Fontenay-le-Comte, Éditions de la Revue du Bas-Poitou, 1949, 84 p. P. MONTAGNE, 1965, "Aspects du comportement de l'armée à Lyon sous la Monarchie de Juillet et la Seconde République", dans Actes du 89e Congrès national des Sociétés savantes, 
Lyon, 1964. Section d'histoire moderne et contemporaine, Paris, Bibliothèque nationale, 1965, pp. 397-412.

L. MORAUZEAU, 1959-1960, "Aspects vendéens de la Seconde République", dans Annuaire de la Société d'émulation de Vendée, 1959, pp. 81-107 et 1960, pp. 63-90.

Charles MORAZÉ, 1949, "Les méthodes en histoire moderne", dans Actes du Congrès historique du Centenaire de la révolution de 1848, Paris, Presses universitaires de France, 1949, pp. 53-74.

Paul MOREAU, 1948, "La révolution de 1848 et l'abolition de l'esclavage", 6e Conférence du cycle 1947-1948, Hôtel du Grand Orient de France, 3 mars 1948, Paris, Foyer philosophique, 1948, $20 \mathrm{p}$.

E. MORELLI, 1949, "Mazzini et la révolution de 1848 en France", dans Actes du Congrès historique du Centenaire de la révolution de 1848, Paris, Presses universitaires de France, 1949, pp. 285-194.

Bernard H. MOSS, 1976, The origins of the French Labor Movement : The Socialism of Skilled Workers, 1830-1914, Berkeley/Los Angeles, University of California Press, 1976, traduction en français, Aux origines du mouvement ouvrier français. Le Socialisme des ouvriers de métier 1830-1914, Paris, Les Belles lettres, 1985.

René MOTHU, 1963, "Le Père Lacordaire, député des Bouches-du-Rhône", dans Annales de la Société scientifique et littéraire de Cannes, tome 15, 1963, p. 59.

Charles MOULIN [dir.], 1948, 1848. Le livre du Centenaire, Paris, Éditions Atlas, 1948.

Inès MURAT, 1987, La Deuxième République (1848-1851), Paris, Librairie Arthème Fayard, $1987,534 \mathrm{p}$.

MUSÉE DE POITIERS, 1948, Rétrospective 1848, février-mars 1948, Poitiers, Impromerie Victor Hugo, 1948, 14 p.

Martin NADAUD, 1976, Mémoires de Léonard, ancien garçon maçon, Paris, Hachette, 1976 (1ere édition 1912), 558 p. (Présentation par Maurice AGULHON).

Edgar Léon NEWMANN, 1975a, "La blouse et la redingote, l'alliance du peuple et de la bourgeoisie à la fin de la Restauration", dans Annales historiques de la Révolution française, octobre-décembre 1975.

, 1975b, "What the Crowd Wanted in the French Revolution of 1830", dans John MERRIMAN [dir.], 1830 in France, New York, 1975.

1990, "Quand les mouchards ne riaient pas : les ouvriers chansonniers, la justice et la liberté pendant la Monarchie de Juillet", dans Philippe VIGIER et Alain FAURE [dir.], Répression et prison politiques en France et en Europe au XIXe siècle, Paris, Créaphis, 1990, pp. 297-303.

Armand NICOLAS, 1967, La révolution anti-esclavagiste de mai 1848 à la Martinique, Fort-deFrance, imprimerie populaire, 1967, $301 \mathrm{p}$.

Claude NICOLET, 1982, L'idée républicaine en France (1789-1924). Essai d'histoire critique, Bibliothèque des histoires, NRF, Paris, Éditions Gallimard, 1982, 513 p.

Linda NOCHLIN, 1965, "Innovation and Tradition in Courbet's Burial at Ornans", dans Essays in Honor of walter Friedlaender Marsyas, 1965, pp. 119-126.

Léon NOEL, 1961, "La révolution de février 1848 vue par un Auxerrois", dans Bulletin de la société des sciences historiques nationales de l'Yonne, volume 89, 1961, pp. 9-28.

1967, Nouvelle histoire de France, tome 28, La république éphémère, 1848 et la IIe République, 1848-1850, Paris, Tallandier, 1967, pp. 3457-3584.

Louis OGÈS, 1949, L'agriculture dans la Finistère au milieu du XIXe siècle, Brest, Imprimerie du Télégramme, 1949, $174 \mathrm{p}$. 
Michel OFFERLÉ, 1984, "Illégitimité et légitimation du personnel politique ouvrier en France avant 1914", dans Annales, économioes, sociétés, civilisations, nº 4, juillet-août 1984. 1993, "L'électeur et ses papiers. Enquête sur les cartes et les listes électorales", dans Genèses, n 13, 1993, pp. 29-53.

Norbert OLSZAK, 1987, "Les conseils de prud'hommes : un archétype judiciaire pour le mouvement ouvrier ?", dans Le Mouvement social, octobre-décembre 1987.

1981, Ornans à l'Enterrement. Tableau historique de figures humaines, Ornans, Musée départemental-Maison natale Gustave Courbet, 1981, 92 p.

Robert PALMIERI, 1949, "1848 en Savoie", dans Annales savoisiennes, 1ère année, $\mathrm{n}^{\circ} 1, \mathrm{n}^{\circ} 2$ et $\mathrm{n}^{\circ}$ 3-4, 1949, pp. 17-30, pp. 29-35 et pp. 56-65.

Michel PAPAUD, 1987, "La répression durant le ministère de Léon Faucher (janvier-mai 1849)", dans Philippe VIGIER et Alain FAURE [dir.], Maintien de l'ordre et polices en France et en Europe au XIXe siècle, Paris, Créaphis, 1987, pp. 87-102.

André PARIS, 1984, "Agriculture, structures agraires et techniques dans un village du Morvan nivernais vers 1850, Corancy", dans Économie et sociétés des pays de montagne, Actes du 108e Congrès national des Sociétés savantes, Grenoble, 1983. Section d'histoire moderne et contemporaine, tome I, Paris, Éditions du Comité des travaux historiques et scientifiques, 1984, pp. 99-120.

1969, Le passage de la société esclavagiste à la société post-esclavagiste aux Antilles au XIXe siècle. Colloque d'histoire antillaise, Pointe-à-Pitre, Centre d'enseignement supérieur littéraire, 1969, 108 p. et $187 \mathrm{p}$.

Pierre PAUL, 1948, "L'agitation républicaine à Toulouse et dans la Haute-Garonne de 1840 à 1848", dans Jacques GODECHOT [dir.], La révolution de 1848 à Toulouse et dans la Haute-Garonne, Toulouse, Comité départemental du Centenaire de la révolution de 1848, 1948, pp. 41-52.

Alain PAUQUET, 1997, "Les représentations de la barricade dans l'iconographie de 1830 à 1848", dans Alain CORBIN et Jean-Marie MAYEUR [dir.], La barricade. Actes du colloque de Paris, 17-19 mai 1995, Paris, Publications de la Sorbonne, 1997, pp. 97-112.

Maurice PAZ, 1984, Un révolutionnaire professionnel, Auguste Blanqui, Paris, Librairie Arthème Fayard, 1984, $315 \mathrm{p}$.

Gilles PÉCOUT, 1994, "La politisation des paysans au XIXe siècle. Réflexions sur l'histoire politique des campagnes françaises", dans Histoire et sociétés rurales, $n^{\circ} \quad 2,2 e$ semestre 1994, pp. 91-125.

Olivier PELLETIER, 1997, "'Figures imposées". Pratiques et représentations de la barricade pendant les journées de décembre 1851", dans Alain CORBIN et Jean-Marie MAYEUR [dir.], La barricade. Actes du colloque de Paris, 17-19 mai 1995, Paris, Publications de la Sorbonne, 1997, pp. 251-268.

Valentin PELOSSE, 1981-1982, "Imaginaire social et protection de l'animal. Des amis des bêtes de l'An X au législateur de 1850", dans L'Homme, tome XX, $\mathrm{n}^{\circ} 4$, octobre-décembre 1981, pp. 5-33 et tome XXI, n 1, janvier-mars 1982, pp. 33-51.

Pierre-Jean PéNAULT, 1968, "La monarchie finit en pays d'Auge (Louis-Philippe en 1848)", dans Pays d'Auge, $n^{\circ}$ 5, 1968, pp. 17-22.

Claude PENNETIER, 1994, "Singulier-pluriel : la biographie se cherche. L'exemple de l'histoire ouvrière", dans Écrire des vies, biographie et mouvement ouvrier XIXe-XXe siècles.-Territoires contemporains, Cahiers de l'IHC, Université de Dijon, n 1, 1994.

Agricol PERDIGUIER, 1977, Mémoires d'un compagnon, Genève, 1854-1855, réédition :

Paris, Maspero, 1977, 419 p. (Présentation par Alain FAURE). 
Antoine PERRIER, 1959, "Un corrézien peu connu : Grégoire Champseix (1817-1863)", dans Bulletin de la société d'histoire de Corrèze, tome 81, 1959, p. 106.

, 1962, "Figures démocratiques de la révolution de 1848 dans le département de la Haute-Vienne", dans Bulletin de la Société archéologique et historique de la Haute-Vienne, tome 117, 1962, pp. 153-164.

1963, "Les frères Villegoureix, démocrates de 1848", dans Bulletin de la Société archéologique et historique du Limousin, tome 90, 1963, pp. 211-213.

, 1966a, "La Société populaire de Limoges en 1848", dans Actes du 90e Congrès des Sociétés savantes de Nice, tome 3, 1966, pp. 271-289.

1966b, "Une candidature de Pierre Leroux à l'Assemblée constituante de 1848 dans la Haute-Vienne", dans Revue d'histoire moderne et contemporaine, tome 13, avril-juin 1966, pp. 157-162.

, 1973, "Pierre-Alfred Talandier (1822-1890)", dans Bulletin de la Société archéologique et historique du Limousin, tome 100, 1973, pp. 229-240.

J. PERRIGAULT, 1948, "Il y a cent ans nous mettions fin à l'esclavage", dans Revue de la Martinique, $\mathrm{n}^{\circ}$ 24, avril 1948.

Michelle PERROT [dir.], 1987, De la révolution à la Grande Guerre, tome 4 de Philippe ARIES et Georges DUBY [dir.], Histoire de la vie privée, Paris, Éditions du Seuil, 1987, 639 p.

François PERROUX, 1955, "Prise de vues sur la croissance de l'économie française, 1780-1950", dans Income and Wealth, série 5, 1955.

Alain PESSIN, 1992, Le mythe du peuple et la société française du XIXe siècle, Paris, Presses universitaires de France, 1992, 280 p.

H. PETITJEAN-ROGET et Nelly SCHMIDT, 1991, Catalogue du Musée Schœlcher, Pointe-àPitre, Guadeloupe, 1991.

Natalie PETITEAU, 1996, "Identité sociale et engagement politique : les anoblis de Napoléon 1er face au bonapartisme (1814-1870)", dans European Review of History/Revue européenne d'histoire, volume 3, n² 2, 1996, pp. 161-170.

Jean-Christian PETITFILS, 1973, La droite en France de 1789 à nos jours, Que sais-je ? n - 1539, Paris, Presses universitaires de France, 1973, 128 p.

Claude PETITFRERE, 1982, "Fête et commémoration en "Vendée militaire" (1814-1914)", dans La fête en milieu rural.-- Études rurales, nº 86, avril-juin 1982, pp. 19-32.

Pierre PIERRARD, 1965, La vie ouvrière à Lille sous le Second Empire, Paris, Bloud \& Gay, 1965, réédition, Condé-sur-Noireau, Editions Charles Corlet, 1991, 532 p. , 1966, Les chansons en patois de Lille sous le Second Empire, Arras, Archives départementales, 1966. 1984, L'Église et les ouvriers en France (1840-1940), Paris, Hachette, 1984, 600 p. 1985, "La "petite loi" Falloux du 11 janvier 1850 et les révocations d'instituteurs communaux en 1850 ", dans Revue du Nord, n² 266, juillet-septembre 1985.

Michel PIERRE, 1982, La terre de la grande punition. Histoire des bagnes de Guyane, Paris, Éditions Ramsay, 1982, 322 p.

Roger PIERROT, 1960, "Balzac. Lettres inédites sur la révolution de 1848", dans Année balzacienne, 1960, pp. 41-72.

Michel PIGENET, 1989a, "Espace rituel de la protestation ouvrière dans les campagnes du Cher au XIXe siècle : l'exemple des marches", dans Fabienne GAMBRELLE et Michel TREBISCH [dir.], Révolte et société.-- Actes du VIe colloque d'Histoire au présent. Tome I, Paris, Publications de la Sorbonne, 1989, pp. 283-290. 
1989b, "Signification des votes ouvriers dans le département du Cher

(1848-1914)", dans Revue française de science politique, volume 39, n 5, octobre 1989, pp. 716-741.

, 1990, Les ouvriers du Cher (fin XVIIIe siècle-1914). Travail, espace et conscience sociale,

Paris, Institut CGT d'histoire sociale, 1990, 449 p.

1994, "Les adjectifs de la République. Voies et conditions de la politisation des milieux populaires. L'exemple du Cher au XIXe siècle", dans Michel VOVELLE [dir.], Révolution et République. L'exception française, Paris, Kimé, 1994, pp. 523-533.

J.P. PIGNARD, 1973, "Villefranche et le Beaujolais en 1848", dans Bulletin de l'Académie de Villefranche-en-Beaujolais, 1973, pp. 88-96.

Pamela L. PILBEAM, 1976, "Popular Violence in Provincial France after the 1830 Revolution", dans The English Historical Review, volume 91, avril 1976.

1990, The Middle Classes in Europe (1789-1914) : France, Germany, Italy and Russia, Themes in Comparativ History, Londres, Macmillan, 1990, 328 p.

, 1991, "Republicanism in Early Nineteenth-Century France, 1814-1835", dans French History, volume 5, $\mathrm{n}^{\circ}$ 1, mars 1991, pp. 30-47.

Stanley J. PINCETL, 1964, "The rupture of diplomatic relations between France and the United State : The Poussin incident" dans Annales de la Faculté de lettres d'Aix, tome 38, fascicule 2, 1964, pp. 389-422.

Philippe PINCHEMEL, 1957, Structures sociales et dépopulation rurale dans les campagnes picardes de 1836 à 1936, Paris, Librairie Armand Colin, 1957, 232 p.

Christiane PINEDE, 1957, "L'émigration dans le Sud-Ouest vers le milieu du XIXe siècle", dans Annales du Midi, tome 69, n³9, 1957, pp. 237-251.

David H. PINKNEY, 1965, "Les ateliers de secours à Paris (1830-1831) précurseurs des ateliers nationaux de 1848", dans Revue d'histoire moderne et contemporaine, tome 12, janvier-mars 1965, pp. 65-70.

, 1986, Decisive years 1840-1847, Princeton, Princeton University Press, 1986.

André PIOGER, 1971-1972, "À propos de l'abolition de l'esclavage dans les colonies françaises", dans Société d'agriculture, des sciences, des arts de la Sarthe, tome 73, n 16, 1971-1972, pp. 334-337.

Christine PLANTÉ, 1986, "Les féministes saint-simoniennes. Possibilités et limites d'un mouvement féministe en France au lendemain de 1830", dans Regards sur le saintsimonisme et les saint-simoniens, Lyon, Presses universitaires de Lyon, 1986.

_-_-_, 1987, "Les Saint-Simoniennes", dans Femmes et contre-pouvoirs, Montréal, Boréal, 1987.

Alain PLESSIS, 1985a, "Les concours de la Banque de France à l'économie (1842-1914)", dans Jean BOUVIER et Jean-Claude PERROT [dir.], États, fiscalités, économies. Actes du cinquième congrès de l'Association française des historiens économistes, 16-18 juin 1983, Paris, Publications de la Sorbonne, 1985, pp. 169-180.

1985b, La politique de la Banque de France de 1851 à 1870, Genève, Librairie Droz, 1985, $354 \mathrm{p}$.

, 1985c, "Les concours de la Banque de France à l'économie (1842-1914) ", dans Jean BOUVIER et Jean-Claude PERROT [dir.], États, fiscalités, économies. Actes du cinquième congrès de l'Association française des historiens économistes, 16-18 juin 1983.- Paris, Publications de la Sorbonne, 1985, pp. 169-180.

1987, " La révolution du crédit en France (1852-1857) ?", dans 1848, révolutions et mutations au XIXe siècle, $\mathrm{n}^{\circ}$ 3, 1987, pp. 31-40. 
1988, "Nobles et actionnaires de la banque de France de 1800 à 1914", dans Les noblesses européennes au XIXe siècle. Actes du colloque de l'École française de Rome, novembre 1985, Rome, École française de Rome/Université de Milan, 1988, pp. 255-265.

1993, "Une France bourgeoise", dans André BURGUIERE [dir.], Les formes de la culture, Histoire de la France (André BURGUIERE et Jacques REVEL [dir.]), Paris, Éditions du Seuil, 1993, pp. 221-300.

1997, "La république était-elle dans l'Empire ?", dans Jean TULARD [dir.], Pourquoi réhabiliter le Second Empire? Actes du colloque de Paris, 21 octobre 1995, Paris, Bernard Giovanangeli éditeur, 1997, pp. 131-134.

[dir.], 1993, Naissance des libertés économiques. Le décret d'Allarde et la loi Le Chapelier, leurs conséquences, 1791-fin XIXe siècle. Actes du colloque de Paris, 28-29 novembre 1991, Paris, Institut d'histoire de l'industrie, 1993, $450 \mathrm{p}$.

Bernard PLONGERON [dir.], 1976a, Le christianisme populaire, les dossiers de l'histoire, Paris, Le Centurion, 1976.

[dir.], 1976b, La religion populaire dans l'Occident chrétien, approches historiques, Paris, Éditions Beauchesne, 1976.

François PLOUX, 1991, "Rixes intervillageoises en Quercy (1815-1850)", dans Violence, brutalité, barbarie.-- Ethnologie française, $\mathrm{n}^{\circ}$ 3, tome 21, juillet-septembre 1991, pp. 269-275. 1992, "L'"arrangement" dans les campagnes du Haut-Quercy (1815-1850)", dans Histoire de la justice, $\mathrm{n}^{\circ}$ 5, 1992, pp. 95-115.

Jacques POCHON, 1966, "Edgar Quinet, défenseur de l'Ain sous la Seconde République (1848-1851)", dans Visages de l'Ain, nº 831966, , pp. 22-25.

Maurice POIGNAT, 1954, "Parthenay et la révolution de 1848", dans Bulletin de la Société d'histoire et d'archéologie de Parthenay, n³, 1954, pp. 29-38.

Jean POMMIER, 1948, Les écrivains davant la révolution de 1848. Lamartine, Hugo, Lamennais, George Sand, Michelet, Béranger, collection du Centenaire de la révolution de 1848, Paris, Presses universitaires de France, 1948, 79 p.

Pierre PONSOT, 1983, "La consommation de viande en Bourgogne du Sud dans la première moitié du XIXe siècle : l'exemple de Cluny, 1827-1849", dans Cahiers d'histoire, tome $28, \mathrm{n}^{\circ} 1,1983$, pp. 51-68.

Félix PONTEIL, 1948, 1848, Paris, Librairie Armand Colin, 1937, 224 p. 1965a, Les institutions de la France de 1814 à 1870, Paris, Presses universitaires de France, 1965, $489 \mathrm{p}$. 1965b, Histoire de l'enseignement en France, 1789-1965, Paris, Sirey, 1965, 454 p. 1968, Les classes bourgeoises et l'avènement de la démocratie (1815-1914), Collection l'Évolution de l'humanité, Paris, Albin Michel, 1968, 576 p.

Pierre POUJOL, 1957, Socialistes et chrétiens, 1848-1924, Paris, Le Cep, 1957, 79 p.

Henry POULAILLE [dir.], 1948, 1848. Le climat, les faits, les hommes.- Maintenant, $\mathrm{n}^{\circ}$ 9-10, $1948,512 \mathrm{p}$.

Yves POURCHER, 1984, "“Des assises de grâce" ? Le jury de la cour d'assises de la Lozère au XIXe siècle", dans Ethnographie de la violence.-- Études rurales, n 95-96, juillet-décembre 1984, pp. 167-180.

, 1987, Les maîtres de granit. Les notables de la Lozère du XVIIIe siècle à nos jours, Paris, Olivier Orban, 1987.

Charles-Hippolyte POUTHAS, 1956, La population française pendant la première moitié du XIXe siècle, Institut national d'études démographique, cahier $n^{\circ} 25$, Paris, Presses universitaires de France, 1956, 225 p. 
Edmond PRÉCLIN, 1948, "La révolution de 1848 en Franche-Comté (1848-1851)", dans Études d'histoire moderne et contemporaine, tome 2, 1948, pp. 276-308.

1949, "Les rapports helvético-comtois de 1848 à 1851 ; leur place dans l'histoire des rapports franco-suisses", dans Actes du Congrès historique du Centenaire de la révolution de 1848, Paris, Presses universitaires de France, 1949, pp. 315-324.

Roger PRICE, 1972, The French Second Republic. A Social History, Londres, B.T. Batsford, 1972, 386 p.

[dir.], 1975, Revolution and Reaction. 1848 and the Second French Republic, Londres/ New York, Croom Helm/Barnes and Nibb, 1975, 333 p.

Giovanna PROCACCI, 1993, Gouverner la misère. La question sociale en France, 1789-1848, Paris, Éditions du Seuil, 1993, 361 p.

1950, Procès-verbaux du gouvernement provisoire et de la commission du pouvoir excécutif (24 février-22 juin 1848), Paris 1950, $432 \mathrm{p}$.

Antoine PROST, 1969, L'Enseignement en France, 1800-1967, Paris, Librairie Armand Colin, 1969.

Claude PRUDHOMME, 1984, Histoire religieuse de La Réunion, Paris, Éditions Karthala, 1984.

1948, "Quarante-huit. L'abolition de l'esclavage à la Guadeloupe", dans Revue Guadeloupéenne, Basse-Terre, Guadeloupe, mars-avril 1948.

Jacques RANCIERE, 1981, La nuit des prolétaires. Archives du rêve ouvrier, Paris, Librairie Arthème Fayard, 1981.

1966, "Raspail et Blanqui, le 15 mai 1848", dans révolution prolétarienne, n² 219, 1966, pp. 215-216.

Michael REARDON, 1971, "The reconciliaion of christianitiy with progress : Philippe Buchez", dans Rev. Politics, volume 33, n 4, 1971, pp. 512-537.

René RÉMOND, 1948, Lamennais et la démocratie, collection du Centenaire de la révolution de 1848, Paris, Presses universitaires de France, 1948, 77 p.

1954, La droite en France de 1815 à nos jours. Continuité et diversité d'une tradition politique, Paris, Aubier, 1954, 323 p.

1969, La vie politique en France depuis 1789. Tome 2 1848-1879, collection U, Paris,

Librairie Armand Colin, 1969, 381 p.

J. RENARD, 1948, "Centenaire de la liberté", dans Revue d'histoire des colonies, n 81, 1948. Raymond RENARD, 1973, "La Martinique de 1848 à 1870", dans Cahiers du GURIC, Groupe universitaire de recherches inter-Caraibes, Université des Antilles et de la Guyane, $\mathrm{n}^{\circ} 12$, 1973, 246 p.

François RENAULT, 1976, Libération d'esclaves et nouvelle servitude. Le rachat des captifs africains pour le compte des colonies françaises après l'abolition de l'esclavage, Dakar/Abidjan, Nouvelles éditions africaines, 1976, $240 \mathrm{p}$.

Jane RENDALL, 1985, The origins of modern feminism. Women in Britain, France and the United-States, 1780-1860, Londres, Mac Millan, 1985.

Paul RENOUVIN, 1949, "L'idée d'États-Unis d'Europe pendant la crise de 1848", dans Actes du Congrès historique du Centenaire de la révolution de 1848, Paris, Presses universitaires de France, 1949, pp. 31-46.

Georges REUCHSEL, 1965, "L'élection présidentielle de 1848 (à Lyon)", dans Tout Lyon, n - 971, 1965, p. 4.

Claire REVERCHON et Pierre GAUDIN, 1986, "Le sens du tragique dans la mémoire historique. Protestants et républicains dans la Drôme", dans André JULLIARD [dir.], Conjurer le malheur... , Le Monde alpin et rhodanien, nº 2-4, 1986, pp. 97-113. 
, 1987, "Une prison de longue durée : la tour de Crest, symbole de la répression antihuguenote et anti-républicaine dans le légendaire historique drômois", dans Philippe VIGIER et Alain FAURE [dir.], Maintien de l'ordre et polices en France et en Europe au XIXe siècle , Paris, Créaphis, 1987, pp. 213-232.

, 1990, "Les insurgés de la Drôme : images héritées, images transmises...", dans

Philippe VIGIER et Alain FAURE [dir.], Répression et prison politiques en France et en Europe au XIXe siècle, Paris, Créaphis, 1990, pp. 159-169.

, 1994, "'Indignés et frémissants..." L'image des insurgés de la Drôme en décembre 1851 à travers l'historiographie", dans Alain FAURE, Alain PLESSIS et Jean-Claude FARCY [dir.], La terre et la cité. Mélanges offerts à Philippe Vigier, Paris, Éditions Créaphis, 1994, pp. 311-328.

1950, La révolution de 1848 à Moulins et dans le département de l'Allier, Moulins, Préfecture de l'Allier, 1950, $300 \mathrm{p}$.

1949, La révolution de 1848 dans le département de l'Isère, Grenoble, Comité départemental du Centenaire de la révolution, 1949, 534 p.

1948, La révolution de 1848 et l'Anjou, Angers, Éditions de l'Ouest, 1948, 29 p. 1948, La révolution de 1848. Exposition organisée par le Comité national du Centenaire de la révolution de 1848, Paris, Bibliothèque nationale, 1948, 206 p.

1965,"La révolution de 1848, vue du château de Pau", dans Bulletin des amis du château de Pau, n 27, 1965, pp. 19-23.

Gabrielle REY, 1962, Le fourieriste Allyre Bureau, 1810-1859, Aix-en-Provence, la Pensée universitaire, 1962, $55 \mathrm{p}$.

Élie REYNIER, 1948, La Seconde République dans l'Ardèche, Privas, Maison de l'Enfance/FOL, 1948.

S. REYNOLDS, 1986, Marianne's citizens. Women, State and Revolution. Essays on Power and Gender in Europe since 1789, Brighton, 1986.

Stéphane RIALS, 1983, "Les royalistes français et le suffrage universel au XIXe siècle", dans Pouvoirs, $n^{\circ} 26,1983$, pp. 145-152.

Georges RIBEILL, 1993, La révolution ferroviaire. La formation des compagnies de chemins de fer en France (1823-1870), Paris, Belin, 1993, 480 p.

Pierre RIBERETTE, 1981, "Un réformateur du XIXe siècle et ses disciples : FrançoisGuillaume Coessin", dans 1848, les utopismes sociaux. Utopie et action à la veille des journées de février, Paris, CDU-SEDES, 1981, pp. 161-179.

Robert RICHARD, 1969, "La révolution à Abbeville", dans Société d'émulation historique littéraire d'Abbeville, 1969, pp. 323-332.

Jean-Claude RICHEZ, 1991, "Le Juif, le forestier et l'Etat : l'affaire de Marmoutier", dans Violence, brutalité, barbarie.-- Ethnologie française, n 3, tome 21, juillet-septembre 1991, pp. 282-291.

Rainer RIEMENSCHNEIDER, 1985, Dezentralisation und Regionalismus in Frankreich um die Mitte des 19. Jahrhunderts.-- Deutschen historischen Institut in Paris, Band 22, Bonn, 1985, $301 \mathrm{p}$.

Pierre RIMBERT, 1972, "La révolution de 1848 et le coup d'État du 2 décembre 1851", dans Ours, n 33, 1972, pp. 16-21.

Yves RINAUDO, 1986, "1848 : les fermes-écoles, premier essai d'un enseignement populaire agricole", dans Annales d'histoire des enseignements agricoles, n 1, octobre 1986, pp. 33-44. 
1988, "La révolution conservatrice : les bois communaux varois au XIXe siècle", dans Denis WORONOFF [dir.], Révolution et espaces forestiers. Colloque des 3 et 4 juin 1987, Paris, Éditions L'Harmattan, 1988, pp. 175-190.

, 1996, "Le vigneron provençal au milieu du XIXe siècle : image et réalité", dans Gilbert GARRIER, Jean-Marie PESEZ et Alessandro STELLA [dir.], Vignerons. Actes du colloque "Les vignerons du Moyen Âge au phylloxéra, Lyon, 18-19 ocobre 1996.-- Bulletin du Centre Pierre Léon d'histoire économique et sociale, $\mathrm{n}^{\circ}$ 3-4, 1996, pp. 127-133.

Marius RIOLLET, 1949, "Le révolution de 1848 à La Tour-du-Pin, d'après deux témoins", dans La révolution de 1848 dans le département de l'Isère, Grenoble, Comité départemental du Centenaire de la révolution, 1949, pp. 437-453.

Michèle RIOT-SARCEY, 1985, "La conscience féministe des femmes en 1848 : Jeanne Deroin et Désirée Gay", dans Stéphane MICHAUD [dir.], Un fabuleux destin : Flora Tristan, Dijon, Presses Universitaires de Dijon, 1985.

1992, "Lecture de la révolution par des femmes en 1848", dans Le XIXe siècle et la Révolution française, Actes des journées d'études de la Société d'histoire de la révolution de 1848 et des révolutions du XIXe siècle, Nanterre, octobre 1989, Paris, Editions Créaphis, 1992, pp. 207-218.

, 1994, La démocratie à l'épreuve des femmes. Trois figures critiques du pouvoir, 1830-1848, Paris, Albin Michel, 1994, 365 p.

1995, "De la représentation et de ses multiples usages", dans Démocratie et Représentation, Paris, Kimé, 1995, pp. 129-143.

Michel RIOU, 1974, "L'élection présidentielle de décembre 1848 en Ardèche", dans Revue du Vivarais, tome LXXVIII, $\mathrm{n}^{\circ} 2,1974, \mathrm{pp} .82-96$.

Marcelle RISLER, 1957, "Quelques précurseurs de l'assistance moderne. La Seconde République et les enfants trouvés en province", dans Cahiers du Musée social, nº 1-2, 1957, pp. 12-70.

Auguste RIVET, 1979, La vie politique dans le département de la Haute-Loire de 1815 à 1974, Le Puy, Les Cahiers de la Haute-Loire, 1979.

Vincent ROBERT, 1990, "Aux origines de la manifestation en France (1789-1848)", dans Pierre FAVRE [dir.], La manifestation, Paris, Presses de la Fondation nationale des sciences politiques, 1990, pp. 69-89.

1996, Les chemins de la manifestation, 1848-1914, Lyon, Presses universitaires de Lyon, 1996, 394 p.

Rodolphe ROB0, 1984, L'Abolition de l'esclavage, la République et Victor Schœlcher, Cayenne, chez l'auteur, 1984, $14 \mathrm{p}$.

Jean-Pierre ROCHER, 1966, "Les élections dans l'Yonne sous la Seconde République et le Second Empire", dans Recherches sur les forces politiques de la France de l'Est depuis 1787.-Cahiers de l'Association interuniversitaire de l'Est, $\mathrm{n}^{\circ}$ 8-9, 1966, pp. 160-188.

1981, "Le comportement politique du canton de Vézelay au milieu du XIXe siècle", dans Annales de Bourgogne, juillet-septembre 1981.

1987, "L'évolution politique et religieuse du département de l'Yonne dans la première partie du XIXe siècle", dans Léo HAMON [dir.], Du jansénisme à la laïcité. Le jansénisme et les origines de la déchristianisation, Premiers Entretiens d'Auxerre, 1983, Paris, Editions de la Maison des sciences de l'homme, 1987, pp. 111-137.

1994, "Les élections dans l'Yonne de 1848 à 1871", dans Léo HAMON [dir.], Les républicains sous le Second Empire, 9es Entretiens d'Auxerre, 1992, Paris, Éditions de la Maison des sciences de l'homme, 1994, pp. 33-72. 
Francis RONSIN, 1992, Les divorciaires. Affrontements politiques et conceptions du mariage dans la France du XIXe siècle, Paris, Aubier, 1992, 390 p.

Guy ROSA, 1974, "Comment on devient républicain ou Hugo représentant du peuple", dans Revue des sciences humaines , tome 39, n 156, 1974, pp. 653-671.

Pierre ROSANVALLON, 1985, Le moment Guizot, Bibliothèque des sciences humaines, Paris, Éditions Gallimard, 1985, 414 p.

, 1992, Le Sacre du citoyen. Histoire du suffrage universel en France, Paris, Gallimard, $1992,490 \mathrm{p}$.

1993, "La République du suffrage universel", dans François FURET et Mona OZOUF [dir.], Le siècle de l'avènement républicain, Bibliothèque des histoires, NRF, Paris, Editions Gallimard, 1993.

Robert ROSE-ROSETTE, 1963, "Hommage à Victor Schœlcher", dans Revue historique de l'armée, $\mathrm{n}^{\circ} 1,1963$, pp. 161-162.

U. ROUCHON, 1948, Le département de la Haute-Loire et la révolution de février 1848, Le Puy, Imprimerie La Haute-Loire, 1948, 82 p.

Jacques ROUGERIE, 1966, "Faut-il départementaliser l'histoire de France ?", dans Annales, économies, sociétés, civilisations, tome 21, n 1, janvier-février 1966, pp. 178-193. , 1968, "Remarques sur l'histoire des salaires à Paris au XIXe siècle", dans Mouvement social, $\mathrm{n}^{\circ}$ 63, 1968, pp. 71-108.

, 1989, "Paris des barricades : un espace populaire", dans Catalogue de l'exposition, Les traversées de Paris, Paris, 1989.

1994, "Le mouvement associatif populaire comme facteur d'acculturation populaire à Paris de la Révolution aux années 1840", dans Annales historiques de la Révolution française, juillet-septembre 1994.

G. ROUGERON et Y. MONCEAU, 1950, La révolution de 1848 à Moulins et dans le département de l'Allier, Moulins, 1950.

Mdeleine ROUSSEAU, 1948, "L'action artistique de la révolution de 1848", dans Musée vivant, $\mathrm{n}^{\circ} 35$, avril 1948.

Xavier ROUSSEAU, 1969, "Jean-Symphor-Gaétan Vaudoré, député de l'Orne (1818-1889)", dans Pays Argentan, $n^{\circ}$ 155, 1969, pp. 99-103.

Marie-Christine ROUX, 1972, "Un exemple de grande industrie dans le Vaucluse au XIXe siècle : l'usine de l'Oseraie (1847-1914)", dans Études vauclusiennes, nº 8, 1972, pp. 17-24.

François ROUYER, 1995, La révolution de 1848 à Tonnerre vue par un Tonnerrois, C. Dormois, Dannemoine, À l'image de l'abeille, 1995, 66 p.

Anthony ROWLEY, 1986, "Deux crises économiques modernes : 1846 et 1848 ?", dans 1848, révolutions et mutations au XIXe siècle, n² 2, 1986, pp. 81-90.

D. ROZENZWEIG, 1971, Barica-Parisului, Bucarest, Ed Enciclica romana, 1971, 232 p. J.B. ROZIER, 1954, "Paysans d'Espinasse dans la première moitié du XIXe siècle", dans Notre Bourdonnais, $\mathrm{n}^{\circ} 109,1954$, pp. 289-292 et n 110, 1954, pp. 309-313.

Maximilien RUBEL, 1960, "Robert Owen à Paris en 1848", dans Actualité de l'histoire, $\mathrm{n}^{\circ} 30$, 1960, pp. 1-12.

Fernand RUDE, 1949a, "La préparation des élections à l'Assemblée constituante (marsavril 1848)", dans La révolution de 1848 dans le département de l'Isère, Grenoble, Comité départemental du Centenaire de la révolution, 1949, pp. 65-83.

1949b, "La révolution de 1848 à Grenoble", dans La révolution de 1848 dans le département de l'Isère, Grenoble, Comité départemental du Centenaire de la révolution, 1949, pp. 87-212. 
1949c, "L'arrondissement de Vienne en 1848", dans La révolution de 1848 dans le département de l'Isère, Grenoble, Comité départemental du Centenaire de la révolution, 1949, pp. 213-436.

Odile RUDELLE, 1988, "L'élaboration de la constitution de 1848", dans P. ISOART, et C. BIDEGARAY, Des Républiques françaises, Paris, Economica, 1988, pp. 388-412.

1992, "Le suffrage universel", dans Jean-François SIRINELLI [dir.], Histoire des droites en France. Tome III : Sensibilités, Paris, Éditions Gallimard, 1992, pp. 251-320.

Victor SABLÉ, 1955, La transformation des Isles d'Amérique en départements français, Paris, Éditions Larose, 1955, 200 p.

B. SACHTER, 1975, "Sensibilité des Caisses d'épargnes sarthoises aux conjonctures économiques, politique et militaire de la Monarchie de Juillet à la IIIe République (1834-1876)", dans Annales de Bretagne, tome 82, n 1, 1975, pp. 69-86.

Pierre-Paul SAGAVE, 1995, "1848: Ateliers nationaux à Paris et travaux d'utilité publique à Berlin", dans Ilja MIECK, Horst MÖLLER et Jürgen VOSS [dir.], Paris und Berlin in der Revolution 1848/Paris et Berlin dans la révolution de 1848. Colloque organisé par la Ville de Paris; l'Historische Kommission zu Berlin et l'Institut historique allemand, Paris, 23-25 novembre 1992, Sigmaringen, Jan Thorbecke Verlag, 1995, pp. 153-160.

Jean SAGNES, 1981, "Un village languedocien face au coup d'État de 1851", dans Études sur Pézenas et l'Hérault, 1981, n² 2, réédité dans Jean SAGNES, Le Midi rouge. Mythe et réalité. Études d'histoire occitane, Paris, Éditions Anthropos, 1982, pp. 25-55.

Peter SAHLINS, 1994, Forest Rites. The War of Demoiselles in Nineteenth-Century France, Cambridge (Mass.), Harvard University Press, 1994, 188 p.

Denis SAILLARD, 1992, "Les premières commémorations officielles de Rouget de Lisle et de la Marseillaise dans le Jura (1836-1918)", dans Travaux présentés par les membres de la Société d'émulation du Jura, 1992, pp. 55-81.

Michelle SAINTE-MARIE-PERRINS, 1970, "La bourgoisie lyonnaise et la question ouvrière sous la Seconde République", dans Bulletin du Centre d'histoire économique et sociale de la région lyonnaise, $\mathrm{n}^{\circ} 3,1970$, pp. 24-28.

Pierre de SAINT-JACOB, 1948, "La situation des paysans de la Côte-d'Or en 1848", dans Études d'histoire moderne et contemporaine, tome 2, 1948, pp. 231-232..

Claude SAINT-JEAN, 1965, "L'élection présidentielle du 10 décembre 1848", dans Revue des deux mondes, $n^{\circ} 23,1965$, pp. 427-431.

Léonard SAINVILLE, 1950, Schœlcher Victor, Paris, Éditions Fasquelle, I950, 272 p.

Frédéric SALMON, 1991, "La "gauche avancée" aux élections de 1849", dans Communisme, 1991, pp. 69-82

1994, "La "gauche avancée" en 1849 et en 1870 : le pourquoi de la chute", dans Léo HAMON [dir.], Les républicains sous le Second Empire, 9es Entretiens d'Auxerre, 1992, Paris, Éditions de la Maison des sciences de l'homme, 1994, pp. 93-110.

1993, Les salons retrouvés. Éclat de la vie artistique dans la France du Nord, 1815-1848, Lille, Association des conservateurs des Musées du Nord-Pas-de-Calais, 1993, 198 p.

Emeterio S. SANTOVENIA, 1949, "L'universalité de la Révolution française de 1848", dans Actes du Congrès historique du Centenaire de la révolution de 1848, Paris, Presses universitaires de France, 1949, pp. 47-51.

Francis SARTORIUS, 1995, "Des débuts de la Monarchie de Juillet à la fin du Second Empire : intellectuels et hommes politiques français en exil en Belgique", dans L'exil.-Revue d'histoire du XIXe siècle (1848, révolutions et mutations au XIXe siècle), nº 11, 1995, pp. 35-49. 
Maurice SATINEAU, 1948, Schœlcher, héros de l'abolition de l'esclavage dans les possessions françaises, Paris, Éditions Mellottée, 1948, 156 p.

Georges SAUNIER, 1970, "Les révolutionnaires feyzinois en 1848", dans Évocations, n 159 , 1970.

Marcel SAURIN, 1964-1965, "L'École d'administration de 1848", dans Politiques, n² 25-32, 1964-1965, pp. 105-196.

A. SCHERER, 1980, Histoire de la Réunion, Que sais-je ?, n 1846, Paris, Presses universitaires de France, 1980, 128 p.

Charles SCHMIDT, 1948, Des ateliers nationaux aux barricades de Juin, collection du Centenaire de la révolution de 1848, Paris, Presses universitaires de France, 1948, 68 p. Nelly SCHMIDT, 1984, "Suppression de l'esclavage, système scolaire et réorganisation sociale aux Antilles : les Frères de l'Instruction Chrétienne, témoins et acteurs, instituteurs des nouveaux libres", dans Revue d'histoire moderne et contemporaine, 1984. 1985, "Politique et religion en Guadeloupe après l'émancipation : l'affaire Dugoujon", dans Espaces Caraibes, Groupe de recherches Caraïbes-Amériques, Université Paris X, II, 1985.

1987, "Le problème de l'ordre colonial après la révolution de 1848 : le cas des colonies françaises des Caraïbes", dans Philippe VIGIER et Alain FAURE [dir.], Maintien de l'ordre et polices en France et en Europe au XIXe siècle, Paris, Créaphis, 1987, pp. 103-116. , 1988a, "Schœlcherisme et assimilation dans la politique coloniale française : de la théorie à la pratique aux Caraibes entre 1848 et les années 1880", dans Revue d'histoire moderne et contemporaine, 1988.

1988b, "Victor Schœlcher, mythe et réalité", dans 1848. Révolutions et mutations au XIXe siècle, Société d'histoire de la révolution de 1848 et des révolutions du XIXe siècle, 1988.

1988c, "Continuités et ruptures dans la politique coloniale française aux Caraïbes : l'apport de documents mal connus, les travaux des premières commissions coloniales post-esclavagistes, I848-1875", dans Sources. Travaux historiques, association Histoire au présent, volume 13, 1988.

1988d, "Chansons des nouveaux libres de Guadeloupe et de Martinique, 1848-1852", dans Itinéraires et contacts de cultures, Publication du Centre d'études francophones de l'Université Paris XIII, Paris, Éditions L'Harmattan, 1988, pp. 107-135. 1989a, "Les paradoxes du développement industriel des colonies françaises des Caraibes pendant la seconde moitié du XIXe siècle. Perspectives comparatives", dans L'industrialisation. Actes du colloque Histoire de l'industrialisation, Paris, 11-12 décembre 1987.-Histoire, économie et société, 3e trimestre 1989, pp. 313-333.

1989b, "La commémoration du Centenaire de l'abolition de l'esclavage dans les colonies françaises, 1848-1948", dans Histoires de centenaires ou le devenir des révolutions.-1848, révolutions et mutations au XIXe siècle, n 5, 1989, pp. 55-64.

1990, "Procès et condamnés politiques en Guadeloupe, 1848-1871", dans Philippe

VIGIER et Alain FAURE [dir.], Répression et prison politiques en France et en Europe au XIXe siècle, Paris, Créaphis, 1990, pp. 77-93.

1992, "Aspects des répercussions de la Révolution aux Caraïbes au XIXe siècle.

Histoire et mythes en situation coloniale", dans Le XIXe siècle et la Révolution française, Actes des journées d'études de la Société d'histoire de la révolution de 1848 et des révolutions du XIXe siècle, Nanterre, octobre 1989, Paris, Editions Créaphis, 1992, pp. 281-294. 
1995a, L'engrenage de la liberté. Caraibes, XIXe siècle, Aix-en-Provence, Publications de l'Université de Provence, 1995, 378 p.

1995b, La correspondance de Victor Schœlcher, Paris, Éditions Maisonneuve et

Larose,1995, $399 \mathrm{p}$.

et Oruno D. LARA, 1994, Victor Schœlcher et l'abolition de l'esclavage, catalogue de

l'exposition réalisée par le Centre de recherches Caraibes-Amériques en collaboration avec le Laboratoire d'ethnologie du Musée de l'Homme, Paris, Éditions.du CERCAM, 1994, $60 \mathrm{p}$.

Bernard SCHNAPPER, 1965, "Les sociétés ouvrières de production pendant la Seconde République : l'exemple girondin", dans Revue d'histoire économique et sociale, volume 43, n -2, 1965, pp. 162-191.

_-_-_, 1978, "La séparation de corps de 1837 à 1914. Essai de sociologie juridique", dans Revue historique, $\mathrm{n}^{\circ}$ 526, avril-juin 1978, pp. 453-466.

, 1980, "La correction paternelle et le mouvement des idées au dix-neuvième siècle (1789-1935)", dans Revue historique, n 534, avril-juin 1980, pp. 319-349.

Robert SCHNERB, 1947, "Les hommes de 1848 et l'impôt", dans 1848 et les révolutions du XIXe siècle, printemps 1947, pp. 5-51, réédité dans Jean BOUVIER et Jacques WOLFF [dir.], Deux siècles de fiscalité française, XIXe-XXe siècle. Histoire, économie, politique, Paris/La Haye, Mouton éditeur, 1973, pp . 105-57.

1948, Ledru-Rollin, collection du Centenaire de la révolution de 1848, Paris, Presses universitaires de France, 1948, 76 p.

Jacques, SCHNETZLER, 1968, "Un demi-siècle d'évolution démographique dans la région de Saint-Étienne (1820-1876)", dans Études foréziennes, tome I, 1968, pp. 157-190.

Edward SHORTER et Charles TILLY, 1974, Strikes in France, 1830-1968, Cambridge, Cambridge University Press, 1974.

Philippe SEGUIN, 1990, Louis Napoléon le Grand, Paris, Editions Grasset \& Fasquelle, 1990, $451 \mathrm{p}$.

Jerrold SEIGEL, 1986, Bohemian Paris. Culture, politics and the boundaries of bourgeois life, 1830-1930, Viking Penguin Inc., 1986, traduction française, Paris bohème. Culture et politique aux marges de la vie bourgeoise, 1830-1930, Bibliothèque des histoires, NRF, Paris, Gallimard, 1991, $421 \mathrm{p}$.

Ernest SEILLIERE, 1967, "À l'occasion d'un anniversaire : Lamartine orateur", dans Marseille, $\mathrm{n}^{\circ} 77,1967, \mathrm{pp} .47-78$.

William SERMAN, 1979, Les origines des officiers français, 1848-1870, Paris, Publications de la Sorbonne, 1979, $406 \mathrm{p}$.

, 1994, La vie professionnelle des officiers français au milieu du XIXe siècle, Paris, Éditions Christian, 1994, $222 \mathrm{p}$.

William H. SEWELL, 1971, "La classe ouvrière de Marseille sous la Seconde République : structure sociale et comportement politique", dans Le Mouvement Ssocial, nº 76, 1971. 1974, "Social change and the rise of working-class politics in nineteenth-century Marseille", dans Past and Present, $n^{\circ}$ 65, 1974, pp. 75-109.

1980, Gens de métier et révolutions. Le langage du travail de l'Ancien Régime à 1848, Paris Aubier, 1983 (édition originale, Cambridge, 1980).

1981, "La confraternité des prolétaires : conscience de classes sous la Monarchie de Juillet", dans Annales, économies, sociétés, civilisations, n 4, juillet-août 1981. 1985, Structure and Mobility, The Men and Women of Marseille, 1820-1870, Cambridge, Cambridge University Press, 1985, 377 p. 
1986, "Artisans, Factory Workers, and the Formation of the French Working Class, 1789-1848", dans Ira KATZNELSON et Aristide R. ZOLBERG [dir.], Working-Class Formation. Nineteenth-Century Patterns in Western Europe and the United States, Princeton, Princeton University Press, 1986, pp. 45-70.

Germain SICARD, 1987, "Les activités du Conseil général de la Haute-Garonne au milieu du XIXe siècle", dans Les pouvoirs régionaux : représentants et élus, Actes du 111e Congrès national des Sociétés savantes, Poitiers, 1986. Section d'histoire moderne et contemporaine, tome I, fascicule 1, Paris, Éditions du Comité des travaux historiques et scientifiques, 1987, pp. 257-282.

Jean SIGMANN, 1970, 1848. Les révolutions romantiques et démocratiques de l' Europe Paris Calmann Lévy, 1970, 365 p.

J. SIMON, 1956-1957, "Gannat sous la Seconde République", dans Notre Bourdonnais, série 5 , n 118,1956, p. 444-448, n 119, 1956, pp. 461-463, n 120, 1956, pp. 477-480, n 121 , 1956, pp. 489-493 et série 5, n 122, 1957, pp. 497-505.

Jonathan SKINNER, 1990, "Une mémoire orale de la Révolution ? Le jacobinisme des Montagnards de l'arrondissement d'Apt en décembre 1851", dans L'espace et le temps reconstruits. La Révolution Française, une révolution des mentalités et des cultures? Actes du colloque de Marseille, 22-24 février 1989, Aix-en-Provence, Publications de l'université de Provence, 1990, pp. 273-280.

Albert SOBOUL, 1948a, "Les troubles agraires de 1848. Documents", dans 1848 et les révolutions $d u$ XIXe siècle, $\mathrm{n}^{\circ} 180$ et $\mathrm{n}^{\circ}$ 181, juin et novembre 1948, pp. 1-18 et pp. 39-61. , 1948b, "La question paysanne en 1848", dans La Pensée, $\mathrm{n}^{\circ} 18, \mathrm{n}^{\circ} 19$ et n²0,1948, pp. 55-66, pp. 25-37 et pp. 48-56, réédité sous le titre "Les troubles agraires de 1848", dans Albert SOBOUL, Problèmes paysans de la Révolution, 1789-1848, Paris, F. Maspero, 1976, pp. 293-334.

1968, "Survivances "féodales" dans la société rurale française au XIXe siècle", dans Annales, économies, sociétés, civilisations, n 5, septembre-octobre 1968, pp. 965-986. 1973, "Mouvements paysans et troubles agraires en France de 1789 jusqu'au milieu du XIXe siècle", dans Les mouvements paysans dans le monde contemporain. Actes du XIIIe congrès international des sciences historiques, Moscou, 16-23 août 1970.-- Cahiers internationaux d'histoire économique et sociale $n^{\circ}$ 6, Genève, Droz, 1973, pp. 125-149, réédité dans, Albert SOBOUL, Problèmes paysans de la Révolution, 1789-1848, Paris, F. Maspero, 1976, pp. 267-292. 1976, Problèmes paysans de la Révolution, 1789-1848, Paris, F. Maspero, 1976, 442 p.

Anne-Marie SOHN, 1981, "Les rôles féminins dans la vie privée : approche méthodologique et bilan de recherches", dans Revue d'histoire moderne et contemporaine, octobre-décembre 1981.

Pierre SORLIN, 1969, La société française. Tome I, 1840-1914., Paris, Artaud, 1969, 310 p. Jean-François SOULET, 1987, Les Pyrénées au XIXe siècle. Tome 1 : Organisation sociale et mentalités. Tome 2 : Une société en dissidence, Toulouse, Éditions Éché, 1987, 2 volumes, 478 p. et $713 \mathrm{p}$.

1988, "Une nouvelle approche de la France rurale au XIXe siècle ? (À propos de thèses récentes sur les Pyrénées)", dans Revue historique, n 566, avril-juin 1988, pp. 381-392.

M.H. SOULET, 1980, "Les organisations professionnelles de représentation de l'agriculture et l'enseignement agricole, 1830-1940", dans Historical Reflections/Réflexions historiques, tome VII, n 2-3, été-automne 1980, pp. 577-586. 
Mary Lynn STEWART-McDOUGALL, 1984, The Artisan Republic. Revolution, Reaction, and Resistance in Lyon, 1848-1851, Kingston and Montreal, McGill-Queen's University Press, 1984,211 p.

Hartmut STENZEL, 1981, "Remarques sur la discussion entre Proudhon et les fourieristes", dans 1848, les utopismes sociaux. Utopie et action à la veille des journées de février, Paris, CDU-SEDES, 1981, pp. 181-189.

André STRAUS et Patrick VERLEY, 1990, "Parisian industries and national capitalism in the first half of the nineteenth century (1830-1850)", dans Philippe JOBERT et Michael MOSS [dir.], The Birth and Death of Companies. An Historical Perspective, Carnforth/Park Ridge New Jersey, The Parthenon publishing, 1990, pp. 89-103.

J. SUFFEL, 1948, 1848, la révolution racontée par ceux qui l'ont vue, Paris, Éditions du Myrte, $1948,640 \mathrm{p}$.

J. SURET-CANALE, 1957, "Les conditions de vie de classe ouvrière en Mayenne au milieu du XIXe siècle", dans Bulletin de la commission historique de Mayenne, série 2, tome 66, 1957, pp. 63-75.

Raphaèl TARDON, 1948, Le combat de Schœlcher, Paris, Éditions Fasquelle, 1948, 128 p. Guy TASSIN, 1996, Un village du Nord avant la mine. Chronique d'Édouard Pierchon, curé d'Haveluy au XIXe siècle, Paris, Éditions L'Harmattan, 1996, 572 p.

Émile TERSEN, 1948a, Le gouvernement provisoire et l'Europe, collection du Centenaire de la révolution de 1848, Paris, Presses universitaires de France, 1948, 77 p. , 1948b, "Juin 1848", dans La Pensée, n 19, 1948, pp. 16-24.

1949, "La Commission d'abolition de l'esclavage (4 mars-21 juillet 1848)", dans Actes du Congrès historique du Centenaire de la révolution de 1848, Paris, Presses universitaires de France, 1949, pp. 295-302.

[dir.], 1948, Esclavage et colonisation, Paris, Presses Universitaires de France, 1948, $220 \mathrm{p}$.

Didier TERRIER, 1989, "Tissage à domicile, litiges et cohésion sociale. Les villages du Cambrésis 1820-1870", dans Gérard GAYOT et Jean-Pierre HIRSCH [dir.], La Révolution française et le développement du capitalisme. Actes du colloque de Lille, 19-21 novembre 1987, Lille, Revue du Nord, 1989, pp. 391-405.

1974, Textes et documents : l'élection présidentielle du 10 décembre 1848 dans le département de l' Allier.-- Notre Bourbonnais, $\mathrm{n}^{\circ}$ 187, 1974, 2 p

Pierre THÉVENON, 1949, "Notice sur Augustin Thevenet", dans La révolution de 1848 dans le département de l'Isère, Grenoble, Comité départemental du Centenaire de la révolution, 1949, pp. 479-497.

Christian THIBON, 1987, "L'ordre public villageois : le cas du Pays de Sault (1848-1914)", dans Philippe VIGIER et Alain FAURE [dir.], Maintien de l'ordre et polices en France et en Europe au XIXe siècle, Paris, Créaphis, 1987, pp. 309-325.

1988, Pays de Sault. Les Pyrénées audoises au XIXe siècle : les villages et l'État, Paris,

Éditions du Centre national de la recherche scientifique, 1988, 278 p.

, 1990, "Les victimes républicaines du Second Empire dans un arrondissement

rural", dans Philippe VIGIER et Alain FAURE [dir.], Répression et prison politiques en France et en Europe au XIXe siècle, Paris, Créaphis, 1990, pp. 145-157.

Édith THOMAS, 1948, Les femmes en 1848, collection du Centenaire de la révolution de 1848, Paris, Presses universitaires de France, 1948, 79 p.

Georges-Michel THOMAS, 1962, Brest la rouge, 1847-1906, Brest, Imprimerie du Télégramme, 1962, 168 p. 
1974, "Les lendemains de la révolution de 1848 en Bretagne", dans Cahier d'Iroise, $\mathrm{n}$

○ 4 , 1974, pp. 1061-1091.

, 1984, "Le coup d'État du 2 décembre 1851 dans le Finistère et à Brest qui accueillit, en transit, les "transportés" en Algérie et en Guyanne", dans Histoire régionale de 1610 à nos jours. Questions diverses, Actes du 107e Congrès national des Sociétés savantes, Brest 1982 Section d'histoire moderne et contemporaine, tome II, Paris, Éditions du Comité des travaux historiques et scientifiques, 1984, pp. 103-116.

Guy THUILLIER, 1959, George Dufaud et les début du grand capitalisme dans la métallurgie en Nivernais au XIXe siècle, Paris, S.E.V.P.E.N., 1959, 254 p.

et Vincent WRIGHT, 1976, "Pour l'histoire du coup d'État, une source à exploiter : les dossiers des pensionnés du décembre 1851", dans Le mouvement social, $\mathrm{n}^{\circ} 94$, janviermars 1976, pp. 97-106.

Charles TILLY, 1970, "The Changing place of the Collective Violence", dans Essay in Theory and History: An approach to the Social Sciences, Cambridge, Harvard University Press, 1970, pp. 139-164.

1971, "How Protest Modernized in France, 1845-1855", dans The Dimensions of Quantitative Research in History, Princeton, Princeton University Press, 1971, pp. 192-255. 1972, "The modernization of Political conflict in France", dans Perspectives on Modernization : Essay in Memory of Ian Weinberg, Toronto, University of Toronto Press, 1972. , 1986, La France conteste de 1600 à nos jours, Paris, Librairie Arthème Fayard, 1986. , Louise TILLY et Richard TILLY, 1975, The Rebellious Century, 1830-1930, Cambridge, Harvard University Press, 1975.

et Lynn LEES, 1974, "Le peuple de Juin 1848", dans Annales, économies, sociétés, civilisations, $\mathrm{n}^{\circ}$ 5, septembre-octobre 1974, pp. 1061-1091.

Jean-Yves TIRAT, 1963, "Problèmes de méthode en histoire sociale", dans Revue d'histoire moderne et contemporaine, tome 10, juillet-septembre 1963, pp. 211-218.

Philippe TOLLU, 1987, Montalembert. Les libertés sous le Second Empire, Paris, Editions Albatros, 1987, 532 p.

Dale TOMICH, 1994, "Visions of Liberty:Martinique in I848", dans J. PRITCHARD [dir.], Proceedings of the Nineteenth Meeting of the French Colonial Historical Society, Cleveland, F.C.H.S., 1994, pp. 164-172.

Alfred TOUCHEMOLIN, 1969, "Les journées révolutionnaires de février 1848 à Paris : souvenirs d'un jeune Alsacien", dans Saisons d'Alsace, n 31, 1969, pp. 331-342.

Yves TOUL, 1961a, "Les élections du 23 avril 1848 à l'Assemblée Constituante dans les Deux-Sèvres", dans Revue du Bas-Poitou, n 6, 1961, pp. 419-437.

1961b, "Géographie de l'élection présidentielle du 10 décembre 1848 dans les Deux-Sèvres", dans Bulletin de la Société d'histoire scientifique des Deux-Sèvres, tome $11, \mathrm{n}^{\circ} 10$, 1961, pp. 435-449.

Muriel TOULOTTE, 1993, Étienne Arago, 1805-1892. Une vie, un siècle, Perpignan, Publications de l'olivier, 1993, $367 \mathrm{p}$.

Maurice TOURNIER, 1969, "Eléments pour une étude quantitative d'une journée de 1848", dans Colloque de Saint Cloud, 1968.-- Cahiers de Lexicologie Paris, volume 14, n 1, 1969, pp. 77-114.

1973, "Le vocabulaire des pétitions ouvrières de 1848 : étude des parentages stastistiques", dans R. ROBIN [dir.], Histoire et linguistique, Paris, Librairie Armand Colin, 1973.

1975, "Le mot peuple en 1848 : désignant social ou instrument politique ?", dans Romantisme, 1975, n 9, pp. 6-20. 
et André SALEM, 1975, "Vocabulaires de quarante-huit, correspondances et classements", dans Annales historiques de la Révolution française, octobre-décembre 1975. Hélène TOUSSAINT, 1979, "Le réalisme de Courbet au service de la satire politique et de la propagande gouvernementale", dans Bulletin de la Société de l'Histoire de l'Art français, année 1979, pp. 233-244.

J. TOUTAIN, 1948, La révolution de 1848 à Rouen, Paris, R. Debresse, 1948, 108 p. Mark TRAUGOTT, 1985, Armies of the Poor. Determinants of Working class Participation in the Parisian Insurrection of June 1848, Princeton, Princeton University Press, 1985. 1988, "The Crowd in the French Revolution of February, 1848", dans American Historical Review, $\mathrm{n}^{\circ}$ 3, 1988.

1989, "Une étude critique des facteurs déteminants des choix politiques des insurrections de février et juin 1848", dans Revue française de sociologie, juillet-décembre 1989.

1997, "Les barricades dans les insurrections parisiennes : rôles sociaux et modes de fonctionnement", dans Alain CORBIN et Jean-Marie MAYEUR [dir.], La barricade. Actes du colloque de Paris, 17-19 mai 1995, Paris, Publications de la Sorbonne, 1997, pp. 71-81.

Rolande TREMPÉ, 1971, Les mineurs de Carmaux, 1848-1914, Paris, Éditions ouvrières, 1971, 2 volumes, $503 \mathrm{p}$. et $509 \mathrm{p}$.

1976, "Pour une meilleure connaissance de la classe ouvrière. L'utilisation des archives d'entreprise : le fichier du personnel", dans Mélanges offerts à Jean Maitron, Paris, Éditions Ouvrières, 1976.

René TRESSE, 1970, "Politique et farandole dans l'arrondissement de Grasse, 1848-1858", dans Annales de la Société des sciences et lettres de Cannes, tome 21, 1970, pp. 93-102.

Micheline TRIBUT, 1981, "La criminalité dans les Hautes-Pyrénées de 1830 à 1852", dans Annales du Midi. Revue de la France méridionale, tome 93, nº 154, octobre-décembre 1981, pp. 419-437.

J. TRICOUT, 1965, "L'emblème des Amis de l'Ordre, 1848", dans Bulletin de la Société française de numismatique, $\mathrm{n}^{\circ}$ 5, 1965, pp. 466-467.

Anne TROISIER de DIAZ [dir.], 1985, Regards sur Émile Ollivier, Paris, Publications de la Sorbonne, 1985, 365 p.

André-Jean TUDESQ, 1957, "La légende napoléonienne en France de 1848", dans Revue historique, tome 218, fascicule I, 1957, pp. 64-85.

1958, "Notables départementaux et centralisation administrative sous la

Monarchie de Juillet", dans Actes du 82e Congrès national des Sociétés savantes, Bordeaux, 1957, Paris, Imprimerie nationale, 1958.

1961, "La Banque de France au milieu du XIXe siècle. Étude des structures sociales", dans Revue historique, tome 226, n 460, 1961, pp. 339-356.

, 1964, Les grands notables en France (1840-1849). Étude historique d'une psychologie sociale

, Paris, Presses universitaires de France, 1964, 2 volumes, 1278 p.

, 1965, L'élection présidentielle de Louis-Napoléon Bonaparte, 10 décembre 1848, Paris, Librairie Armand Colin, 1965, 272 p.

1967, Les conseillers généraux en France au temps de Guizot, 1840-1848, Cahiers de la Fondation nationale de science politique, $n^{\circ}$ 157, Paris; Librairie Armand Colin, 1967, $292 \mathrm{p}$.

1968, "La presse de 1848 devant la mort de Chateaubriand", dans Colloque Chateaubriand, Rennes 1968.-- Annales de Bretagne, tome 75, n 3, 1968, pp. 490-500. 
1969, "Institutions locales et histoire sociale : la loi municipale de 1831 et ses premières applications", dans Annales de la faculté des lettres et sciences humaines de Nice, 1969, pp. 327-363.

1971, La démocratie en France depuis 1815, Sup histoire, Paris, Presses universitaires de France, 1971, 199 p.

1981, "Le monde paysan dans le système politique censitaire : un absent ou un enjeu ?", dans Les paysans et la politique.-- Annales de Bretagne et des pays de l'Ouest, numéro spécial, 1981.

, 1982, "Le monde paysan dans le système politique censitaire : un absent ou un enjeu ?", dans Annales de Bretagne et des pays de l'Ouest, tome 89, n² 2, 1982, pp. 215-235. Jean TULARD, 1971, Le mythe de Napoléon, collection U2, Paris, Librairie Armand Colin, $1971,240 \mathrm{p}$.

1985, Les révolutions de 1789 à 1851, Histoire de France, Paris, Librairie Arthème Fayard, 1985, 501 p.

1997, "De Badinguet à Louis-Napoléon le Grand", dans Jean TULARD [dir.], Pourquoi réhabiliter le Second Empire? Actes du colloque de Paris, 21 octobre 1995, Paris, Bernard Giovanangeli éditeur, 1997, pp. 9-16.

Yves TURIN, 1968, "1848 : extinction du paupérisme et projet coloniaux", dans Revue histoire et civilisation du Maghreb, $\mathrm{n}^{\circ}$ 5, 1968, pp. 79-89.

1961, "Un projet de nationalisation des chemins de fer en 1848", dans Bulletin d'économie et de finances, $\mathrm{n}^{\circ} 13,1961, \mathrm{pp} .113-117$.

E. VAILLÉ, 1949, "Étienne Arago, la direction de l'administration générale des Postes et le cabinet noir en 1848", dans Actes du Congrès historique du Centenaire de la révolution de 1848, Paris, Presses universitaires de France, 1949, pp. 303-312.

Pierre VAISSE, 1985, "Considérations sur la Seconde République et les Beaux-Arts", dans 1848, révolutions et mutations au XIXe siècle, n 1, 1985, pp. 59-85.

Jacques VALENTIN, 1948, "En marge d'un centenaire : Quelques épisodes de l'histoire de Thiers sous la Seconde République", dans Revue d'Auvergne, n 62, 1948, pp. 49-67.

Jacques VALETTE, 1981, "Utopie sociale et utopistes sociaux en France vers 1848", dans 1848, les utopismes sociaux. Utopie et action à la veille des journées de février, Paris, CDU-SEDES, 1981, pp. 11-110.

Pierre VALLIN, 1985, Paysans rouges du Limousin. Mentalités et comportement politique à Compregnac et dans le nord de la Haute-Vienne (1870-1914), Paris, L'Harmattan, 1985, 362 p. Jean VANEL, 1958, "Victor de Puységur, représentant du peuple en 1848" dans Écho Rabastens, $\mathrm{n}^{\circ}$ 40, 1958, pp. 13-19.

Gabriel VANLAER, 1973, "Comment en 1848, dans l'euphorie de la IIe République, un médecin de Tourcoing (Ferdinan Vanlaer) envisage la Sécurité sociale", dans Études sociales, n 95-96, 1973, pp. 3-17.

Paul VAUTHIER ADAMS, 1990, "The Determinants of Local Variations in Fertility in BasLanguedoc and Roussillon during the Mid-Nineteenth-Century", dans Démographie des villes et des campagnes.-- Annales de démographie historique, 1990, pp. 156-172.

Patrick VERLEY, 1989, L'industrialisation, 1830-1914, tome 2 de André GUESLIN [dir.], Nouvelle histoire économique de la France contemporaine, Paris, La Découverte, 1989, 128 p. Arthur J. VERMEERSCH, 1967, "L'opinion belge devant la révolution française de 1848", dans Revue du Nord, tome 49, n 194, 1967, pp. 483-508.

Jacques VIARD, 1990, "'La Révolution fut une religion en Germe" (Pierre Leroux). Introduction au "Carosse le Monsieur Aguado"", dans L'espace et le temps reconstruits. La Révolution Française, une révolution des mentalités et des cultures? Actes du colloque de Marseille, 
22-24 février 1989, Aix-en-Provence, Publications de l'université de Provence, 1990, pp. 281-293.

Jean VIDALENC, 1948a, Louis Blanc, collection du Centenaire de la révolution de 1848, Paris, Presses universitaires de France, 1948.

1948b, "La province et les journées de juin", dans Études d'histoire moderne et contemporaine, tome 2, 1948, pp. 83-144.

1949, "Les résultats de l'enquête sur le travail prescrite par l'Assemblée constituante dans le département de l'Eure", dans Actes du Congrès historique du Centenaire de la révolution de 1848, Paris, Presses universitaires de France, 1949, pp. 325-342.

, 1954, "La situation économique et sociale des Basses-Alpes en 1848", dans Études, Bibliothèque de la révolution de 1848, tome XVI, Paris, Société d'histoire de 1848, 1954, pp. 124-140.

1969-1972, La société française de 1815 à 1848. Tome 1 : Le peuple des campagnes. Tome 2 : Le peuple des villes et des bourgs, Paris, Marcel Rivière, 1969-1972, 2 volumes, 401 p. et 543 p.

A.R. VIDLER, 1964, A Century of Social Catholicism 1820-1920, Londres, 1964, 171 p.

Frédéric VIEY, 1994, "La famille Javal", dans Léo HAMON [dir.], Les républicains sous le Second Empire, 9es Entretiens d'Auxerre, 1992, Paris, Éditions de la Maison des sciences de l'homme, 1994, pp. 73-92.

Philippe VIGIER, 1963a, La Seconde République dans la région alpine. Étude politique et sociale. Tome I, Les notables (vers 1845-fin 1848). Tome II, Les paysans (1849-1852), Paris, Presses universitaires de France, 1963, 2 volumes, 328 p. et 534 p.

1963b, Essai sur la répartition de la propriété foncière dans la région alpine. Son évolution des origines du cadastre à la fin du Second Empire, Paris, S.E.V.P.E.N., 1963, 276 p.

1967a, La Seconde République, Que sais-je ? n²95, Paris, Presses universitaires de

France, 1967, $128 \mathrm{p}$.

, 1967b, " Lyon et l'évolution politique de la province française au XIXe siècle.

Quelques directions de recherche ", dans Richard GASCON et Pierre LÉON [dir.], Rencontres franco-suisses d'histoire économique et sociale.- Cahiers d'histoire, tome 12, n 1-2, 1967, pp. 193-207.

1973, "Élections municipales et prise de conscience politique sous la Monarchie de Juillet", dans La France au XIXe siècle. Mélanges offert à Charles Hippolyte Pouthas, Paris, Publications de la Sorbonne, 1973, pp. 278-286.

1975, "Un quart de siècle de recherches historiques sur la province", dans Annales historiques de la révolution française, $\mathrm{n}^{\circ}$ 222, octobre-décembre 1975, pp. 622-645. , 1977, "Le bonapartisme et le monde rural", dans Karl HAMMER et Peter Claus HARTMANN [dir.], Le bonapartisme. Phénomène historique et mythe politique. Actes du $13 e$ colloque historique franco-allemand, Augsbourg, 26-30 septembre 1975, Munich, Artemis Verlag, 1977, pp. 11-21.

1980, "Les troubles forestiers du premier XIXe siècle français", dans Société et forêts. Actes du colloque de l'Association des ruralistes français "Forêt et société", Lyon, 22-23 novembre 1979.-- Revue forestière française, numéro spécial, 1980, pp. 128-135.

1982, La vie quotidienne en province et à Paris pendant les journées de 1848, Paris, Hachette, 1982, 443 p.

, 1985, "Le ralliement du personnel orléaniste au bonapartisme", dans Eugène Rouher, Journées d'étude de Riom et Clermont-Ferrand, 16-17 mars 1984, Clermont-Ferrand, Institut d'études du Massif Central, 1985, pp. 21-29.

1987, "Présentation", dans Philippe VIGIER et Alain FAURE [dir.], Maintien de l'ordre et polices en France et en Europe au XIXe siècle, Paris, Créaphis, 1987, pp. 7-11. 
1990, "Présentation", dans Philippe VIGIER et Alain FAURE [dir.], Répression et prison politiques en France et en Europe au XIXe siècle, Paris, Créaphis, 1990, pp. 5-7.

, 1991, "La République à la conquête des paysans, les paysans à la conquête du suffrage universel", dans La politique en campagnes.-- Politix, $\mathrm{n}^{\circ} 15$, 3e trimestre 1991, pp. 7-11.

1992, "Grégoire Bordillon", dans Jacques-Guy PETIT, Jacques MAILLARD et JeanLuc MARAIS [dir.], Républiques et républicains d'Anjou. Actes du colloque d'Angers-Cholet, 15-17 octobre 1992.-- Annales de Bretagne et des pays de l'Ouest, tome 99, n 4, 1992, pp. 431-440.

1995, "Le coup d'État de Louis Napoléon Bonaparte", dans L'histoire, n 193, novembre 1995, pp. 64-71.

et G. ARGENTON, 1949, "Les élections dans l'Isère sous la Seconde République. Essai géographique", dans La révolution de 1848 dans le département de l'Isère, Grenoble, Comité départemental du Centenaire de la révolution, 1949, pp. 3-64.

et Alain FAURE [dir.], 1987, Maintien de l'ordre et polices en France et en Europe au XIX e siècle, Paris, Créaphis, 1987, 415 p.

et Alain FAURE [dir.], 1990, Répression et prison politiques en France et en Europe au XIXe siècle, Paris, Créaphis, 1990, 329 p.

Marcel VIGREUX, 1983, "Une expérience agricole originale dans l'Autunois : la fermeécole de Tavernay, 1840-1850", dans Actes du 53e congrès de l'Association bourguignonne des Sociétés savantes, Le Creusot, 4-6 juin 1982, Dijon, 1983, pp. 141-144.

, 1987, Paysans et notables du Morvan au XIXe siècle, jusqu'en 1914, Château-Chinon, Académie du Morvan, 1987, 756 p.

1988, "Comportements révolutionnaires en Morvan central au milieu du

XIXe siècle : structures foncières, sociales et mentales, souvenir de l'Ancien Régime et de la Révolution", dans Jean BART [dir.], Le Morvan révolutionnaire. Recherches sur les origines des traditions politiques en Morvan (XVIIIe-XIXe siècles).-- Annales historiques de la Révolution française, octobre-décembre 1988, pp. 87-103.

1990, La Société d'agriculture d'Autun (1833-1914), Dijon, Éditions universitaires de Dijon, 1990, $242 \mathrm{p}$.

Nicole VILLA, 1955, "L'iconographie militaire de la Seconde République au Cabinet des espampes", dans L'armée et la Seconde République. Études, Bibliothèque de la révolution de 1848, tome XVIII, Paris, Société d'histoire de 1848, 1955, pp. 17-27.

Jean-Claude VIMONT, 1990, "Enfermer les politiques : la mise en place progressive des "régimes politiques" d'incarcération (1815-1848)", dans Philippe VIGIER et Alain FAURE [dir.], Répression et prison politiques en France et en Europe au XIXe siècle, Paris, Créaphis, 1990, pp. 189-203.

Monique VINCIENNE et Hélène COURTOIS, 1956, "Notes sur la situation religieuse de la France en 1848 d'après l'enquête cantonale ordonnée par le Comité du Travail", dans Archives de sociologie des religions, $\mathrm{n}^{\circ}$ 6, 1956.

Maurice VINCK, 1971, "La révolution de 1848 dans les Deux -Sèvres", dans Bulletin de la Société d'histoire et des sciences des Deux-Sèvres, tome 4, n 2-3, 1971, pp. 253-285.

Marcel VITTE, 1969, "Mâcon-Genève ou Lyon-Genève. Un épisode des compétitions ferroviaires au milieu du XIXe siècle", dans Colloque franco-suisse d'histoire économique et sociale. Genève, 5-6 mai 1967, Genève, Georg \& Cie, 1969, pp. 167-182.

1973, "Vive la République ! Der Pariser Februar und die folgen in Deutschland, 1848", dans Augenzengen der Revolution, 1973, pp. 33-115. 
Nadine VIVIER, 1992, Le Briançonnais rural aux XVIIIe et XIXe siècles, Paris, Éditions L'Harmattan, 1992, 296 p. , 1994, "Le débat autour des communaux durant la crise du milieu du XIXe siècle", dans Alain FAURE, Alain PLESSIS et Jean-Claude FARCY [dir.], La terre et la cité. Mélanges offerts à Philippe Vigier, Paris, Éditions Créaphis, 1994, pp. 67-83.

Odette VOILLARD, 1978, Nancy au XIXe siècle, 1815-1871, Une bourgeoisie urbaine, Paris, Ophrys, 1978, $391 \mathrm{p}$.

1948, Volume du centenaire de la révolution de 1848 dans le Jura.-- Mémoires de la Société d'émulation du Jura pour 1946-1948, Lons-le-Saunier, 1948, 361 p.

Marc VUILLEMIER, 1963, "Les républicains français réfugiés à Genève, 1848-1851, quelques documents inédits", dans Bulletin de la Société d'histoire et d'archéologie de Genève, tome 12 , livraison 3, 1963, pp. 244-245.

1969, "Un quarante-huitard inconnu : le citoyen François-Elisée Guyon", dans Musée de Genève, $\mathrm{n}^{\circ}$ 94, 1969, pp. 4-8.

Whitney WALTON, 1989, "Political Economists and Specialized Industrialization during the French Second Republic, 1848-1852", dans French History, volume 3, n 3, septembre 1989, pp. 293-311.

Simone WAQUET, 1990, "Tristes destins : le sort des victimes de 1851 dans l'arrondissement de Clamecy", dans Philippe VIGIER et Alain FAURE [dir.], Répression et prison politiques en France et en Europe au XIXe siècle, Paris, Créaphis, 1990, pp. 97-111.

Charles K. WARNER, 1969, "Le Journal d'agriculture pratique et la question paysanne sous la Monarchie de Juillet et la Seconde République", dans Charles K. WARNER [dir.], From the Ancien Regime to the Popular Front. Essays in the History of Modern France in Honor of Shepard B. Clough, New York/Londres, Columbia University Press, 1969.

Eugen WEBER, 1980, "The Second Republic, Politics and the Peasants", dans French Historical Studies, tome 11, 1980, pp. 521-551.

Georges WEILL, 1965, "La représentation parlementaire de la Meuse depuis la Seconde République", dans Bulletin de la Société d'histoire et d'archéologie de la Meuse, n² 2, 1965, pp. 79-94.

Michael WERNER, 1995, "Étrangers et immigrants à Paris autour de 1848 : l'exemple des Allemands", dans Ilja MIECK, Horst MÖLLER et Jürgen VOSS [dir.], Paris und Berlin in der Revolution 1848/Paris et Berlin dans la révolution de 1848. Colloque organisé par la Ville de Paris; l'Historische Kommission zu Berlin et l'Institut historique allemand, Paris, 23-25 novembre 1992, Sigmaringen, Jan Thorbecke Verlag, 1995, pp. 199-214.

Gordon WRIGHT, 1958, "A poet in politics. Lamartine and the Revolution of 1848", dans History Today, volume 8, $\mathrm{n}^{\circ}$ 9, 1958, pp. 616-627.

Vincent WRIGHT, 1969, "Religion et politique dans les Basses-Pyrénées pendant la Deuxième République et le Second Empire", dans Annales du Midi, tome 81, octobredécembre 1969, pp. 409-442. 1970a, "Députés et conseillers généraux des Basses-Pyrénées de 1848 à 1870", dans Bulletin de la Société des sciences et des lettres de Pau, série 4, tome 5, 1970, pp. 156-167. 1970b, "Les élections dans les Basses-Pyrénnées de 1848 à 1870", dans Société scientifique et littéraire de Bayonne, $\mathrm{n}^{\circ}$ 122, 1970, pp. 1-31. , 1976, ", L'École nationale d'administration de 1848-1849 : un échec révélateur", dans Revue historique, $\mathrm{n}^{\circ}$ 517, janvier-mars 1976, pp. 21-42. Witold ZANIEWICKI, 1969, "L'armée au lendemain de la révolution de février 1848", dans Cahiers d'histoire, tome 14, $\mathrm{n}^{\circ}$ 4, 1969, pp. 393-419. 
1975, "Un moyen de recherches en histoire militaire : l'étude des mouvements de troupes (le retour de l'armée à Paris, mars-juin 1848)", dans Revue d'histoire moderne et contemporaine, tome 22, octobre-décembre 1975, pp. 583-600.

Claude ZARKA, 1958, "Un exemple de pôle de croissance : l'industrie textile du Nord de la France, 1830-1870", dans Revue d'économie, $\mathrm{n}^{\circ}$ 1, 1958, pp. 65-106.

N.E. ZASTENKER, 1961, "Proudhon et la révolution de février 1848", dans Annuaire des études françaises, 1961, pp. 388-425.

Théodore ZELDIN, 1959, "Government Policy in the French General Election of 1849", dans English Historical Review, tome 74, 1959, pp. 240-248.

1973-1977, France 1848-1945. Volume I : Ambition, Love and Politics. Volume II : Intellect, Taste and Anxiety, Oxford, Clarendon Press, 1973-1977, 2 volumes, 823 p. et 1202 p., traduction française : Histoire des passions françaises, 1848-1945. Tome 1 : Ambition et amour. Tome 2: Orgueil et intelligence. Tome 3 : Goût et corruption. Tome 4 : Anxiété et hypocrisie. Tome 5 : Colère et politique, Paris, Encres/Recherches, 1978-1979, 5 volumes, 422 p., 393 p., 467 p., 550 p. et 483 p.

[dir.], 1970, Conflicts in French Society : Anticlericalism, Education and Morals in the Nineteenth Century, Londres, Oxford University Press, 1979.

Line ZORKA, 1994, "Le coup d'État de 1851 et ses répercussions dans l'Yonne", dans Léo HAMON [dir.], Les républicains sous le Second Empire, 9es Entretiens d'Auxerre, 1992, Paris, Éditions de la Maison des sciences de l'homme, 1994, pp. 1-14.

\section{ABSTRACTS}

Cette bibliographie ne prétend pas être exhaustive. Les ouvrages et articles sont classés par ordre alphabétique des noms d'auteur, et pour chaque auteur selon l'année de parution. Ne sont mentionnés ici que les ouvrages et articles publiés depuis 1948, à l'exception des travaux dactylographiés ou ronéotés.

INDEX

Mots-clés: 1848, Bibliographie, Historiographie 